\title{
Contribution of resuspended sedimentary particles to dissolved iron and manganese in the ocean: An experimental study
}

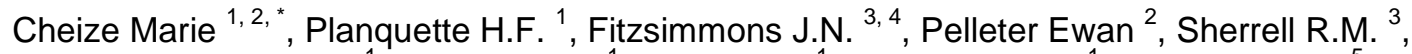 \\ Lambert Christophe ${ }^{1}$, Bucciarelli E. ${ }^{1}$, Sarthou G. ${ }^{1}$, Le Goff Marion ${ }^{1}$, Liorzou Celine ${ }^{5}$, \\ Chéron Sandrine ${ }^{2}$, Viollier E. ${ }^{6}$, Gayet Nicolas ${ }^{7}$
}

${ }^{1}$ Institut Universitaire Européen de la Mer, Laboratoire des Sciences de l'Environnement Marin (LEMAR), UMR 6539 CNRS, UBO, IRD, Ifremer, Place Nicolas Copernic, 29280 Plouzané, France

2 Ifremer, Centre de Brest, Géosciences Marines, Laboratoire des Cycles Géochimiques (LCG), 29280

Plouzané, France

${ }^{3}$ Department of Marine and Coastal Sciences, Department Earth and Planetary Sciences, Rutgers

University, 71 Dudley Road, New Brunswick, NJ 08901-8521, United States

${ }^{4}$ Department of Oceanography, Texas A\&M University, 403A Eller O\&M Building, 3146 TAMU, College Station, TX 77843-3146, United States

${ }^{5}$ Institut Universitaire Européen de la Mer, Laboratoire Géosciences Océan (LGO), UMR 6538 UMS

3113, Place Nicolas Copernic, 29280 Plouzané, France

${ }^{6}$ Institut de Physique Globe de Paris, Biogéochimie Environnementale, 1, rue Jussieu, 75238 Paris

cedex 05, France

${ }^{7}$ Ifremer, Centre de Brest, Laboratoire Environnement Profond, (LEP), 29280, Plouzané, France

* Corresponding author : Marie Cheize, email address : $\underline{\text { Marie.Cheize@ifremer.fr }}$

\begin{abstract}
:
A number of trace metals play essential roles in marine ecosystem structure and biological productivity. Until recently, it has been argued that phytoplankton access primarily dissolved iron, while particulate iron was considered a refractory material with little use biologically and limited interaction with the dissolved pool. In order to assess the transfer mechanisms between sediment-sourced particulate trace metals and the dissolved pool, we conducted a 14-month incubation that reacted resuspended sediments with natural seawater, both originating from the Kerguelen area (KEOPS cruises; Southern Ocean), in the dark, and at concentrations replicating natural conditions. Three types of sediments were investigated (named BioSi, BioSi + Ca, and Basalt), mostly composed of (i) biogenic silica (bSiO2), (ii) bSiO2 and calcite, and (iii) basaltic fragments, respectively. The release of dissolved silicon (dSi), iron $(\mathrm{dFe})$ and manganese $(\mathrm{dMn})$ was monitored regularly throughout the incubation, as well as living bacteria density and Fe organic ligands. Depending on the origin and composition of the sediment, unique $\mathrm{dFe}$ and $\mathrm{dMn}$ fluxes were observed, including a strong decoupling between $\mathrm{dFe}$ and $\mathrm{dMn}$. The basaltic sediment released up to $1.09 \pm 0.04 \mathrm{nmol} \mathrm{L-1}$ of dFe and $0.28 \pm 0.09 \mathrm{nmol} \mathrm{L}-1$ of $\mathrm{dMn}$, while the biogenic sediments released a higher $3.91 \pm 0.04 \mathrm{nmol} \mathrm{L}-1$ and $8.03 \pm 0.42 \mathrm{nmol} \mathrm{L}-1$ of $\mathrm{dFe}$ and $\mathrm{dMn}$, respectively. Several factors influencing the release and removal of $\mathrm{dFe}$ and $\mathrm{dMn}$ were discernable at the temporal sampling resolution of the incubation, including the structural composition of the sediment, bacterial abundance, and the formation of manganese oxides. The regular sampling over short
\end{abstract}


timescales and the extended sampling over one year proved to be critical to constrain the processes and exchanges that govern the contribution of the particulate to the dissolved pools. Overall, this incubation provides a strong basis for reassessing the role of resuspended sedimentary particles in the marine biogeochemical cycles of $\mathrm{Fe}$ and $\mathrm{Mn}$. Indeed, we show that biogenic silica, calcite-rich and basaltic particles can contribute substantial dissolved Fe and $\mathrm{Mn}$ to the overlying water column. In the future, the global extent of this previously overlooked external metal source should be quantified through further process studies and biogeochemical models.

This article is part of a special issue entitled: "Cycles of trace elements and isotopes in the ocean GEOTRACES and beyond" - edited by Tim M. Conway, Tristan Horner, Yves Plancherel, and Aridane G. González.

\section{Highlights}

- Resuspended sedimentary particles contribute to a substantial flux of trace metals into the overlying oceanic water column. The release of dissolved Fe and $\mathrm{Mn}$ from resuspended sedimentary particles is decoupled through time

Keywords: Suspended particle dissolution, Sediment, Iron, Manganese, Biogenic silica, Southern Ocean, Kerguelen 


\section{Introduction}

Suspended particles play an essential role in many natural physical, biological, and chemical oceanic processes and are thus responsible for maintaining most element concentration gradients in the ocean (Jeandel et al., 2015). Among these elements, iron (Fe) and manganese (Mn) exert a pivotal role in modulating ocean productivity (e.g. Boyd and Ellwood, 2010; Martin and Fitzwater, 1988; Sunda, 2012), as they are involved in many cellular processes including photosynthesis. Iron and manganese exist at nanomolar concentrations in the world's oceans (e.g. Elderfield, 1976, Johnson et al., 1997), despite the high abundances in the Earth's crust (Taylor and McLennan, 1995). To date, there are still substantial uncertainties on their biogeochemical cycles, including the relative contribution of various external sources. Dust deposition from the atmosphere (e.g. Baker et al., 2006)and inputs from the sediments (e.g. Chase et al., 2005; Homoky et al., 2013), rivers (e.g. da Cunha and Buitenhuis, 2013; Landing and Bruland, 1980), and hydrothermal vents (e.g. Fitzsimmons et al., 2017; Tagliabue et al., 2010) deliver $\mathrm{Fe}$ and $\mathrm{Mn}$ in a variety of chemical and physical forms, with the relative influence of each of these sources subject to spatio-temporal variability (Raiswell and Canfield, 2012). Dust deposition has been emphasized as the major iron source over the last two decades (e.g. Jickells et al., 2005), but recent in-situ observations have shown that more iron than previously estimated is being delivered from continental slopes and margins to the open ocean (e.g. Dale et al., 2015; Jeandel et al., 2011; Slemons et al., 2010; Lam et al., 2006) and that the particulate phase dominates the input of most elements to the oceans (Jones et al., 2012a; Jones et al., 2012b; Oelkers et al., 2011).

In addition, dissolved $\mathrm{Fe}$ ( $\mathrm{dFe},<0.2 \mu \mathrm{m}$ fraction) was historically assumed to be the only form available to phytoplankton and bacteria, such that most studies have focused on the supply of dFe to the ocean, with the role of the particulate iron as an oceanic iron source to the ocean or to phytoplankton being largely ignored. At present, global biogeochemical models reproduce the main features of the global dFe distribution but largely underestimate the spatial scales required for lateral transport of iron released from sediments (Tagliabue et al., 2014a; Tagliabue et al., 2009). In these simulations, $\mathrm{dFe}$ of sedimentary origin was predicted to be very rapidly removed from the water column by scavenging and thus would not be advected over long distances (Borrione et al., 2014; Gorgues et al., 2009). This traditional view has been challenged recently by observational and experimental evidence. For example, Pearce et al., (2013) have shown that sediment-seawater exchange during marine particulate weathering exert a major control on the oceanic isotopic composition of neodymium $(\varepsilon \mathrm{Nd})$ and rare earth elements (REE) and that particle dissolution should be considered in all marine budgets, corroborating experimental results of Jones et al. (2012a) on riverine particulate discharge. Satellite data confirmed that the naturally $\mathrm{Fe}$ - and $\mathrm{Mn}$-fertilized areas located in the Southern Ocean and characterized by high chlorophyll concentrations extend over hundreds to thousands of kilometers downstream of islands and continental shelves, as in the Drake passage (Hatta et al., 2013; Middag et al., 2012), east of South Georgia Island (Borrione and Schiltzer, 2013; Schlosser et al., 2017), Crozet Islands (Castrillejo et al., 2013; Planquette et al., 2007 ; Planquette et al., 2011) or Kerguelen Islands (Bucciarelli et al., 2001; van der Merwe et al., 2015; Quéroué et al., 2015). In fact, resuspended sediment can be transported over several hundred kilometers by local internal waves or strong currents (e.g. Diekmann et al., 2004; Sherrell et al., 1998), and some of the sedimentary Fe may dissolve/desorb, even far from its original resuspension site (Labatut et al., 2014; Laës et al., 2007; Lam and Bishop, 2008; Middag et al., 2012; Schallenberg et al., 2015). A review by Jeandel and Oelkers, (2015) stresses the role of terrigenous particle dissolution as a slowy-released source of $\mathrm{dFe}$ and a continuous 'fertilizer' at ocean margins, while lateral transport may extend this influence to open ocean phytoplankton communities. We emphasize, however, that the mechanism and rate of this particle dissolution is to date largely unknown.

Such dissolution of particles can also occur within nepheloid layers, that are formed when strong deepsea currents resuspend and transport the surface sediments (e.g. Biscaye and Ettreim, 1977; Ewing and Thorndike, 1965; Gardner et al., 2018; Mc Cave, 2009). Nepheloid layers are widespread in the global ocean, and the most intense nepheloid layers are found in areas of strong western boundary currents and in regions where the bottom current regime is thought to be more variable due to penetration of eddy energy from the surface (Gardner et al., 2018). Such resuspension events reintroduce deposited 
material into the water column, leading to a redistribution of material and potential dissolution of particles or desorption from their surfaces. Although potentially important for trace element biogeochemical cycles, nepheloid layers have received little attention, and studies remain scarce. Baker and Feely (1978) showed that particles within nepheloid layers are enriched in aluminium, silicon, iron and manganese relative to the overlying waters in the eastern Equatorial Pacific Ocean, while Bishop and Biscaye (1982) showed that when a series of resuspension events occur, particles within the nepheloid layer match the properties of the underlying sediments in the North Atlantic Ocean. However, the magnitude of the resuspended sedimentary sources of particulate $\mathrm{Fe}$ and $\mathrm{Mn}$ and the releasing processes affecting this phase have never been well constrained nor quantified. As a consequence, the role of nepheloid layers and resuspended sedimentary particulate dissolution in the $\mathrm{Fe}$ and $\mathrm{Mn}$ biogeochemical cycles is still unclear despite its potentially widespread importance. Around the Kerguelen islands, Copin-Montégut and Copin-Montégut (1978) showed evidence of siliceous sediment resuspension along the shelf with deep total particulate silicon concentration approximately doubling from the surface to $500 \mathrm{~m}$. This increase in silica, mainly considered as silicious tests, was accompanied by an increase in particulate aluminium, iron, and magnesium, suggesting that clay minerals were also significantly brought into suspension. In later work, resuspended sediments were invoked as a source of dFe (e.g. Blain et al., 2008; Bucciarelli et al., 2001; Chever et al., 2010; Venchiarutti et al., 2008), but the magnitude of this source and the mechanisms leading to the dissolution of these particles have remained obscured. On the contrary, scavenging processes have been reported in well-developed benthic nepheloid layers in the western North Atlantic (Bacon and van der Loeff, 1989; Kretschmer et al., 2011) but to our knowledge have never been investigated further. Finally, few dissolution experiments reproducing open ocean environmental conditions have been reported compared to riverine and coastal environments on which most of the studies have been focused historically. Remobilization of particles during coastal resuspension events have been widely studied using laboratory approaches over short time scales (from hours to months, e.g. Balls 1989; Saulnier and Mucci, 2000; Kalnejais et al., 2007) at fairly high suspended particle concentrations chosen to mimic river discharge conditions (e.g. Jones et al., 2012a). However, the understanding of processes driving micronutrient behavior, such as $\mathrm{Fe}$ and $\mathrm{Mn}$, has been limited because of experimental design and analytical detection limits.

In this paper, we present the results of a 14-month incubation that aims to address the long-term fate of sedimentary particles in seawater. We incubated sediments of varying composition with natural seawater, both originating from the Kerguelen area (KEOPS cruises), at concentrations replicating natural conditions in nepheloid layers. Transfer of sediment-sourced trace metals between the dissolved and particulate pools were monitored regularly through measurements of dissolved $\mathrm{Si}(\mathrm{dSi})$, $\mathrm{Fe}(\mathrm{dFe})$, and $\mathrm{Mn}(\mathrm{dMn})$, as well as the evolution of bacterial concentrations and $\mathrm{Fe}$ organic ligands. We show that resuspended sedimentary particles can contribute substantially to the dissolved pool of $\mathrm{Fe}$ and $\mathrm{Mn}$, or can remove $\mathrm{dFe}$ and $\mathrm{dMn}$ through scavenging interactions depending on initial particle mineralogy and bacterial activity. 


\section{Materials and methods}

\subsection{Sediment incubation design}

The sediment dissolution incubation was run in 10-L LDPE $\left(\right.$ Nalgene $\left.{ }^{\circledR}\right)$ carboys over a 14-month period. All of the LDPE material used in this study was previously cleaned following GEOTRACES protocols ${ }^{1}$, and all manipulations were carried out in a Class 100/ISO 5 clean laboratory to minimize contamination issues. Southern Ocean Seawater (SOSW) was collected during the KEOPS-2 cruise (Quéroué et al., 2015) at $40 \mathrm{~m}$ depth at station E5 (Fig. 1a), filtered through acid-cleaned $0.2 \mu \mathrm{m}$ filter cartridges (Pall Acropak and Sartorius Sartobran ${ }^{\circledR} 300$ ), and stored in 20-L acid cleaned PP carboys $\left(\right.$ Nalgene $\left.^{\circledR}\right)$ until use. Three sediments from Kerguelen Island, named A3, C11 and C1 were collected using core top sediment during the KEOPS-1 cruise (Blain et al., 2007). Sediment A3, which we have renamed BioSi for ease of understanding, was sampled over Kerguelen plateau, in an area where an intense phytoplankton bloom is observed each year (Blain et al., 2007), at $530 \mathrm{~m}$ water depth (Table 1). Sediment $\mathrm{C} 11$, which we have renamed $\mathrm{BioSi}+\mathrm{Ca}$, was collected at $3350 \mathrm{~m}$ depth, east of the Plateau where phytoplankton blooms are rare, while basaltic sediment $\mathrm{C}$, which we have renamed Basalt, was collected at $150 \mathrm{~m}$ depth near Heard Island, which is located within a moderate bloom area. These sediments were chosen for their distinct compositions as a main criterion. They were sampled between 8 and $13 \mathrm{~cm}$ depth from the ocean/sediment interface (Table 1), and therefore have been potentially altered by early diagenesis. After sampling, slices of sediment cores were kept frozen at $-20^{\circ} \mathrm{C}$ until freeze-dried in the lab onshore. This method avoids most of the solid phase destabilization that can occur in classical drying at $105^{\circ} \mathrm{C}$. They were finally stored in clean centrifuge tubes $\left(\right.$ Falcon $\left.^{\circledR}\right)$ until use.

In each of the three incubators, $\sim 50 \mathrm{mg}$ of each sediment (BioSi, Biosi+Ca, and Basalt) was added to $\sim 11 \mathrm{~L}$ of SOSW (Table 1). This suspended particle matter (SPM) concentration of $\sim 5 \mathrm{mg} \mathrm{L}^{-1}$ corresponds to maximum SPM concentrations of intense nepheloid layers (e.g. nearby Nova Scotia rise (Gross et al., 1988) or in the Mediterranean Sea (e.g. Puig et al., 2013). Immediately after the addition of the sediments to SOSW, the caps of the incubators were tightened and remained closed during the entire incubation period. To allow sampling, an acid-cleaned Teflon ${ }^{\circledR}$ tube was introduced into each carboy through the top (Fig. 1b-4). This tube terminated in a PTFE threaded fitting closed with an airtight PTFE plug to close the system, which was fully enclosed within a plastic bag. To generate the sediment resuspension, carboys were placed horizontally on a rotating rod table that rotates the carboys like a rock tumbler. Once in place, the carboys were kept in the dark in a temperature-controlled room at $15{ }^{\circ} \mathrm{C}$ with a mixing rate of approximately $5 \mathrm{rpm}$. An air filled headspace $(\sim 100 \mathrm{~mL}$ initially, increasing to $\sim 2000 \mathrm{~mL}$ during the final incubation interval, between sampling events at 282 to 423 days), allowed gas exchange through the air-seawater interface in order to maintain the oxygen level. In addition to the dissolved oxygen concentration in the initial SOSW (i.e. $~ 250 \mu \mathrm{mol} \mathrm{L} \mathrm{L}^{-1}$, at $15^{\circ} \mathrm{C}$ (Roy-Barman and Jeandel, 2016)), the headspace contribution resulted in an initial equilibrated total dissolved oxygen concentration of $\sim 330 \mu \mathrm{mol} \mathrm{L} \mathrm{L}^{-1}$. A fourth carboy containing $17 \mathrm{~L}$ of unamended SOSW (Control hereafter) was also left in the clean laboratory over the course of the 14-month incubation and was dedicated to test the biochemical evolution of the seawater, in the absence of sediments (Fig. 1b3).

The incubation progress was monitored regularly by measuring several variables including $\mathrm{pH}$, dissolved silicon $(\mathrm{dSi})$, dissolved iron $(\mathrm{dFe})$, and dissolved manganese $(\mathrm{dMn})$ concentrations; dissolved Fe organic ligand concentrations $(\mathrm{dFeL})$, their associated conditional stability constant (Log $\mathrm{K}_{\mathrm{Fe}+\mathrm{L}}$ ); and viable bacteria density. Dissolved $\mathrm{Fe}$ and $\mathrm{Mn}$, together with $\mathrm{pH}$ and bacteria, were sampled twice per month, with a higher resolution (1 to 10 days) during the first four weeks, whereas $\mathrm{dFeL}$ and $\mathrm{dSi}$ were sampled five and six times respectively, over the 14-month incubation. Sampling resulted in no more than $20 \%$ loss of seawater volume in each carboy by the end of the 14-months incubation.

\footnotetext{
${ }^{1}$ www.geotraces.org
} 
One hour before subsampling, the rotation was stopped and the incubators were placed vertically in the dark to let the particles settle. In the meantime, three Teflon ${ }^{\circledR} /$ Tygon $^{\circledR}$ independent sampling lines, connected together with Luer Lock ${ }^{\circledR}$ and Peek ${ }^{\circledR}$ connectors, were assembled in the clean laboratory under a laminar flow hood (ISO 5) (Fig. 1b). Those lines were (i) cleaned with $100 \mathrm{~mL}$ of $1 \mathrm{M}$ hydrochloric acid $\left(\mathrm{HCl}\right.$, Suprapur grade, Merck ${ }^{\circledR}$ ), using a peristaltic pump (Gilson ${ }^{\circledR}$ ), (ii) connected to three $0.22 \mu \mathrm{m}$ Millex ${ }^{\circledR}$ mixed esters membrane filters, (iii) cleaned with an additional $400 \mathrm{~mL}$ of acid (Fig.1b-1), and (iv) rinsed with $250 \mathrm{~mL}$ of ultra-pure water (MQ, $18.2 \mathrm{M} \Omega . \mathrm{cm}$, Fig.1b-2).

Then, $500 \mathrm{~mL}$ of SOSW, directly sampled in the Control carboy, was passed through the filter, with the first $10 \mathrm{~mL}$ discarded to flush out the remaining MQ in the filtration line (Fig. 1b-3). At the output of the filtration device, a set of samples referred as Control, were collected. This, allow to check for metal contamination of the sampling device and to follow the chemical evolution of the SOSW in the absence of incubated sediments. The first $60 \mathrm{~mL}$ was collected in a LDPE bottle (Nalgene ${ }^{\circledR}$ ) dedicated to assessing $\mathrm{dFe}$ and $\mathrm{dMn}$ (Control), while the following $15 \mathrm{~mL}$ and $125 \mathrm{~mL}$ were dedicated to $\mathrm{dSi}$ and $\mathrm{dFeL}$, and were collected in a $15 \mathrm{~mL}$ Falcon ${ }^{\circledR}$ polypropylene centrifuge tube and a $125 \mathrm{~mL}$ LDPE bottle, respectively. In addition, $2 \mathrm{~mL}$ of unfiltered SOSW was collected in a sterile Cryovial ${ }^{\circledR}$ to follow the evolution of viable bacteria density and an additional $2 \mathrm{~mL}$ was used to measure $\mathrm{pH}$.

Afterwards, the incubators were brought in the clean laboratory and the sampling lines were connected to the caps of each carboy, replacing the PTFE plug. Each step was repeated from the Control sampling procedure for sampling dissolved seawater transformations in the presence of incubated sediments, and the Millex ${ }^{\circledR}$ filter was finally removed for sampling unfiltered seawater transformations (Fig. 1b-4).

At the end of a sampling session, the sampling lines were disconnected from the cap of the incubators, and the PTFE plugs were put back in place. The Luer Lock ${ }^{\circledR}$ and Peek ${ }^{\circledR}$ connectors, and the Teflon ${ }^{\circledR}$ lines were placed in an $\mathrm{HCl}$ bath $5 \%$ (v/v; Suprapur grade; Merck ${ }^{\circledR}$ ) until the next sampling session while re-assembling with a set of new Tygon ${ }^{\circledR}$ tubing.

At the end of the incubation (423 days), sediments were recovered on a Supor ${ }^{\circledR}$ filter (47 mm diameter, $0.45 \mu \mathrm{m}$ ) by filtration of the remaining seawater (between 9.3 and $9.5 \mathrm{~L}$ ) in order to investigate their final mineralogical composition by XRD and SEM-EDS.

\subsection{Sediment characterization}

XRD and SEM-EDS analyses were carried out to identify the mineralogical composition of the sediments prior to and at the end of the dissolution incubation. Prior to the incubation, XRD analysis of the sediment (hereafter termed initial sediment) was performed on both $50 \mathrm{mg}$ (i.e. representative of the amount of sediment added for the incubation) and ca. $1 \mathrm{~g}$ of sediment. Because of the large variation in particle size, the Basalt initial sedimentwas run in triplicate. At the end of the incubation, the mineralogy of the sediment (hereafter referred to as final sediment) was obtained by XRD analysis on a low-Si background sample holder to optimize the analysis given the small amount of sample available. All analyses were run with an angle ranging from 5 to $70^{\circ}$ for the diffraction angle (2theta) and a step size of $0.01^{\circ}$ and $1 \mathrm{~s}$ counting time per step on either a D8 ADVANCE or a D2 PHASER Bruker X-Ray diffractometer. The proportion of the mineral phases was estimated using Bruker DIFFRAC ${ }^{\text {plus }}$ TOPAS software, using Rietveld method (i.e. Titschack et al., 2015).

For SEM secondary electron images and EDS element maps, typically, a small amount of sediment was mounted on pin stubs and coated with carbon. Scanning electron microscopy and energy dispersive X-ray spectroscopy were performed with a FEI Quanta 200 coupled with OXFORD XMAX Silicon Drift Detector (detector size: $80 \mathrm{~mm}^{2}$ ).

Sediment-specific elemental composition was determined following the analytical procedure of Cotten et al., (1995). Typically, 50 to $150 \mathrm{mg}$ of sediment were dissolved in closed screw-top Teflon vessels (Savillex ${ }^{\circledR}$ ) at about $90^{\circ} \mathrm{C}$ for one day using $1.5 \mathrm{~mL}$ of concentrated hydrofluoric acid (HF) and 0.5 $\mathrm{mL}$ of concentrated nitric acid $\left(\mathrm{HNO}_{3}\right)$. All reagents used were analytical grade $\left(\mathrm{Merck}^{\circledR}\right)$. Next, 48 $\mathrm{mL}$ of boric acid aqueous solution $\left(20 \mathrm{~g} \mathrm{~L}^{-1}, \mathrm{H}_{3} \mathrm{BO}_{3}\right)$ was added to neutralize excess $\mathrm{HF}$ and dissolved fluorides. Standardization curves were made using certified standards with different concentrations digested under the same conditions as the samples. The boron, included in the neutralization solution, was used as an internal standard. Elemental concentrations were measured by Inductively Coupled 
Plasma-Atomic Emission Spectrometry (ICP-AES) using a Horiba Jobin Yvon ${ }^{\circledR}$ Ultima 2 spectrometer. Validations were made using international standards, AC-E (granite powder, Centre de Recherches Pétrographiques et Géochimiques, CNRS), Jsd-2 and Jsd-3 (stream sediment powder, Geological Survey of Japan), Lksd-1 (Lake sediment powder, NRC), and were all within certified values. The elemental composition was expressed as weight percent with associated error corresponding to one standard deviation of the whole measurements (i.e., $\mathrm{n}=4$ for $\mathrm{BioSi}$, and $\mathrm{n}=6$ for $\mathrm{BioSi}+\mathrm{Ca}$ and Basalt).

\subsection{Seawater monitoring}

$\boldsymbol{p H}$ - The variation of $\mathrm{pH}$ during the incubation was followed with a Mettler-Toledo ${ }^{\circledR} \mathrm{pH}$ meter $( \pm 0.01$ $\mathrm{pH}$ units; temperature compensated) and glass electrode, regularly calibrated against 4.01, 6.87 and 9.18 buffer solutions $\left(25^{\circ} \mathrm{C}\right.$; Bioblock Scientific).

Dissolved Silicon- dSi samples were stored at $4^{\circ} \mathrm{C}$ for up to 8 months before analysis with a Technicon Auto-analyzer 3 (Bran+Luebbe $\left.{ }^{\circledR}\right)$ following the colorimetric method of Aminot and Kérouel, (2007). The detection limit was $0.03 \mu \mathrm{mol} \mathrm{L}^{-1}$ for dSi and the method was certified using the Reference Material for Nutrients in Seawater (RMNS; Kanso ${ }^{\circledR}$ ).

Viable bacteria density- Samples were stored at $4{ }^{\circ} \mathrm{C}$ immediately after sampling to reduce bacterial growth prior to analyses. Analyses were performed within 24 hours according to Grégori et al., (2001), using a flow cytometer FacsVerse (Becton-Dickinson ${ }^{\circledR}$, San Jose, USA) equipped with 405, 488 and $640 \mathrm{~nm}$ lasers and a flow sensor device measuring the volume of each of the analyzed samples. Briefly, $500 \mu \mathrm{L}$ of unfiltered seawater was incubated for one hour in the dark with $5 \mu \mathrm{L}$ of a $1 / 100$ dilution in MQ water of the $\mathrm{SYBR}^{\circledR}$ Green I commercial solution (Molecular Probes, \#S7563) and 5 $\mu \mathrm{L}$ of a $1 \mathrm{mg} \mathrm{mL}^{-1}$ propidium iodide (PI, Sigma ${ }^{\circledR}$ ) solution in MQ. The SYBR ${ }^{\circledR}$ Green I stain is a DNA permeant probe allowing detection of viable bacteria (green fluorescence) while PI is a non-permeant DNA probe allowing detection of membrane damaged bacteria (considered as dead bacteria, orange/red-fluorescence). Viable bacteria were detected according to their green fluorescence (SYBR ${ }^{\circledR}$ Green) and distinguished from dead cells showing orange/red fluorescence (IP). Results were given as concentration of viable bacteria in cells per $\mathrm{mL}$. In order to operate the flow cytometer under optimal conditions (max 10000 events s$^{-1}$ ), samples were diluted in nearby Bay of Brest seawater sequentially filtered at $8.0 \mu \mathrm{m}$ and $0.2 \mu \mathrm{m}$. Sampling was done in duplicate starting at day 57 to the end of the incubation, with associated error corresponding to one standard deviation of both measurements, allowing statistical comparison with ANOVA including multiple range tests. Before day 57, duplicate samples were not collected, and thus no standard deviation could be calculated.

Dissolved Fe and Mn- After collection, the $60 \mathrm{~mL}$ samples dedicated to dFe and dMn measurements were immediately acidified to $0.012 \mathrm{M}$ with $\mathrm{HCl}$ (Ultrapure grade; Merck $^{\circledR}$ ) and divided into two 30 $\mathrm{mL}$ LDPE bottles $\left(\right.$ Nalgene $\left.{ }^{\circledR}\right)$. The dMn concentration was measured in the first aliquot by automated extraction, offline Inductively Coupled Plasma Mass Spectrometry (ICP-MS) using an ESI SeaFAST pico system at Rutgers University, in a method analytically similar to that of Lagerström et al., (2013). Samples were analyzed within 3 to 8 months after acidification, using external standardization for Mn, with standards at experimentally-relevant concentrations ( 0 to $11 \mathrm{nM}$ in SOSW) carried through the entire extraction process. The external precision (5\% RSD) was demonstrated through the replicate analysis of an Amundsen Sea in-house consistency standard. The average Mn blank was $0.006 \mathrm{nmol}$ $\mathrm{L}^{-1}$ and the detection limit (defined as three times the standard deviation of the blank) was $0.008 \mathrm{nmol}$ $\mathrm{L}^{-1}$. Three North Pacific GEOTRACES reference seawater materials were used to assess $\mathrm{dMn}$ accuracy, including SAFe S $\left(0.917 \pm 0.047 \mathrm{nmol} \mathrm{L}^{-1}, \mathrm{n}=6\right)$, SAFe D2 $\left(0.474 \pm 0.025 \mathrm{nmol} \mathrm{L}^{-1}, \mathrm{n}=8\right)$, and SAFe D1 (0.436 $\left.0.026 \mathrm{nmol} \mathrm{L}^{-1}, \mathrm{n}=6\right)$, which were all within error of the community consensus values for these samples (http://www.geotraces.org/sic/intercalibrate-a-lab/standards-and-referencematerials). The second aliquot was analyzed for dFe by Flow Injection Analysis (FIA) with online solid phase extraction onto 8-hydroxyquinoline (8-HQ) resin and chemiluminescence detection, (Obata et al., 1993; Sarthou et al., 2003). All analyses were conducted inside a laminar flow hood (ISO 5) within a clean laboratory. Each sample was analyzed in triplicate with a mean blank value equal to $0.020 \pm 0.017 \mathrm{nmol} \mathrm{L}^{-1}(\mathrm{n}=13)$ and a mean detection limit of $0.012 \pm 0.005 \mathrm{nmol} \mathrm{L}{ }^{-1}$. Accuracy was 
checked thoroughly using the North Pacific GEOTRACES reference seawater materials, SAFe $\mathrm{S}$ $\left(0.100 \pm 0.012 \mathrm{nmol} \mathrm{L}^{-1}, \mathrm{n}=12\right)$ and SAFe D2 $\left(0.915 \pm 0.042 \mathrm{nmol} \mathrm{L}^{-1}, \mathrm{n}=12\right)$, and the results were in agreement with the consensus values. The external precision of the dFe measurements was assessed through the replicate analysis of two in-house standards collected in the Southern Ocean (SOSW) $\left(0.09 \pm 0.03 \mathrm{nmol} \mathrm{L}^{-1} ; \mathrm{n}=148\right)$ and in the Mediterranean Sea $\left(0.25 \pm 0.05 \mathrm{nmol} \mathrm{L}^{-1} ; 1 \mathrm{SD}, \mathrm{n}=42\right)$.

Using the whole dataset of $\mathrm{dFe}, \mathrm{dMn}$ and $\mathrm{dSi}$ (i.e. from day 0.21 to day 423 ), we calculated net $\mathrm{dFe}$, $\mathrm{dMn}$ and $\mathrm{dSi}$ dissolution rates using linear regressions between dissolved concentrations and time. The zero order relation between dissolved concentrations and time gave higher correlation coefficients than the first and second order relations and were thus used.

Dissolved Fe organic speciation- A Competitive Ligand Exchange Adsorptive Cathodic Stripping Voltammetry (CLE-ACSV) method was used to measure the dissolved Fe organic speciation, allowing the determination of the Fe organic ligand concentrations and the associated conditional stability constant $\left(\log \mathrm{K}_{\mathrm{Fe} 3+\mathrm{L}}\right)$. This method measured the excess organic ligand concentrations through a competition for Fe between an added artificial ligand ((2-(2-Thiazolylazo)-p-cresol), TAC) and natural

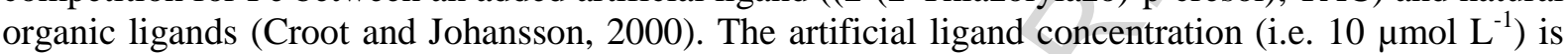
the same as Gerringa et al. (2008) used to measure the Fe organic speciation in the Southern Ocean during the KEOPS-1 cruise.

The samples were immediately frozen at $-20^{\circ} \mathrm{C}$ after filtration and were defrosted at $4{ }^{\circ} \mathrm{C}$ prior to measurement. Then $10 \mathrm{~mL}$ was deposited into each of 10 acid cleaned PFA vials (Savillex ${ }^{\circledR}$ ) and buffered at pH 8 using 8HQ-purified EPPS Buffer (Sigma ${ }^{\circledR} \geq 99.5 \%$ ) within the clean laboratory under a laminar flow hood (ISO 5). The added $\mathrm{Fe}$ (between 0 and $25 \mathrm{nmol} \mathrm{L}^{-1}$ ) was left to equilibrate with the natural ligands for one hour at ambient temperature. Then, TAC was added and the sample left to equilibrate overnight before analysis. The voltammetric equipment consisted of an Autolab Type III Model 663 VA Stand (Metrohm ${ }^{\circledR}$, France) coupled with a sample processor (Metrohm ${ }^{\circledR} 778$ ). A threeelectrode system was used, consisting of a large static mercury drop electrode, a double-junction saturated $\mathrm{AgCl}$ reference electrode with a salt bridge filled with $3 \mathrm{M} \mathrm{KCl}$, and a glassy carbon rod as a counter electrode. Samples were poured automatically into the PFA cup with the sample processor. Each Teflon vial was used consistently for a given Fe addition, with the PFA cup only rinsed with MQ between analyses. The samples were analyzed in the order of increasing $\mathrm{Fe}$ concentrations to minimize contamination. Two samples without any $\mathrm{Fe}$ addition were run before and after each sample sequence as a check for possible contamination of the cell. The voltammetric procedure was differential pulse mode (Croot and Johansson, 2000), with a one minute air purge applied to the sample. Data processing was performed using the van den Berg-Ruzic linearization (Gledhill and van den Berg, 1994; Ruzic, 1982), and excess Fe organic ligand concentrations were calculated by subtracting the dFe concentrations from the total organic ligand concentrations. 


\section{Results}

\subsection{Initial and final sediment composition}

BioSi - This sediment was collected below productive surface waters and contained a dense assemblage of diatom detritus. Whole centric and pennate diatoms were identified (Fig. 2a, b), with diameter and apical length ranging from 10 to $100 \mu \mathrm{m}$.

The SEM observations led to the identification at the genus level (Fragilariopsis sp., coscinodiscus sp. and Thalassiosira sp.), and at the species level (Eucampia antarctica) (Fig. 2b). The presence of diatom detritus was consistent with the elevated concentration of $\mathrm{SiO}_{2}$ measured in this sediment (73.7 $\pm 0.68 \%$ weight, Table 1) and with the detection of hydrous-amorphous silica on the XRD diffractogram, (i.e., deviation of the baseline of the $\mathrm{X}$-axis between $18^{\circ}$ and $28^{\circ}$ (2-Theta-Scale) (Fig. A1)). The lithogenic contribution to the BioSi silica content was estimated using the initial Al abundance (\% weight, Table 1) and with the $\mathrm{Si} / \mathrm{Al}$ weight ratio in mean upper crustal material (3.83; Taylor and McLennan, 1995). The biogenic $\mathrm{Si}\left(\mathrm{bSiO}_{2}\right)$ content was determined by subtracting the lithogenic contribution from the total $\mathrm{Si}$ content. We estimated that the $\mathrm{bSiO}_{2}$ in sediment $\mathrm{A} 3$ accounted for $87 \pm 1 \%$ of the initial particulate $\mathrm{Si}$ stock, i.e., $0.25 \mathrm{mmoles}$ of $\mathrm{bSiO}_{2}$ was introduced initially in the particulate phase in the incubator. This approach was consistent with the SEM observations. According to XRD analyses, the remaining $13.0 \%$ of Si likely consists of plagioclases and clinopyroxene (Table 1). Overall, Fe, Al, and $\mathrm{Mn}$ initial abundances (\% dry weight) in BioSi were only $1.62 \pm 0.16 \%, 2.20 \pm 0.12 \%$, and $0.021 \pm 0.002 \%$, respectively (Table 1 ).

At the end of the incubation, SEM imaging analyses on the BioSi sediment showed that diatom frustules and fragments were still present in the particulate phase and had formed aggregates that were up to $500 \mu \mathrm{m}$ wide (Fig. 2c). Bacillus shaped bacteria, similar to those shown in Fig.4.e, were incorporated into a dense biofilm that covered the biogenic fragments, presumably composed of extracellular exudates (Fig. 2d). Very few lithic grains of $5 \mu \mathrm{m}$ width were observed by SEM-EDS. Due to the small amount of sediment introduced initially in the incubator and recovered at the end of the 14-month incubation, changes in crystallographic assemblages were difficult to determine, and only plagioclase was detected during XRD analysis. 
BioSi+Ca - This sediment, collected east of the plateau and away from the Fe fertilized phytoplankton blooms (Blain et al., 2007), consisted of a dense assemblage of pennate and centric diatomaceous detritus including diatoms such as Fragilariopsis sp. and Eucampia antarctica, interspersed with biogenic calcium carbonate (e.g. foraminiferal tests) and lithogenic fragments (Figs. 3a, b, c and A4).

The silicon content was $44 \%$ less abundant in the BioSi+Ca than in the BioSi sediment (Table 1), and only a slight deviation of the baseline between $18^{\circ}$ and $28^{\circ}$ (2-Theta-Scale) was observed during XRD analysis (Fig. A2). The presence of $\mathrm{bSiO}_{2}$ supports the $73 \pm 5 \%$ estimate of excess silica, calculated using Taylor and Mc Lennan, (1995) Si/Al weight ratio of 3.83. It corresponds to 0.12 mmoles of $\mathrm{bSiO}_{2}$ introduced initially into the carboy, which was $52 \%$ lower than for the BioSi sediment. In addition to diatoms, large structures $(100 \mu \mathrm{m})$ composed mainly of calcite were identified as foraminiferal tests by SEM-EDS analysis (Fig. 3c). These abundant calcite structures corroborated the high calcite percentage (Table 1) and the high proportion of $\mathrm{CaO}(27.1 \pm 1.20 \%$ weight of all crystalline structures) (Table 1). The scattered lithogenic grains corresponded to basaltic to trachybasaltic fragments or glass shards (Fig.3b), in agreement with the minerals detected by XRD (i.e. plagioclase and K-feldspars) (Table 1). The Fe, Al, and Mn initial abundances were $1.42 \pm 0.12$ $\%, 2.61 \pm 0.10 \%$, and $0.038 \pm 0.002 \%$, respectively (Table 1 ).

At the end of the incubation, diatom frustules and fragments, foraminifera tests, and lithogenic fragments were still present (Fig. 3d). Spotty and smaller aggregates than in BioSi sediment were visible and again, bacillus shaped bacteria incorporated into biofilms covered the biogenic and lithogenic fragments (Fig. 3d). The proportion of calcite diminished (Fig. A2), and clays minerals were identified in the replicate XRD analysis at the end of the incubation, while they were not detected in the same $\mathrm{BioSi}+\mathrm{Ca}$ sediments prior to the incubation.

Basalt - The Heard Island sedimenthad the largest grain size of all sediments considered for this study, with some grains up to few millimeters in size (Fig. 4a). Heard Island is located within a moderatebloom area and thus had both lithogenic and biogenic components in the particulate phase.

The sediment was composed of plagioclase (46 to $53 \%$ ), clinopyroxene ( 25 to $39 \%$ ), K-feldspars ( 7 to $14 \%$ ), and olivine ( 2 to $10 \%$ ) (Table 1 ), a common mineral assemblage observed in basalt and trachybasalt. In addition, mono-mineralogical grains such as olivine and coarse basaltic fragments (Fig.4a) were observed. The SEM-EDS analyses revealed the presence of abundant Fe-Ti oxide phases in agreement with the $3.63 \pm 0.10 \%$ of the $\mathrm{TiO}_{2}$ reported in Table 1. Vesicular basalt glass shards were also identified (Fig. 4b), housing centric and pennate diatom detritus, but their highly fragmented state did not allow identification. None of these biogenic fragments were observed by Pearce et al. (2013) in the same sediment sample.Our estimation of $\mathrm{bSiO}_{2}$ content using the $\mathrm{Si} / \mathrm{Al}$ weight ratio of a typical Heard Island basalt (i.e. 3.26 for basalt basanite sample 69287, Barling et al., 1994) did not reveal a significant percentage of $\mathrm{bSiO}_{2}$, and the SEM observations did not provide any evidence of calcite structures. The Basalt sediment had the highest Fe and Mn initial abundances, 11.6 $\pm 0.64 \%$ and $0.142 \pm 0.007 \%$, respectively, and an $\mathrm{Al}$ initial abundance of $13.1 \pm 0.79 \%$ (\% weight, Table 1).

At the end of the incubation, no obvious physical change in Basalt grain appearance was observed, and biogenic fragments were still present. However, the mineralogical phases were certainly modified during the incubation since a significant proportion of clays were newly detected at the end of the incubation (Fig. A3). The inspection at high magnification showed differences in the basaltic glass surfaces in the final sample (Fig. 4e) compared to the initial structure (Fig. 4c). Indeed, the final surface exhibited a glass with a cellular microstructural surface, namely honeycomb-like texture as described in Geptner (2001). Bacillus and filamentous shaped bacteria were identified within a biofilm that covered the majority of the basaltic grains hosting biogenic diatom fragments (Fig. 4d, e, f). The SEM-EDS mapping and spectra at the end of the incubation revealed that the biofilm was enriched in $\mathrm{Fe}$ and others elements such as chlorine, magnesium, and titanium (Fig. 5). 


\subsection{Fluxes of $d F e, d M n$ and $d$ Si during the incubation}

$\boldsymbol{d F e}$ - The mean $\mathrm{dFe}$ concentration of the SOSW Control over the course of the incubation was $0.09 \pm$ $0.03 \mathrm{nmol} \mathrm{L}^{-1}(\mathrm{n}=148)$ and showed no obvious evolution in the absence of sediments over the 14monthsincubation period. This mean value was calculated with SOSW dFe Control samples collected at the beginning of each sampling session on each sampling device line (Fig1.b.3). The mean $\mathrm{dFe}$ concentrations were $0.09 \pm 0.03 \mathrm{nmol} \mathrm{L}^{-1}(\mathrm{n}=50) ; 0.10 \pm 0.03 \mathrm{nmol} \mathrm{L}^{-1}(\mathrm{n}=46)$, and $0.09 \pm 0.03 \mathrm{nmol}$ $\mathrm{L}^{-1}(\mathrm{n}=52)$ for the BioSi, BioSi+Ca and Basalt filtration line respectively. In contrast, in all of the sediment incubation carboys, $\mathrm{dFe}$ concentrations increased over the 14 months, with different starting time of release and the degree of dissolution and desorption depending on the type of sediment. Overall, the largest quantities of $\mathrm{Fe}$ and $\mathrm{Si}$ were released by $\mathrm{BioSi}$, while the most $\mathrm{Mn}$ was released by $\mathrm{BioSi}+\mathrm{Ca}$ (Table 2, Figs. 6a and 6b).

In the BioSi incubation, dFe concentrations did not vary over the first 41 days (Fig. 6a and Table 2). Between day 41 and day 113, the dFe values increased, then continued to increase but at a lower rate between day 113 and day 282. Then, during the last 140 days, BioSi was characterized by a maximum rate of $\mathrm{dFe}$ release of $17.4 \pm 1.6 \mathrm{pmol} \mathrm{L}^{-1} \mathrm{~d}^{-1}$ between day 283 and day 423. Overall, in BioSi incubation the net $\mathrm{dFe}$ dissolution rate was $7.77 \pm 0.61 \mathrm{pmol} \mathrm{L}^{-1} \mathrm{~d}^{-1}\left(\mathrm{R}^{2}=0.90 ; \mathrm{p}<0.0001 ; \mathrm{n}=20\right)$. At the end of the incubation, $\mathrm{dFe}$ concentrations reached $4.00 \pm 0.01 \mathrm{nmol} \mathrm{L}^{-1}$ (Table 2), meaning that net $\mathrm{dFe}$ release for the bSiO2-rich sediment was $3.91 \pm 0.04 \mathrm{nmol} \mathrm{L}^{-1}$ (Table 3).

In the BioSi+Ca incubation, the $\mathrm{dFe}$ concentrations remained close to the initial SOSW $\mathrm{dFe}$ value during the first 57 days (Fig. 6a). From day 57 to day 282, the dFe concentration increased in a somewhat stepwise fashion to $0.42 \pm 0.01 \mathrm{nmol} \mathrm{L}^{-1}$. Overall, the mean dissolution rate was $1.74 \pm 0.18$ pmol L $\mathrm{d}^{-1}\left(\mathrm{R}^{2}=0.84 ; \mathrm{p}<0.0001 ; \mathrm{n}=20\right)$, leading to an enrichment of $0.94 \pm 0.04 \mathrm{nmol} \mathrm{L} \mathrm{L}^{-1} \mathrm{dFe}$ by the end of the incubation (Table 3 ).

In the Basalt incubation, (Fig. 6a), the dFe concentrations also remained close to the initial SOSW dFe value during the first 18 days. Then, a short Fe-release phase was observed between day 18 and day 57. Over the next 40 days, dFe concentrations remained constant $\left(\sim 0.14 \pm 0.05 \mathrm{nmol} \mathrm{L}^{-1}\right)$. From day 98 to the end, there was a regular increase in $\mathrm{dFe}$ concentrations resulting in an overall dissolution rate of $2.57 \pm 0.16 \mathrm{pmol} \mathrm{L}^{-1} \mathrm{~d}^{-1}\left(\mathrm{R}^{2}=0.93 ; \mathrm{p}<0.0001 ; \mathrm{n}=20\right)$. This led to a $\mathrm{dFe}$ enrichment of $1.09 \pm 0.04$ $\mathrm{nmol} \mathrm{L} \mathrm{L}^{-1}$ by the end of the incubation (Table 3 ).

Overall, BioSi and $\mathrm{BioSi}+\mathrm{Ca}$ sediments released, respectively, $0.40 \pm 0.04 \%$ and $0.11 \pm 0.01 \%$ of the initial particulate $\mathrm{Fe}(\mathrm{pFe})$ stocks contained in the sediment while Basalt sediment only released 0.015 $\pm 0.001 \%$ (Table 3). The initial dFe SOSW pool was enriched by factors of 44, 10 and 12, respectively, at the end of the incubations in the $\mathrm{BioSi}, \mathrm{BioSi}+\mathrm{Ca}$ and Basalt carboys.

$\boldsymbol{d M n}$ - The initial dMn concentration of SOSW was $0.26 \pm 0.07 \mathrm{nmol} \mathrm{L}^{-1}(\mathrm{n}=40)$. The $\mathrm{dMn}$ temporal patterns weredifferent from the $\mathrm{dFe}$ patternsand revealed very distinct trends among the three sediment types (Table 2, Fig. 6b).

A drastic depletion of the $\mathrm{dMn}$ in BioSi was observed from day 2 to day 57 , after which dMn stabilized at around $0.04 \pm 0.02 \mathrm{nmol} \mathrm{L}^{-1}$ through day 220. From day 220 to the end, dissolution of $\mathrm{dMn}$ occurred, but only very slowly. At the end of the incubation, the dMn pool remained depleted by $0.16 \pm 0.07 \mathrm{nmol} \mathrm{L}^{-1}$ relative to the initial concentration (Table 3). Overall, the $\mathrm{Mn}$ dissolved pool in BioSi incubation lost $0.40 \pm 0.18 \mathrm{pmol} \mathrm{L}^{-1} \mathrm{~d}^{-1}\left(\mathrm{R}^{2}=0.20\right.$; ANOVA; $\left.\mathrm{p}=0.0454 ; \mathrm{n}=20\right)$ (Table 3).

In the $\mathrm{BioSi}+\mathrm{Ca}$ incubation, rapid $\mathrm{dMn}$ release occurred immediately after the sediment addition (Fig. $6 b)$. During the first two days, Mn dissolution was high before slowing thereafter until day 282 when a plateau was reached. That remained until the end with $8.03 \pm 0.42 \mathrm{nmol} \mathrm{L}^{-1}$ of $\mathrm{dMn}$ released with a net dissolution rate of $17.0 \pm 3.23 \mathrm{pmol} \mathrm{L}^{-1} \mathrm{~d}^{-1}\left(\mathrm{R}^{2}=0.61 ; \mathrm{p}<0.0001 ; \mathrm{n}=20\right)$ (Table 3).

The evolution of dMn concentration in the Basalt incubation had five distinct stages (Fig. 6b). During the first week, the initial SOSW dMn content increased by $0.33 \pm 0.09 \mathrm{nmol} \mathrm{L}^{-1}$. Between day 8 and 
57, the concentration dramatically decreased, returning approximately to the initial value. Over the following 20 days, dMn was quickly and strongly released until day 71 . This was followed by a $150-$ day period of slow depletion of the dMn pool until day 220. Finally, during the last 200 days, the previous depletion phase was counter-balanced by a dissolution period. At the end of the incubation period, the initial dMn pool was enriched by $0.28 \pm 0.09 \mathrm{nmol} \mathrm{L}^{-1}$ and the net dissolution rate achieved $0.09 \pm 0.19 \mathrm{pmol} \mathrm{L}^{-1} \mathrm{~d}^{-1}\left(\mathrm{R}^{2}=0.01\right.$; ANOVA; $\left.\mathrm{p}=0.64 ; \mathrm{n}=20\right)$ (Table 3).

After 423 days of incubation, the dissolution percentage of the initial particulate $\mathrm{Mn}$ (pMn) stock in $\mathrm{BioSi}+\mathrm{Ca}$ was the highest of all 3 incubaors at $30.0 \pm 2.9 \%$, such that the initial dMn SOSW content was enriched by a factor of 33. Dissolution dominated in the Basalt incubation leading to a final $\mathrm{dMn}$ concentration equal to twice the initial value, yet only $0.28 \pm 0.10 \%$ of initial $\mathrm{pMn}$ was estimated to have dissolved (Table 3). dMn removal dominated in the BioSi incubation, leading to an 8-fold decrease in initial SOSW dMn content, equivalent to a final enrichment of the initial particulate stock by $1.06 \pm 0.42 \%$.

$\boldsymbol{d S i}$ - The initial dSi concentration in SOSW was $11.70 \pm 0.05 \mu \mathrm{mol} \mathrm{L} \mathrm{L}^{-1}$. After addition of sediment, dSi concentrations increased in all reactors but with different release rates over time (Table 2, Fig. 6c). The highest rates were measured during the first 28 days for $\mathrm{BioSi}$ and $\mathrm{BioSi}+\mathrm{Ca}$ and the first 98 days for the Basalt. In the Basalt incubator, after day 98, a plateau was reached at $11.81 \pm 0.06 \mu \mathrm{mol} \mathrm{L}^{-1}$. In the BioSi and BioSi+Ca incubations, concentrations increased until the end of the study, albeit more slowly than during the first 28 days. At the end of the incubation period, the net release of dSi was equal to $5.48 \pm 0.07 \mu \mathrm{mol} \mathrm{L}^{-1}$ for the BioSi sediment, $2.84 \pm 0.10 \mu \mathrm{mol} \mathrm{L}^{-1}$ for the BioSi+Ca sediment and $0.13 \pm 0.05 \mu \mathrm{mol} \mathrm{L}^{-1}$ for the Basalt sediment with net dissolution rates achieving respectively $11.62 \pm 2.75 \mathrm{nmol} \mathrm{L} \mathrm{L}^{-1} \mathrm{~d}^{-1}\left(\mathrm{R}^{2}=0.82 ;\right.$ ANOVA; $\left.\mathrm{p}=0.01 ; \mathrm{n}=6\right), 6.26 \pm 1.28 \mathrm{nmol} \mathrm{L} \mathrm{d}^{-1} \mathrm{~d}^{-1}\left(\mathrm{R}^{2}=0.86\right.$; ANOVA; $\mathrm{p}=0.008 ; \mathrm{n}=6)$ and $0.33 \pm 0.11 \mathrm{nmol} \mathrm{L}^{-1} \mathrm{~d}^{-1}\left(\mathrm{R}^{2}=0.67\right.$; ANOVA; $\left.\mathrm{p}=0.05 ; \mathrm{n}=6\right)($ Table 3$)$.

Overall, $9.23 \pm 0.20 \%$ and $8.30 \pm 0.64 \%$ of the initial particulate $\mathrm{Si}$ (pSi) stocks of BioSi and $\mathrm{BioSi}+\mathrm{Ca}$ incubations dissolved respectively, whereas this percentage only reached $0.33 \pm 0.04 \%$ in the Basalt carboy.

To summarize, $\mathrm{dFe}, \mathrm{dMn}$ and $\mathrm{dSi}$ pools were enriched at the end of the incubation period in all treatments, with the exception of dMn depletion in the BioSi treatment.

\subsection{Variation of $\mathrm{pH}$, bacterial abundance and Fe organic ligands}

$\boldsymbol{p H}$ - After the addition of sediments, a rapid decrease in $\mathrm{pH}$ from the initial value of 8.03 was observed in all three incubators, while the Control did not vary more than $0.18 \mathrm{pH}$ unit during the entire incubation period (Table 2). Overall, $\mathrm{pH}$ in the three sediment treatments decreased by $\sim 0.4 \mathrm{pH}$ unit by the end of the incubation.

Viable bacteria- Bacterial abundance was monitored in Control SOSW and in each carboy over the first 282 days of the incubation. Unfortunately, a flow cytometer failure prevented data collection on the last day of the incubation (Table 2). Despite having been filtered at $0.22 \mu \mathrm{m}$ when collected, the SOSW contained $3 \times 10^{5}$ cells $\mathrm{mL}^{-1}$ of viable bacteria when the incubation began. During the incubation period, the bacterial population in the Control SOSW fluctuated around the initial concentration and did not exceed $8.1 \times 10^{5}$ cells $\mathrm{mL}^{-1}$. Similar fluctuations were observed over the first 41 days for the three sediment treatments (Fig. 7b). After 41 days, bacterial populations in the three incubators increased differentially. In the Basalt carboy, the bacterial concentration increased 6-fold by day 71, then remained constant until day 178 where a maximum was reached $\left(2.14 \pm 0.02 \times 10^{6}\right.$ cells $\mathrm{mL}^{-1}$, Table 2). In BioSi and BioSi+Ca carboys, bacterial concentrations increased by 14 - and 18 -fold, respectively, between day 41 and day 129, with the maximum cell densities reached earlier than in the Basalt carboy, both at day $129\left(5.4 \pm 0.1 \times 10^{6}\right.$ cells $\mathrm{mL}^{-1}$ in BioSi and $4.2 \pm 0.410^{6} \mathrm{cells} \mathrm{mL}^{-1}$ in $\mathrm{BioSi}+\mathrm{Ca}$ ). Finally, between day 129 and day 283, the bacterial population decreased drastically in the $\mathrm{BioSi}$ and $\mathrm{BioSi}+\mathrm{Ca}$ treatment by 3.5 and 2.7 , respectively. This last period was characterized by bacterial mortality in all three sediment incubations. 
Fe Organic speciation- Specific trends were observed for each incubation (Table 2, Fig 7b). In the BioSi carboy, no excess ligand was measured at day 0.21, indicating an initial saturation of the ligands. Then the concentration increased to reach $1.33 \pm 0.43 \mathrm{nEq}$ of $\mathrm{Fe}(\mathrm{III})$ at day 98 (Fig. $7 \mathrm{~b}$ ). At days 220 and 282, no excess Fe organic ligand was detected. The pool of free Fe organic ligands was highest in the BioSi+Caincubation, increasing between day $0.21(0.49 \pm 0.11 \mathrm{nEq}$ of $\mathrm{Fe}(\mathrm{III}))$ and day $98(1.99 \pm 0.09 \mathrm{nEq}$ of $\mathrm{Fe}(\mathrm{III}))$ (Fig. $7 \mathrm{~b})$. The pool was then stable at day 220 and no excess ligands were detected at day 282. In the Basalt carboy, free ligand concentrations were $0.76 \pm 0.06 \mathrm{nEq}$ of $\mathrm{Fe}(\mathrm{III}))$ at day 0.21 , increased at day $220(1.96 \pm 0.02 \mathrm{nEq}$ of $\mathrm{Fe}(\mathrm{III}))$ and decreased at the end of the incubation $(0.68 \pm 0.11 \mathrm{nEq}$ of $\mathrm{Fe}(\mathrm{III}))$ (Fig. $7 \mathrm{~b})$.

The average stability constants of the natural organic ligand pool were $22.35 \pm 0.12 ; 22.78 \pm 0.22$ and $23.28 \pm 0.06$ in the BioSi, BioSi+Ca and Basalt incubations, respectively (Table 2). These values

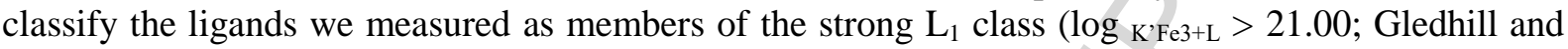
Buck, 2012). 


\section{Discussion}

Throughout the course of the 14-month incubation, the composition of SOSW evolved differently as a function of time depending on the sediment added. Our results reveal that the flux of trace metals from the resuspended sediments to the dissolved trace metal pool is not only dependent on the initial sediment trace metal content. In the following, we will first discuss how the mineralogical and elemental composition of the sediment and bio-mediated processes can explain the release of $\mathrm{dFe}$ and $\mathrm{dMn}$. Then, we estimate the impact of the resuspended sediment pool on the water column around Kerguelen Islands, an area that has been extensively studied for natural iron fertilization processes, and finally, we explore the differences in $\mathrm{Fe}$ and $\mathrm{Mn}$ behavior observed during the incubation.

\subsection{Factors controlling the release of Fe and Mn from particles of sedimentary origin}

\subsubsection{The mineralogical and elemental composition of the sediments}

Although similar initial stocks of $\mathrm{pFe}$ were present in the two sediments collected over the Kerguelen plateau (BioSi) and off the plateau (BioSi+Ca) (Table 1), the BioSi sediment released 4.2 times more $\mathrm{dFe}$ than the $\mathrm{BioSi}+\mathrm{Ca}$ sediment. In addition, the BioSi initially contained just $15 \%$ of the total $\mathrm{pFe}$ in the Basalt sediment collected close to Heard Island, but 3.6 times more dFe was released from BioSi than from Basalt. In contrast, Mn displayed the opposite behavior: despite similar initial pMn content in BioSi and in BioSi+Ca sediments, the BioSi+Ca incubation had a net release of $8.03 \pm 0.42 \mathrm{nmol} \mathrm{L}^{-}$ ${ }^{1}$ of $\mathrm{dMn}$ while the BioSi carboy was depleted in $\mathrm{dMn}\left(-0.16 \pm 0.07 \mathrm{nmol} \mathrm{L}^{-1}\right)$ at the end of the incubation. On the other hand, the Basalt sediment released just 3\% dMn of that released by $\mathrm{BioSi}+\mathrm{Ca}$. Again, this large difference was not proportional to the initial pMn loading.

\subsubsection{Sediments dominated by the presence of biogenic silica}

The BioSi and $\mathrm{BioSi}+\mathrm{Ca}$ sediments were composed of a high percentage of $\mathrm{bSiO}_{2}$ (87 and $73 \%$ respectively). TheSEM imaging revealed the abundance of preserved diatoms and diatom fragments in BioSi and $\mathrm{BioSi}+\mathrm{Ca}$, which supports the diatom-laden observations in sediments collected at the same stations at the seawater/sediment interface (Armand et al., 2008). Indeed, the majority of the diatom groups identified by Armand et al. (2008) were present at both sites. The large release of dSi observed during the incubation of both $\mathrm{bSiO}_{2}$ rich sediments (Fig. 6c) was likely a result of $\mathrm{bSiO}_{2}$ dissolution, because inorganic ordered silica phases (e.g., kaolinite) have dissolution kinetics that are orders of magnitude slower than those of biosiliceous ooze (Van Cappellen and Qiu 1997; Dixit et al., 2001). This was also consistent with the very low concentration of dSi released by the Basalt sediment (Fig. 6c).

Over the course of the incubation, the $\mathrm{dFe}$ released by $\mathrm{BioSi}$ and $\mathrm{BioSi}+\mathrm{Ca}$ showed a significant linear correlation with released $\mathrm{dSi}$, when $\Delta \mathrm{dSi}$ concentrations range from $\sim 2$ to $\sim 6 \mu \mathrm{mol} \mathrm{L}^{-1}$ (Fig. $8 \mathrm{a}, \mathrm{R}^{2}=$ 0.70; ANOVA; $\mathrm{p}=0.005 ; \mathrm{n}=9$ ). 
Therefore, $70 \%$ of the variability of the $\mathrm{dFe}$ released can be explained by the release of dSi resulting from $\mathrm{bSiO}_{2}$ dissolution. It is known that $\mathrm{Fe}$ and other trace metals can be incorporated into diatom frustules as observed in culture experiments for Thalassiosira pseudonana (Ellwood and Hunter, 2000) and Cyclotella meneghiniana (de Jonge et al., 2010). Ingall et al. (2013) confirmed the structural incorporation of $\mathrm{Fe}$ into the diatom frustule of Fragilariosis spp. collected in the Ross Sea (Southern Ocean). These diatoms were present in both our $\mathrm{bSiO}_{2}$ rich sediments (Fig $2 \mathrm{~b}$ and A4). Using the median Fe:Si ratio of $328 \mu \mathrm{mol} \mathrm{mol}^{-1}$ determined by Ingall et al. (2013), we can calculate a theoretical $\mathrm{dFe}$ release associated with the net release of $\mathrm{dSi}$ at the end of the incubation. This $\mathrm{dFe}$ theoretical release corresponds to $1.80 \pm 0.02 \mathrm{nmol} \mathrm{L}^{-1}$ for the BioSi sediment and $0.93 \pm 0.03 \mathrm{nmol} \mathrm{L}$

${ }^{1}$ for the $\mathrm{BioSi}+\mathrm{Ca}$ sediment. These values are in the range of net $\mathrm{dFe}$ release measured at the end of the incubation (Table 3), and are in agreement with the fact that BioSi sediment contained 2.1 times more $\mathrm{bSiO}_{2}$ than $\mathrm{BioSi}+\mathrm{Ca}$ sediment. Based on this calculation , the dissolution of $\mathrm{bSiO} 2$ explains 50 $\%$ of the total $\mathrm{dFe}$ released in the BioSi treatment, yet it supports the entire dFe flux in the BioSi+Ca treatment. ForBioSi, in addition to the Fe incorporated into the frustule, some quantity of Fe could have been adsorbed onto the frustule surface and would be released when the frustules dissolved. Also, the organic matter present at the surface of some diatomaceous debris (Fig. A5) may contain $\mathrm{Fe}$ that was released over the course of the incubation. .

If $\mathrm{bSiO}_{2}$ in $\mathrm{BioSi}$ and $\mathrm{BioSi}+\mathrm{Ca}$ sediments were the main reservoir of $\mathrm{dFe}$ in this incubation, the instantaneous release of $\mathrm{dSi}$ at the beginning of the experiment should have been linked to an instantaneous release of $\mathrm{dFe}$ before day 28 for $\mathrm{BioSi}$ and before day 98 for $\mathrm{BioSi}+\mathrm{Ca}$. However, no obvious increase of dFe was measured over these two periods (Fig 8a), although Fe organic ligands were present in excess and could have stabilized some of the Fe released to the dissolved phase (Fig. 7b). Uptake by the bacterial community cannot explain an apparent lack of increase in the dFe pool either, because the bacterial $\mathrm{Fe}$ requirement did not exceed $40 \mathrm{pmol} \mathrm{L}^{-1}$ (see section 4.1.2.2) which was well below what we measured. We propose that instantaneous release of dFe did occur, but that most of the released $\mathrm{dFe}$ was adsorbed onto reactive (nano-)minerals (e.g. Fe-Mn oxyhydroxydes and clays), meaning that,adsorption onto particle surfacse outcompeted dissolved ligands for the released $\mathrm{Fe}(\mathrm{III})$.

The release of $\mathrm{dMn}$ also appeared to be link linked to the release of $\mathrm{dSi}$ (Fig 8b) by the BioSi+Ca sediment $\left(\mathrm{R}^{2}=0.87, \mathrm{p}=0.006\right)$. We suggest, however, that this relationship was misleading. Indeed, if the dissolution of $\mathrm{bSiO}_{2}$ sediment were responsible for the release of $\mathrm{dMn}$, a similar correlation should have been observed for BioSi sediment, which contained similar diatom species, including Fragilariopsis spp. (Fig. S4). In addition, the BioSi sediment contained two times more initial biogenic silica than the BioSi+Ca sediment and as such, it should have released more $\mathrm{dMn}$. This was not the case. We therefore suggest that the dMn flux observed in the BioSi+Ca incubation originates from others particles than diatoms. This is discussed in section 4.1.1.2 below.

Interestingly, during the first 28 days on the BioSi incubation, dMn decreased while no dFe (Fig. 6a and b) was released. Later, around day 50, dMn concentrations stabilized, while dFe release increased. Along the same lines, in the BioSi+Ca incubation, the release of $\mathrm{dFe}$ only started when $\mathrm{dMn}$ concentration stabilized between day 50 and day 98. The oxidation and precipitation of dissolved $\mathrm{Mn}(\mathrm{II})$ as $\mathrm{Mn}$ oxyhydroxides (Ahrland, 1975) could be responsible of the decrease in $\mathrm{dMn}$ concentrations over the first 28 days of resuspension in the BioSi treatment. Similar processes should have occurred in the BioSi+Ca incubation but the high level of dMn released might have partly obscured the precipitation of Mn oxyhydroxides.

Mn oxyhydroxides are often recognized as "scavengers of the sea" (Goldberg, 1954) because of their high sorptive capacities that allow them to adsorb a wide range of ions, and ultimately to control the distribution and the bioavailability of many toxic and essential elements (Tebo et al., 2004). Because $\mathrm{Fe}$ is one of the cations whose cycling is affected by these processes (Tebo et al., 2004), the formation of Mn oxyhydroxides that scavenged $\mathrm{dFe}$ could have driven the lack of initial $\mathrm{dFe}$ release in the BioSi incubation until day 28 and in the $\mathrm{BioSi}+\mathrm{Ca}$ treatment until day 98 . We can also infer that this process was prevailing over organic complexation of $\mathrm{Fe}$ by the ligands produced in solution, particularly in the 
BioSi incubation, where the removal of dMn was so intense that $90 \%$ of the initial dMn of the SOSW was removed from solution by the end of the incubation.

As the dMn level was still below the SOSW initial concentration at the end of the incubation for BioSi, we suppose that $\mathrm{Mn}$ oxyhydroxides were still present in thecarboy. Although no $\mathrm{Mn}$ oxyhydroxide could be detected by SEM-EDS imaging at the end of the incubation, this could be due to the low level of Mn present $(<0.05 \mathrm{wt} \%$ in the initial sediments, Table 1) or because this $\mathrm{Mn}$ oxyhydroxide fraction was associated with particles too small (i.e. $<0.22-0.45 \mu \mathrm{m}$ ) to be collected on the filter at the end of the incubation. However, given the variations in the concentrations of $\mathrm{dMn}$ and $\mathrm{dFe}$ in the incubations, it seems likely that the formation of Mn oxides exerted a strong control on the release of $\mathrm{dFe}$ from $\mathrm{bSiO}_{2}$ dissolution and its transfer from the particulate to the dissolved pool (e.g. Balistrieri and Murray, 1984).

Clays are another particle type onto which $\mathrm{dFe}$ and $\mathrm{dMn}$ may have adsorbed. The conversion of $\mathrm{bSiO}_{2}$ into authigenic clays has already been observed through laboratory experiments with Amazon River delta sediments by Michalopoulos et al. (2000). More recently, Loucaides et al. (2010) observed with TEM-EDX the amorphous accumulation of various types of precipitates containing $\mathrm{Mg}, \mathrm{Fe}, \mathrm{Mn}, \mathrm{Al}$, and $\mathrm{P}$ at the surface of diatom frustules $(\sim 1 \mu \mathrm{m}$ wide) and/or incorporation of Fe and $\mathrm{Mn}$ into nanostructures of the frustules during dissolution of $\mathrm{bSiO}_{2}$ in the presence of terrigenous sediments. The time scale of these processes varied between 10 to 23 months (Loucaides et al., 2010, Michalopoulos et al., 2000), i.e., they may have occured near the end of our incubation period. Clays were indeed detected by XRD and SEM-EDS analysis in the BioSi+Ca treatment at the end of the incubation period. They appeared as small precipitates $(\sim 2 \mu \mathrm{m}$ wide) with a composition similar to clay and including Fe (Fig. A6). In the BioSi carboy, clays were not detected at the end of the incubation.

Overall, the dissolution of $\sim 10 \%$ of the initial $\mathrm{bSiO}_{2}$ stock explained $70 \%$ of the variance of the released $\mathrm{dFe}$ in $\mathrm{BioSi}$ and $\mathrm{BioSi}+\mathrm{Ca}$ incubations at the end of the incubation, while the remaining $30 \%$ was possibly associated with the dissolution of particulate organic matter or to the dissolution of others structures hosting Fe such as calcite (see below, section 4.1.1.2). Finally, the release of dFe and $\mathrm{dMn}$ was most likely influenced by the formation of $\mathrm{Mn}$ oxyhydroxides throughout the incubation (and especially over the first month for BioSi and the first three months for $\mathrm{BioSi}+\mathrm{Ca}$ ) and by the formation of clays at the end of the incubation period.

\subsubsection{Calcite-rich sediments}

Calcite was dominant $(80 \mathrm{wt} \%)$ in the mineralogical composition of the sediment collected off the plateau (BioSi+Ca, Table 1). Calcite was only $8 \mathrm{wt} \%$ in BioSi sediment, while no calcite was identified in the Basalt sediment after XRD analysis as well as SEM-EDS imaging.

Calcite results from the accumulation of biogenic calcium carbonate foraminifera tests that were indeed observed in the BioSi+Ca sediment (Fig. 3c). Calcite dissolution likely occurred during our sediment incubation, as traced by the $\mathrm{pH}$ decrease of $\sim 0.4$ in the $\mathrm{BioSi}$ and $\mathrm{BioSi}+\mathrm{Ca}$ treatments (Table 2, Fig. 7a). Indeed, the development of heterotrophic bacteria with the associated release of $\mathrm{CO}_{2}$ in the carboys must have changed the carbonate equilibrium and may have dissolved the calcite (e.g. Haynert et al., 2011; Kleypas and Langdon 2013). The specific role of bacteria will be discussed further in section 4.1.2. Moreover, calcite is known to hold impurities including $\mathrm{Fe}$ and $\mathrm{Mn}$ (de Nooijer et al., 2007; Pena et al., 2008; Prentice et al., 2014) and could thus be an additional source of dissolved trace metals. Based on the $\mathrm{Fe} / \mathrm{Ca}$ and $\mathrm{Mn} / \mathrm{Ca}$ ratios measured in foraminifera skeletons of planktonic and benthic organisms (Lea, 2003), we estimated the potential implication of calcite dissolution in the release of dissolved trace metals. Assuming that all the $\mathrm{Ca}$ measured in $\mathrm{BioSi}+\mathrm{Ca}$ sediment was assigned to foraminifera tests (the plagioclase contribution was considered to represent less than $1.5 \mathrm{wt} \% \mathrm{Ca}$ ), we multiplied the $\mathrm{Ca}$ concentration (Table 1) by $\mathrm{Fe} / \mathrm{Ca}$ and $\mathrm{Mn} / \mathrm{Ca}$ ratios provided by Lea (2003) ( $0.1 \mu \mathrm{mol}$ of $\mathrm{Fe}^{2+}$ and between 100 and $500 \mu \mathrm{mol}$ of $\mathrm{Mn}^{2+}$ per mol of Ca). For 
BioSi, due to a significant proportion of Ca-bearing silicates (up to 68\%; e.g. plagioclase and clinopyroxene, Table 1), we assumed that only one third of the Ca concentration determined by ICPAES was related to foraminifera tests. The particulate TM stocks potentially associated with calcite were divided by the volume of seawater in each carboy for BioSi and $\mathrm{BioSi}+\mathrm{Ca}$ sediments to estimate the maximum release of TM, assuming complete dissolution of calcite structures. Based on this calculation, calcite dissolution would lead to a maximum of $0.3 \mathrm{nmol} \mathrm{L}^{-1}$ and $8 \mathrm{pmol} \mathrm{L}^{-1}$ of $\mathrm{dFe}$ released in the $\mathrm{BioSi}+\mathrm{Ca}$ and $\mathrm{BioSi}$ treatments respectively. This was a rather small reservoir when compared to $\mathrm{bSiO}_{2}$, strengthening the hypothesis that biogenic silica can be considered as the main reservoir of $\mathrm{dFe}$ in the $\mathrm{BioSi}$ and $\mathrm{BioSi}+\mathrm{Ca}$ incubations.

Using the same calculation, calcite dissolution could have led to a release of $0.5 \mathrm{nmol} \mathrm{L}{ }^{-1}$ of $\mathrm{dMn}$ in the BioSi treatment. However, dMn decreased systematically, leading to a strong depletion of the initial SOSW dMn concentration, with almost complete exhaustion of the dMn stocks after 57 days. It was thus possible that $\mathrm{dMn}$ from calcite dissolution rapidly precipitates as Mn oxyhydroxides, as demonstrated in section 4.1.1.1, and contributes to the depletion in dMn observed during the first 57 days of the incubation. In the $\mathrm{BioSi}+\mathrm{Ca}$ treatment, calcite dissolution would lead to a maximum $\mathrm{dMn}$ concentration of $12.0 \mathrm{nmol} \mathrm{L}^{-1}$, which is the same order of magnitude as the concentration measured at the end of the incubation (i.e. $8.03 \mathrm{nmol} \mathrm{L}^{-1}$ ). This final $\mathrm{dMn}$ concentration would correspond to the dissolution of 60 to $70 \%$ of the initial calcite stock, which is in agreement with the decrease observed by XRD at the end of the incubation. These high levels of dMn released obscured any evidence of $\mathrm{dMn}$ depletion by Mn oxyhydroxide formation, if it occurred. It seems therefore highly plausible that calcite dissolution has supplied most of the $\mathrm{dMn}$ in the $\mathrm{BioSi}+\mathrm{Ca}$ incubation, explaining at the same time the misleading correlation between $\mathrm{dMn}$ and the release of $\mathrm{bSiO}_{2}$ (Fig. 8b).

These calculations allowed identifying calcite as the potential main reservoir of $\mathrm{dMn}$ in the $\mathrm{BioSi}+\mathrm{Ca}$ treatment and probably in the BioSi treatment as well despite a rapid precipitation process. They also strengthened the hypothesis of the essential role of $\mathrm{bSiO}_{2}$ in supplying the $\mathrm{dFe}$ flux in $\mathrm{BioSi}$ and $\mathrm{BioSi}+\mathrm{Ca}$ incubations, as calcite could only supply picomolar levels of $\mathrm{dFe}$. Overall, two main reservoirs of particulate trace metals appear to have been available for dissolution in BioSi and $\mathrm{BioSi}+\mathrm{Ca}$ sediments: $\mathrm{bSiO}_{2}$ for $\mathrm{pFe}$ and calcite for $\mathrm{pMn}$.

\subsubsection{Sediment dominated by the presence of basaltic grains}

SEM observations combined with XRD analyses confirmed the basaltic origin of the Basalt sediment collected close to Heard Island. This mineralogical description was also in good agreement with the mineralogy identified by Pearce et al. (2013) on the same sample, and its elemental composition was similar to the composition of a series of basalt samples collected at Heard Island (i.e. basalt basanite sample 69287, Barling et al. (1994)).

Based on our $\mathrm{bSiO}_{2}$ estimation, no significant percentage of $\mathrm{bSiO}_{2}$ was identified in Basalt sediment, despite the presence of a small amount of frustule debris identified by SEM in some of the basalt glass vesicles (Fig. 4b). Thus, the initial Fe and Mn particulate stocks in the Basalt treatment were mainly of lithogenic origin, which strongly contrasts with the BioSi and $\mathrm{BioSi}+\mathrm{Ca}$ sediments.

Olivine, Clinopyroxene, Fe-Ti oxides, as well as the basaltic glass were the main carriers of $\mathrm{Fe}$ and $\mathrm{Mn}$ in the Basalt sediment (Fig. A7). The small amount and rapid stabilization of the dSi released compared to the release of $\mathrm{dSi}$ by biogenic sediments, the detection of clay and the alteration of the surface basaltic glass at the end of the incubation (Fig. 4e) confirmed the transformation of this Basalt sediment. The release of $\mathrm{dSi}, \mathrm{dMn}$ and $\mathrm{dFe}$ was expected from the alteration of basaltic glasses (i.e.palagonitization) even if the extent and direction of element mobility can vary with changes in physico-chemical parameters (e.g. Stroncik and Schmincke, 2002). The lack of correlation between $\mathrm{dSi}, \mathrm{dFe}$ and dMn (ANOVA; $0.14<\mathrm{p}<0.46)$ underline the complex feedback mechanisms related with the palagonitization. The possibility of olivine as the source of $\mathrm{dFe}$ and $\mathrm{dMn}$ cannot be ruled out. Pearce et al., (2013), who carried out a sediment-seawater reaction study using the same Basalt sediment, but used a rock/water ratio 200 times higher than in the current incubation, reported a 
significant decrease in the olivine fraction at the end of their 4-months experiment. In our study, the high error associated with the low final olivine percentage prevents us from drawing a statistically significant conclusion.

Overall, the time series of $\mathrm{dFe}$ and $\mathrm{dMn}$ showed a distinct enrichment over the initial SOSW concentration by the end of the incubation by a factor of 13 and 2 respectively. Depletion periods observed right after day 0.21 until day 18 for $\mathrm{dFe}$, and from day 8 to day 57 for dMn were similar to observations in other studies involving riverine basalts resuspended in seawater, though those employed lower water/rock ratios than our incubation (i.e. 3.6 and 115 to 130 for Jones et al. (2012b) and Stefánsdóttir and Gíslason (2005) respectively). Jones et al. (2012b) suggested that Mn was incorporated into a precipitating secondary phase while Stefánsdóttir and Gíslason, (2005) argued that $\mathrm{dFe}$ was consumed by formation of an Fe-phase, most likely amorphous $\mathrm{Fe}(\mathrm{OH})_{3}$. Precipitating secondary phases including Mn oxyhydroxides that could have scavenged Fe were not detected by SEM analysis performed at the end of the incubation. But this set of final observations might not reflect the state of the basaltic grains during the first 50 days, when dFe slightly decreased. However, SEM-EDS mapping revealed a positive Fe anomaly in the biofilm covering the surface of the Basalt grains at the end of the incubation (Fig. 5), while no biofilm was observed on the sediment before resuspension. This will be investigated in the next section (4.1.2), where bio-mediated processes are discussed.

Overall, despite an initial Fe content in the Basalt sediment that was 7.2 and 8.2 times higher than in BioSi and BioSi+Ca, respectively, only $1.09 \pm 0.04 \mathrm{nmol} \mathrm{L}^{-1}$ of $\mathrm{dFe}$ was released by the end of the incubation, yielding the lowest dissolution percentage of the three sediments (i.e. $0.015 \pm 0.001 \%$ ) (Table 3). The initial Basalt pMn content was 3.8 and 6.8 times greater than in BioSi and BioSi+Ca sediments respectively, yielding a release of $1.16 \pm 0.06 \mathrm{nmol} \mathrm{L}^{-1}$ (Table 3). The flux of metals from the Basalt sediment to the dissolved pool was much lower than the contribution of $\mathrm{bSiO}_{2}$ to $\mathrm{Fe}$ and of calcite to $\mathrm{Mn}$.

\subsubsection{Potential bio-mediated processes}

The initial bacterial abundance measured in the ControlSOSW, despite filtration at $0.22 \mu \mathrm{m}$ upon collection, was in the range of bacterial concentrations encountered over Kerguelen plateau within the upper wind mixed layer, both inside and outside the naturally fertilized area (Christaki et al., 2014; Christaki et al., 2008). Such initial bacterial concentrations were also in the range typically reported for natural benthic nepheloid layers (i.e. from $10^{4}$ to $10^{5}$ cells $\mathrm{mL}^{-1}$; e.g. Boetius et al., 2000 and Ziervogel et al., 2016). Several studies describe at least a 2-fold increase in microbial activity within the nepheloid layers compared to the intermediate water column (e.g. Boetius et al., 2000; Wainright 1987). In laboratory experiments under natural environmental conditions, more than a 2 -fold increase in bacterial population (i.e. from 2.0 to $4.9 \times 10^{5}$ cells $\mathrm{mL}^{-1}$ ) was observed in roller bottles filled with natural bottom seawater with resuspended sediments originating from the benthic nepheloid layer formed in the deep Gulf of Mexico, compared to the sediment-free seawater control (Ziervogel et al., 2016). These data suggest that the formation of benthic nepheloid layers in this area involves the transport of sedimentary organic matter into bottom waters and stimulates bacterial food web interactions. Therefore, the upper range of bacterial concentrations observed around day 130 in $\mathrm{BioSi}$ and $\mathrm{BioSi}+\mathrm{Ca}$ treatments and later at day 178 for the Basalt treatment could be due to a nutrient input originating from the sediments, such as particulate organic matter.

Input of organic matter may have caused bacterial growth and could also have led to oxygen consumption. To investigate whether the initial oxygen stock was sufficient to maintain oxic conditions over the course of the incubation, we evaluated the bacterial activity in terms of dioxygen consumption. We multiplied respiration rates from Kerguelen area (i.e. $0.02-0.07 \mathrm{fmol} \mathrm{O}_{2}$ cell $^{-1} \mathrm{~d}^{-1}$ at Stations A3 and $0.06 \mathrm{fmol} \mathrm{O}_{2}$ cell $^{-1} \mathrm{~d}^{-1}$ at station $\mathrm{C} 11$ (Obernorsterer et al., 2008) by the bacterial cell density measured at each time step (assuming that cell density was constant from one sampling step to the next) and finally by the number of days elapsed between each sampling period. Based on these calculations, 90 - 98\% of the initial oxygen stock was still available in each sediment-seawater system 
after 282 days of the incubation (bacterial concentrations not available at day 423). Therefore, variations in oxygen concentrations over the course of the first 282 days do not seem to be a critical point for the redox conditions of our incubation. If we also considered the oxygen diffusivity through the wall of the LDPE carboy over the course of the incubation, estimated to supply few $\mu$ mol of $\mathrm{O}_{2} \mathrm{~L}^{-1}$ $\mathrm{d}^{-1}$ (Kjeldsen, 1993), therefore the incubations very likely remained oxic throughout.

\subsubsection{On the particulate TM reservoirs}

Biogenic silica- During the incubation, the $\mathrm{dSi}$ concentrations of both $\mathrm{bSiO}_{2}$ rich sediments $(\mathrm{BioSi}$ and $\mathrm{BioSi}+\mathrm{Ca}$ ) showed a significant correlation with the growth of bacteria (ANOVA, $\mathrm{p}=0.0216, \mathrm{n}=10$ ). Bacteria are known to accelerate the physico-chemical dissolution of $\mathrm{bSiO}_{2}$ through the degradation of the organic coating surrounding the frustules (Bidle and Azam, 1999; Patrick and Holding, 1985). SEM-EDS indeed identified several cases of carbon-rich coatings, for example on a broken frustule in the BioSi sediment (Fig. A5), demonstrating the initial presence of organic matter. The degradation of this organic matter combined with the release of essential micronutrients such as $\mathrm{Fe}$ and $\mathrm{Mn}$ could have therefore promoted bacterial growth in both BioSi and BioSi incubations. It is well known that bacteria directly influence the transfer of $\mathrm{pFe}$ to the dissolved pool in seawater (e.g. through siderophore production). Our results show that bacteria may also indirectly increase the dFe pool by increasing $\mathrm{bSiO}_{2}$ dissolution, suggesting an additional role for bacteria in the $\mathrm{Fe}$ biogeochemical cycle. Calcite- The growth of heterotrophic bacteria and associated release of $\mathrm{CO}_{2}$ was likely responsible for the decrease of $\mathrm{pH}$ observed in all treatments $(0.4 \mathrm{pH}$ unit, Table 2), as a significant relationship was found between the decrease of $\mathrm{pH}$ and the increase of bacteria populations (ANOVA; $\mathrm{p}=0.0023$; $\mathrm{n}=48$ ). Since both the $\mathrm{BioSi}$ and $\mathrm{BioSi}+\mathrm{Ca}$ incubations contained calcite, the increasing $\mathrm{CO}_{2}$ concentration might have changed the carbonate equilibrium and led to dissolution of calcite (e.g. Haynert et al., 2011; Kleypas and Langdon 2013) leading to a release of calcite-associated dMn over the course of the incubation. Therefore, we suggest that bacterial growth indirectly impacted the release of dMn, especially in the $\mathrm{BioSi}+\mathrm{Ca}$ treatment, through the dissolution of calcite.

Basalt- The altered surface of the basaltic glass observed at the end of the incubation (Fig $4 \mathrm{e}$ and $\mathrm{f}$ ) hosted bacteria cells that seemed to be embedded into the basaltic matrix. Specific etch-bacteria morphologies have already been observed in previous incubation experiments conducted with (i) basaltic glass samples immersed in growth media at room temperature for up to 394 days and inoculated with bacteria derived from a natural altered pyroclastic deposit (Thorseth et al., 1995) and (ii) with nuclear-waste glass incubated with sterile and nonsterile seawater over 410 days (Staudigel et al., 1995). Both studies showed that bacteria that had attached to the glass produced etching marks in the surface, corresponding in size and shape to the dimensions of the cells. Comparison between the composition of the whole cells and that of the cell walls shows that $\mathrm{Al}, \mathrm{Si}$ and sometimes $\mathrm{Fe}$ had accumulated within the bacterial cell wall or in the extracellular polymers with traces of Ti detected in some cells (Thorseth et al., 1995). Staudigel et al. (1995) observed that microbiological activity greatly enhanced local corrosion of glass surfaces relative to inorganic control experiments. The local corrosion that we observed should have released dFe and dMn over the course of the incubation.

\subsubsection{On the temporal variations of $d T M$ during the incubation}

Through dTM uptake and ligand production- Micronutrients, such as $\mathrm{Fe}$ and $\mathrm{Mn}$, are required by bacteria as enzyme co-factors during metabolic activity. To investigate if bacterial iron uptake could have driven $\mathrm{dFe}$ temporal variations, the uptake of Fe was estimated in the BioSi treatment where the bacterial population was the most abundant at day $129\left(5.4 \times 10^{6}\right.$ cell $\left.\mathrm{mL}^{-1}\right)$. The concentration of bacteria was converted into carbon biomass using the same conversion factor as Christaki et al. (2008) to convert the bacterial abundance measured over Kerguelen plateau during KEOPS-1 cruise (12.4 fg $\mathrm{C}$ cell $^{-1}$; Fuduka et al., 1998). Combined with the $\mathrm{Fe} / \mathrm{C}$ molar ratio for open ocean heterotrophic bacteria of $7.5 \mu \mathrm{mol}$ of $\mathrm{Fe} / \mathrm{mol}$ of $\mathrm{C}$ (Tortell et al., 1999), we estimated that the entire bacterial population could have taken up $42 \mathrm{pmol} \mathrm{L}^{-1}$ at day 129. With picomolar level influence on $\mathrm{dFe}$ concentrations, bacterial uptake can therefore be considered negligible compared to other processes such as scavenging of Fe onto Mn oxyhydroxides, as discussed in section 4.1.1.1. This conclusion also holds for the BioSi+Ca and Basalt incubations since the BioSi treatment had the highest population of 
bacteria. Similarly, if bacterial uptake had a significant impact, dMn concentrations would have decreased when bacteria density was maximum on day 129 in the $\mathrm{BioSi}$ and $\mathrm{BioSi}+\mathrm{Ca}$ treatments, but this was not observed.

Additionally, bacterial metabolic activity can lead to exudation of ligands such as polysaccharides (Hassler et al., 2011) and siderophores as a strategy to acquire Fe (Sandy and Butler, 2009). Our analytical window was on the upper end of the stability constants reported for polysaccharides (from 20.4 to 21.0) and encompasses the range of siderophore stability constants (from 21.6 to over 24 (Rue and Bruland, 1995; Witter et al., 2000)). These molecules contribute to the free organic ligand pool in the ocean and one of their known roles in the ocean is to keep Fe in solution (Gledhill and Buck, 2012). A significant correlation was found between the sum of dFe and excess ligands and the concentration of bacteria in the three incubations (ANOVA, $\mathrm{p}=0.0022 ; \mathrm{n}=9$ ), implicating bacteria in partially driving the organic $\mathrm{Fe}$ ligand concentrations.The presence of $\mathrm{Fe}$-specific organic ligands during this incubation therefore likely played a role in the flux of dFe from sediments and enhanced the capacity of the SOSW to solubilize Fe. This was in line with previous incubation experiments revealing that siderophores enhance the release of Fe from suspended volcanic ash in contact with glacial meltwater-rich river waters from southern Iceland (Bau et al., 2013) and that some ligands such as citrate enhance the dissolution rate of Fe and Mn from basalt, granite (Hausrath et al., 2009), and clay minerals (Luther et al., 1992). Mechanisms driving the dissolution are not well constrained but they might include a direct effect of ligands on the mineral surface, whereby ligands polarize and weaken the bond between the cation and the lattice (Stumm et al., 1985). Indirect mechanisms whereby the complexation of the ion in solution indirectly affects the dissolution of the mineral surface were also proposed (Kubicki and Apitz, 1999a; Kubicki et al., 1999b; Oelkers and Schott, 1998). Finally, it was also possible that the sediments themselves can act as an additional source of organic Fe ligands as highlighted by Gerringa et al. (2008) who measured high concentrations of ligands at station A3 (where BioSi was collected) and $\mathrm{C} 11$ (where $\mathrm{BioSi}+\mathrm{Ca}$ was collected) in the water column near the sediment surface. Yet, conditional stability constants determined in their study were significantly lower than the conditional stability constants we have measured in our incubations, meaning that if sediment sourced ligands were part of the organic ligand pools, stronger Fe organic ligands exuded by bacteria would be responsible for the high conditional stability constant values in each treatment.

Through Mn oxyhydroxide formation- As mentioned earlier, the formation of $\mathrm{Mn}$ (III, IV) oxyhydroxide minerals might have been thermodynamically favored at the beginning of the incubation given the relatively high $\mathrm{pH}$ and the presence of oxygen. Moreover, bacteria are known to catalyze the oxidation of $\mathrm{Mn}$ (II) to $\mathrm{Mn}$ (III, IV) oxyhydroxide minerals (Tebo et al., 2004); indeed, Mn(II)oxidizing bacteria have been identified in a growing number of divergent phylogenetic lineages in the bacterial domain (Tebo et al., 2005). Biological Mn(II) oxidation is faster than abiotic Mn(II) oxidation processes, which suggests that biological $\mathrm{Mn}$ (II) oxidation dominates in many environments such as the sediment/seawater interface in the Pacific (Landing and Bruland, 1987), the Black Sea (Lewis and Landing, 1991) and the Gulf of Mexico (Van Cappellen et al., 1998).

During our incubation, in the BioSi treatment, the decrease in $\mathrm{dMn}$ concentration was correlated to bacterial abundance except at the highest bacterial concentration (Fig. 9). We suggest that this decrease in $\mathrm{dMn}$ was related to Mn oxyhydroxide formation due to bacterial oxidation.

In the $\mathrm{BioSi}+\mathrm{Ca}$ treatment, there was no relationship between $\mathrm{dMn}$ and bacteria. This may have been due to the high levels of $\mathrm{dMn}$ released that obscured the effects of Mn oxyhydroxide formation.

In the Basalt reactor, no direct relationship was observed despite a precipitation process of 50 days occurring after the first week of the incubation. The low level of $\mathrm{dMn}$ released in the Basalt treatment could explain the lack of relationship, although the presence of bacteria with different metabolic requirements could also be involved.

Through biofilm formation- SEM imaging showed a dense biofilm covering diatom fragments and basaltic grains at the end of the incubation in the BioSi, $\mathrm{BioSi}+\mathrm{Ca}$ and Basalt treatments. This biofilm 
was not present on the sediments at the start of the incubations. SEM-EDS revealed a positive $\mathrm{Fe}, \mathrm{Mg}$, and $\mathrm{Ti}$ anomaly in the biofilm probably generated by bacteria that enhanced the alteration of the basaltic grains (Fig. 5). Because SEM-EDS mapping requires a relatively smooth surface, such analyses were not accurate on the $\mathrm{BioSi}$ and $\mathrm{BioSi}+\mathrm{Ca}$ biofilms, compared to the surface of the basaltic grains. $\mathrm{Mg}, \mathrm{Cl}$, and $\mathrm{Fe}$, to a lesser extent could have been taken up by the growing biota over the course of the incubation or, as demonstrated above, they could have been taken up directly from the basalt itself (especially for Ti). Such biofilms are defined as the effective interface between glass and water and may serve as a diffusive barrier, limiting the rate of dissolution and chemical exchange between glass and water (Oelkers et al., 2015; Staudigel et al., 1995). Bacteria, through biofilm formation, could thus act as a trap for $\mathrm{Fe}$ in the Basalt treatment but also in the BioSi and $\mathrm{BioSi}+\mathrm{Ca}$ treatments.

To sum up, bacterial metabolic requirements may have increased the dissolution of $\mathrm{bSiO}_{2}$ in both $\mathrm{BioSi}$ and $\mathrm{BioSi}+\mathrm{Ca}$ incubations, potentially influencing the flux of $\mathrm{dFe}$ released from $\mathrm{bSiO}_{2}$. Second, their growth lowered the $\mathrm{pH}$, causing the dissolution of calcite, supplying an important flux of $\mathrm{dMn}$ in the $\mathrm{BioSi}+\mathrm{Ca}$ treatment. In addition, bacterial abundance was significantly correlated with the removal of $\mathrm{dMn}$ in the BioSi treatment. This may have increased scavenging of $\mathrm{dFe}$, and prevented the release of $\mathrm{dFe}$ to become observable over the first three months of the incubation. In contrast, in the Basalt treatment, biofilm development sequestered Fe. Overall, organic Fe ligands likely increased the $\mathrm{Fe}$ solubilization capacity of the SOSW, and increased the flux of Fe from the particulate to the dissolved pool. As bacteria could be involved in many processes during sediment resuspension events, they will need to be identified in the next generation of sediment incubation experiments and more generally particle dissolution experiments, using genomic approaches,for example.

\subsection{Implications for Fe and Mn Biogeochemical Cycles Close to Kerguelen Island}

The first cruise component of the KEOPS project that took place in late austral summer highlighted vertical upwelling from the plateau sediments (Blain et al., 2008) and lateral advection of water that had been in contact with the continental shelf of Heard Island (Chever et al., 2010) as the dominant sources of dissolved and particulate Fe to surface waters. Recent conclusions on the KEOPS-2 cruise carried out in austral spring confirmed that the plateau itself is a major source of Fe through resuspended shelf sediments at station A3 especially, below the mixed layer. Fluvial and glacial runoff into coastal waters in combination with resuspension of shallow coastal sediments were also described as Fe sources east and north east of Kerguelen Island (Bowie et al., 2015; Quéroué et al., 2015; van der Merwe et al., 2015).

Concentrations of $\mathrm{dFe}$ that were measured near the bottom of station $\mathrm{A} 3$ (BioSi) were of the same order of magnitude as our value of $\mathrm{dFe}$ released in the BioSi incubation. In summer at station $\mathrm{A} 3, \mathrm{dFe}$ was $\sim 0.4 \mathrm{nmol} \mathrm{L}^{-1}$ (Blain et al., 2008), a concentration that was achieved after 2-3 months of resuspension in the carboy containing BioSi. In spring, dFe at $480 \mathrm{~m}$ at station A3-2 was $1.3 \mathrm{nmol} \mathrm{L}^{-1}$ (Quéroué et al., 2015) and corresponds to 6-9 months of resuspension of BioSi sediment.

The $\mathrm{dFe}$ concentration at station $\mathrm{C} 1\left(0.80 \mathrm{nmol} \mathrm{L}^{-1}\right.$ at $120 \mathrm{~m}$; Blain et al., 2008) is also consistent with the long-term (9-14 months) capacity of the basaltic grains to release dFe. No comparison could be made at station $\mathrm{C} 11$, as this station was not sampled close to the seafloor. Also, no dMn concentrations were available at $\mathrm{A} 3, \mathrm{C} 1$ and $\mathrm{C} 11$, preventing comparison with our results.

To assess the role of resuspended sedimentary particles in Fe and Mn biogeochemical cycles, we crudely estimated the contribution of a simulated benthic nepheloid layer (BNL) and the associated $\mathrm{dFe}$ vertical gradient at each sediment sampling site in the vicinity of Kerguelen Island. For this calculation, we considered a BNL 70 meters thick at station A3 (Blain et al., 2007). As SPM concentrations were not available for KEOPS cruises, we use an upper value of $5 \mathrm{mg} \mathrm{L}^{-1}$, which is representative of the highest SPM encountered within intense nepheloid layers (i.e. nearby Nova Scotia rise as reported by Gross et al. (1988)). 
We then integrated the dFe released after 3 and 14 months (respectively 83 and 423 days) of resuspension in our incubation, between the top of the BNL and the bottom of the MLD. As a MLD of $150 \mathrm{~m}$ was reported at station A3 (Blain et al., 2008; Bowie et al., 2015), we applied this depth for stations $\mathrm{A} 3$ and $\mathrm{C} 11$ to allow comparison between these sites, and we considered the entire water column at $\mathrm{C} 1$ due to homogenous mixing and homogenous $\mathrm{dFe}$ concentrations observed from the surface to the bottom (i.e. $150 \mathrm{~m}$; Blain et al., 2008).

At station A3, Blain et al. (2008) estimated a linear dFe gradient of $1.12 \mathrm{nmol} \mathrm{m}^{-4}$ and Park et al. (2014) estimated a mean vertical eddy diffusivity coefficient $\left(\mathrm{K}_{\mathrm{z}}\right)$ of $2.210^{-5} \mathrm{~m}^{2} \mathrm{~s}^{-1}$ below the seasonal pycnocline. By multiplying this coefficient by the vertical gradient of $\mathrm{dFe}$ of resuspended sedimentary origin (between $150 \mathrm{~m}$ and $460 \mathrm{~m}$ ), we estimated an upward diapycnal flux varying from 4 to $24 \mathrm{nmol}$ $\mathrm{m}^{-2} \mathrm{~d}^{-1}$, respectively, after 3 and 14 months of resuspension

At the same station, Bowie et al. (2015) estimated this vertical flux at $93 \mathrm{nmol} \mathrm{m}{ }^{-2} \mathrm{~d}^{-1}$ at the end of the austral spring whereas Blain et al. (2007) calculated a total dFe vertical flux of $31 \mathrm{nmol} \mathrm{m}^{-2} \mathrm{~d}^{-1}$ in the austral summer. Our incubation experiment suggests that the dissolution of resuspended sediment could account for 4 to $23 \%$ of the spring flux and for 13 to $77 \%$ of the summer flux depending on the temporal variability of the nepheloid layer. Moreover, Bowie et al. (2015) estimated the winter stock of $\mathrm{dFe}$ in the mixed layer at $54 \mu \mathrm{mol} \mathrm{m} \mathrm{m}^{-2}$, while in austral summer it was estimated at $4.7 \mu \mathrm{mol} \mathrm{m}$ (Bowie et al., 2015, recalculated from Blain et al., 2007). Over a winter period of 150 days, we calculated a maximum contribution of vertical diffusion of nepheloid-derived dFe material at $3.6 \mu \mathrm{mol}$ $\mathrm{m}^{-2}$, which represents around $7 \%$ of the winter stock in spring and $77 \%$ of the remaining winter stock in summer. Vertical diffusivity is only one of the vertical fluxes that supply dFe to the MLD. Deepening of the mixed layer in winter (entrainment) and upwelling also supply external $\mathrm{Fe}$ to the mixed layer at station A3, with entrainment delivering $70 \%$ of the total vertical supply (Bowie et al., 2015) highlighting the potential role of sediment dissolution for fertilization of surface waters.

Close to Heard Island, at station $\mathrm{C} 1$, we can also estimate dFe vertical diffusive flux from resuspended sediments using the average vertical diffusivity coefficient of $14.710^{-5} \mathrm{~m}^{2} \mathrm{~s}^{-1}$ (Park et al., 2014). The dFe diffusive flux was estimated at between 4 and $92 \mathrm{nmol} \mathrm{m}^{-2} \mathrm{~d}^{-1}$ depending on the lifetime of the $\mathrm{BNL}$ and using a vertical $\mathrm{dFe}$ gradient of resuspended sedimentary origin between the surface and 150 $\mathrm{m}$. This vertical diffusive flux originating from lithogenic particles was 4 times greater than at $\mathrm{A} 3$, due to the shallower depth and a higher $\mathrm{K}_{\mathrm{z}}$ at this station. A similar calculation for Mn gives a maximum diffusive flux of dMn of $24 \mathrm{nmol} \mathrm{m} \mathrm{m}^{-1}$. These fluxes were far from negligible and have the potential for seeding surface waters with $\mathrm{dFe}$ and $\mathrm{dMn}$ and to contribute to the support of the bloom as estimated for $\mathrm{dFe}$ by Chever et al. (2010). Indeed, water masses circulated from the south to the north of Kerguelen plateau bypassing Heard Island to reach the waters on the eastern side of Kerguelen Island (Park et al., 2008).

We also estimated the dFe vertical diffusivity originating from resuspended sediments at the deepest station C11 (3350m) off Kerguelen plateau, using a $\mathrm{K}_{\mathrm{z}}$ of $3.210^{-4} \mathrm{~m}^{2} \mathrm{~s}^{-1}$ (Blain et al., 2008) and a vertical dFe gradient of resuspended sedimentary origin between $150 \mathrm{~m}$ and $3280 \mathrm{~m}$. We used a linear $\mathrm{dFe}$ gradient as Blain et al. (2008) stated. The dFe diffusive flux was estimated between 1 and $8 \mathrm{nmol}$ $\mathrm{m}^{-2} \mathrm{~d}^{-1}$ depending on the lifetime of the BNL. Even if this flux was 3 times lower than over the plateau, nepheloid material diffusion could account for the entire diffusive flux of dFe estimated at $\mathrm{C} 11$ (i.e. 4 $\mathrm{nmol} \mathrm{m} \mathrm{m}^{-2} \mathrm{~d}^{-1}$ in austral summer (Blain et al., 2007)). A similar calculation for dMn gives a flux of 71 $\mathrm{nmol} \mathrm{m} \mathrm{m}^{-2} \mathrm{~d}^{-1}$ due to the high concentration of $\mathrm{dMn}$ released by this calcite rich sediment.

Overall, our estimates need to be regarded as a first attempt to constrain the contribution of resuspended sediment in iron-deprived regions. However, to improve these estimates, entrainment and upwelling should also be estimated. Indeed, in the Southern Ocean, the winter entrainment pulse supplies much more Fe to surface waters than diapycnal diffusion and upwelling (Tagliabue et al., 2014b). Resuspended sediments could also contribute to the dFe budget via lateral water mass advection but we could not constrain this with available data. Nonetheless, nepheloid material should be seen as a non-negligible reservoir of dTM that need to be better understood and constrained in particular with future modelling studies. 


\subsection{Implications for Mn as a tracer for Fe cycling}

Many in-situ studies have shown coincident enrichments of dissolved Fe and Mn close to the seafloor, often suggesting inputs from sediments, either by resuspension of particles and subsequent dissolution or desorption of $\mathrm{Fe}$ and $\mathrm{Mn}$, or by dissolved $\mathrm{Fe}$ and $\mathrm{Mn}$ release from porewaters (e.g. Klinkhammer and Bender, 1980; Saager et al., 1989; Bucciarelli et al., 2001; Noble et al., 2012). In this incubation, while $\mathrm{Fe}$ was likely coming from the dissolution of $\mathrm{bSiO}_{2}$-rich material, $\mathrm{Mn}$ was likely associated with calcite. Moreover, formation of Mn oxides and bacterial activity played a key role in the release of dissolved $\mathrm{Fe}$ and $\mathrm{Mn}$. By decreasing $\mathrm{pH}$, bacteria increased calcite dissolution and release of $\mathrm{dMn}$. This $\mathrm{dMn}$ can be transferred back into the particulate pool by Mn-oxidizing bacteria, and the resulting Mn oxyhydroxides can then scavenge Fe. Fe scavenging likely occurred until Mn oxyhydroxide formation ceased, and all adsorption or co-precipitation sites for Fe were occupied. This means that the use of $\mathrm{dMn}$ as a tracer for sedimentary $\mathrm{dFe}$ inputs may be misleading, in particular when low $\mathrm{dMn}$ concentrations are measured close to the seafloor. Such a decoupling has also been reported from water column measurements near the South Shetland Islands in the Drake Passage (Hatta et al., 2013).

\section{Conclusions}

Our study sheds new light on the contribution of the resuspended sediments to the $\mathrm{dFe}$ and $\mathrm{dMn}$ pools. Release of $\mathrm{dFe}, \mathrm{dMn}$ and $\mathrm{dSi}$ were the result of processes differing in their rates and duration. These processes were discernable thanks to our frequent temporal sampling resolution. The sampling schedule proved to be critical to better constrain the processes and exchanges that govern the contribution of the particulate to the dissolved pools for $\mathrm{Fe}, \mathrm{Mn}$ and $\mathrm{Si}$.

Several factors that can influence the dissolution process can be inferred, in particular, the mineralogical composition of the sediment, the bacterial abundance and the formation of biofilms, as well as the formation of manganese oxides (Fig.10). However, the relevant regional setting will also exert a strong influence. Water column depth, horizontal advection and vertical mixing intensities will determine the magnitude of $\mathrm{dFe}$ and $\mathrm{dMn}$ fluxes from resuspended sediments. Indeed, resuspension of BioSi sediment led to the highest $\mathrm{dFe}$ concentration in the incubations, but our flux estimates indicated a lower contribution of the sediment to the water column dFe inventory at $\mathrm{A} 3$ than at $\mathrm{C} 1$ and $\mathrm{C} 11$, due to the plateau depth and the vertical diffusivity coefficient. The contribution of resuspended sediments from a deep nepheloid layer (BioSi+Ca, 3350m) was still significant for both $\mathrm{dFe}$ and $\mathrm{dMn}$ diffusive fluxes. In the future, the global extent of this external source will have to be quantified, probably by incorporating it into biogeochemical models.

\section{Acknowledgements:}

This work was funded by ANR Retour Post Doctorants 2012 BITMAP, (ANR-12-PDOC-0025-01; P.I. H. Planquette). We thank Brivaela Moriceau for lending us the rotating rod table for more than a year, and we thank Béatriz Becker for providing her expertise in identifying diatoms in biogenic sediment samples. Finally, we also thank Sébastien Hervé for the support provided in the final figure design. 


\section{References}

Ahrland, W., 1975. Metal complexes present in seawater, The Nature of Seawater. Dahlem Konferenzen, Berlin, pp. 219-244.

Armand, L.K., Crosta, X., Quéguiner, B., Mosseri, J., Garcia, N., 2008. Diatoms preserved in surface sediments of the northeastern Kerguelen Plateau. Deep Sea Research Part II: Topical Studies in Oceanography, 55(5-7): 677-692.

Bacon, M.P., Rutgers van der Loeff, M.M., 1989. Removal of thorium-234 by scavenging in the bottom nepheloid layer of the ocean. Earth and Planetary Science Letters, 92(2): 157-164.

Baker, A.R., Jickells, T.D., Witt, M., Linge, K.L., 2006. Trends in the solubility of iron, aluminium, manganese and phosphorus in aerosol collected over the Atlantic Ocean. Marine Chemistry, 98(1): 43-58.

Baker, E.T., Feely, R.A., 1978. Chemistry of Oceanic Particulate Matter and Sediments: Implications for Bottom Sediment Resuspension. Science, 200(4341): 533-535.

Balistrieri, L.S., Murray, J.W., 1984. Marine scavenging: Trace metal adsorption by interfacial sediment from MANOP Site H. Geochimica et Cosmochimica Acta, 48(5): 921-929.

Balls, P.W., 1989. The partition of trace metals between dissolved and particulate phases in european coastal waters: A compilation of field data and comparison with laboratory studies. Netherlands Journal of Sea Research, 23(1): 7-14.

Barling, J., Goldstein, S.L., Nicholls, I.A., 1994. Geochemistry of Heard Island (Southern Indian Ocean): Characterization of an Enriched Mantle Component and Implications for Enrichment of the Sub-Indian Ocean Mantle. Journal of Petrology, 35(4): 1017-1053.

Bau, M., Tepe, N., Mohwinkel, D., 2013. Siderophore-promoted transfer of rare earth elements and iron from volcanic ash into glacial meltwater, river and ocean water. Earth and Planetary Science Letters, 364: 30-36.

Benitez-Nelson, C.R., Vink, S.M., Carrillo, J.H., Huebert, B.J., 2003. Volcanically influenced iron and aluminum cloud water deposition to Hawaii. Atmospheric Environment, 37(4): 535-544.

Bidle, K.D., Azam, F., 1999. Accelerated dissolution of diatom silica by marine bacterial assemblages. Nature, 397(6719): 508-512.

Biscaye, P.E., Eittreim, S.L., 1977. Suspended Particulate Loads and Transports in the Nepheloid Layer of the Abyssal Atlantic Ocean*. In: Bruce, C.H. (Ed.), Developments in Sedimentology. Elsevier, pp. 155-172.

Bishop, J.K.B., Biscaye, P.E., 1982. Chemical characterization of individual particles from the nepheloid layer in the Atlantic Ocean. Earth and Planetary Science Letters, 58(2): 265-275.

Blain, S. et al., 2007. Effect of natural iron fertilization on carbon sequestration in the Southern Ocean. Nature, 446(7139): 1070-1074.

Blain, S., Quéguiner, B., Trull, T., 2008. The natural iron fertilization experiment KEOPS (KErguelen Ocean and Plateau compared Study): An overview. Deep Sea Research Part II: Topical Studies in Oceanography, 55(5-7): 559-565.

Boetius, A., Springer, B., Petry, C., 2000. Microbial activity and particulate matter in the benthic nepheloid layer (BNL) of the deep Arabian Sea. Deep Sea Research Part II: Topical Studies in Oceanography, 47(14): 2687-2706.

Borrione, I., Aumont, O., Nielsdóttir, M.C., and Schlitzer, R., 2014. Sedimentary and atmospheric sources of iron around South Georgia, Southern Ocean: a modelling perspective,. Biogeosciences, 11(7): 1981-2001.

Borrione, I., Schlitzer, R., 2013. Distribution and recurrence of phytoplankton blooms around South Georgia, Southern Ocean. Biogeosciences, 10(1): 217-231.

Bowie, A.R., van der Merwe, P., Quéroué, F., Trull, T., Fourquez, M., Planchon, F., Sarthou, G., Chever, F., Townsend, A.T., Obernosterer, I., Sallée, J.B., Blain, S., 2015. Iron budgets for three distinct biogeochemical sites around the Kerguelen Archipelago (Southern Ocean) during the natural fertilisation study, KEOPS-2. Biogeosciences, 12(14): 4421-4445.

Boyd, P.W., Ellwood, M.J., 2010. The biogeochemical cycle of iron in the ocean. Nature Geosciences, 3(10): 675-682.

Bucciarelli, E., Blain, S., Tréguer, P., 2001. Iron and manganese in the wake of the Kerguelen Islands (Southern Ocean). Marine Chemistry, 73(1): 21-36. 
Castrillejo, M., Statham, P.J., Fones, G.R., Planquette, H., Idrus, F., Roberts, K., 2013. Dissolved trace metals (Ni, $\mathrm{Zn}, \mathrm{Co}, \mathrm{Cd}, \mathrm{Pb}, \mathrm{Al}$, and $\mathrm{Mn}$ ) around the Crozet Islands, Southern Ocean. Journal of Geophysical Research: Oceans, 118(10): 5188-5201.

Chase, Z., Johnson, K.S., Elrod, V.A., Plant, J.N., Fitzwater, S.E., Pickell, L., Sakamoto, C.M., 2005. Manganese and iron distributions off central California influenced by upwelling and shelf width. Marine Chemistry, 95(3-4): 235-254.

Chever, F., Sarthou, G., Bucciarelli, E., Blain, S., Bowie, A.R., 2010. An iron budget during the natural iron fertilisation experiment KEOPS (Kerguelen Islands, Southern Ocean). Biogeosciences, 7(2): 455-468.

Christaki, U., Lefèvre, D., Georges, C., Colombet, J., Catala, P., Courties, C., Sime-Ngando, T., Blain, S., Obernosterer, I., 2014. Microbial food web dynamics during spring phytoplankton blooms in the naturally iron-fertilized Kerguelen area (Southern Ocean). Biogeosciences, 11(23): 6739-6753.

Christaki, U., Obernosterer, I., Van Wambeke, F., Veldhuis, M., Garcia, N., Catala, P., 2008. Microbial food web structure in a naturally iron-fertilized area in the Southern Ocean (Kerguelen Plateau). Deep Sea Research Part II: Topical Studies in Oceanography, 55(5-7): 706-719.

Copin-Montegut, C., Copin-Montegut, G., 1978. The chemistry of particulate matter from the south Indian and Antarctic oceans. Deep Sea Research, 25(10): 911-931.

Cotten, J., Le Dez, A., Bau, M., Caroff, M., Maury, R.C., Dulski, P., Fourcade, S., Bohn, M., Brousse, R., 1995. Origin of anomalous rare-earth element and yttrium enrichments in subaerially exposed basalts: Evidence from French Polynesia. Chemical Geology, 119(1-4): 115-138.

Croot, P.L., Johansson, M., 2000. Determination of Iron Speciation by Cathodic Stripping Voltammetry in Seawater Using the Competing Ligand 2-(2-Thiazolylazo)-p-cresol (TAC). Electroanalysis, 12(8): 565-576.

da Cunha, L.C., Buitenhuis, E.T., 2013. Riverine influence on the tropical Atlantic Ocean biogeochemistry. Biogeosciences, 10(10): 6357-6373.

Dale, A.W., Nickelsen, L., Scholz, F., Hensen, C., Oschlies, A., Wallmann, K., 2015. A revised global estimate of dissolved iron fluxes from marine sediments. Global Biogeochemical Cycles, 29(5): 691-707.

de Jonge, M.D., Holzner, C., Baines, S.B., Twining, B.S., Ignatyev, K., Diaz, J., Howard, D.L., Legnini, D., Miceli, A., McNulty, I., Jacobsen, C.J., Vogt, S., 2010. Quantitative 3D elemental microtomography of Cyclotella meneghiniana at $400-\mathrm{nm}$ resolution. Proceedings of the National Academy of Sciences, 107(36): 15676-15680.

de Nooijer, L.J., Reichart, G.J., Dueñas-Bohórquez, A., Wolthers, M., Ernst, S.R., Mason, P.R.D., van der Zwaan, G.J., 2007. Copper incorporation in foraminiferal calcite: results from culturing experiments. Biogeosciences, 4(4): 493-504.

Diekmann, B., Kuhn, G., Gersonde, R., Mackensen, A., 2004. Middle Eocene to early Miocene environmental changes in the sub-Antarctic Southern Ocean: evidence from biogenic and terrigenous depositional patterns at ODP Site 1090. Global and Planetary Change, 40(3-4): 295-313.

Elderfield, H., 1976. Manganese fluxes to the oceans. Marine Chemistry, 4(2): 103-132.

Ellwood, M.J., Hunter, K.A., 2000. The incorporation of zinc and iron into the frustule of the marine diatom Thalassiosira pseudonana. Limnology and Oceanography, 45(7): 1517-1524.

Elrod, V.A., Berelson, W.M., Coale, K.H., Johnson, K.S., 2004. The flux of iron from continental shelf sediments: A missing source for global budgets. Geophysical Research Letters, 31(12): L12307.

Ewing, M., Thorndike, E.M., 1965. Suspended Matter in Deep Ocean Water. Science, 147(3663): 1291-1294.

Fitzsimmons, J.N., Boyle, E.A., Jenkins, W.J., 2014. Distal transport of dissolved hydrothermal iron in the deep South Pacific Ocean. Proceedings of the National Academy of Sciences, 111(47): 16654-16661.

Fitzsimmons, J.N., John, S.G., Marsay, C.M., Hoffman, C.L., Nicholas, Sarah L., Toner, B.M., German, C.R., Sherrell, R.M., 2017. Iron persistence in a distal hydrothermal plume supported by dissolved-particulate exchange. Nature Geoscience, 10: 195. 
Fuduka, R., Ogawa, H., Nagata, T., Koike, I., 1998. Direct determination of carbon and nitrogen contents of natural bacterial assemblages in marine environments. Applied and environmental microbiology, 64(9): 3352-3358.

Gardner, W.D., Richardson, M.J., Mishonov, A.V., 2018. Global assessment of benthic nepheloid layers and linkage with upper ocean dynamics. Earth and Planetary Science Letters, 482: 126134.

Gerringa, L.J.A., Blain, S., Laan, P., Sarthou, G., Veldhuis, M.J.W., Brussaard, C.P.D., Viollier, E., Timmermans, K.R., 2008. Fe-binding dissolved organic ligands near the Kerguelen Archipelago in the Southern Ocean (Indian sector). Deep Sea Research Part II: Topical Studies in Oceanography, 55(5-7): 606-621.

Gledhill, M., Buck, K.N., 2012. The organic complexation of iron in the marine environment: A review. Frontiers in Microbiology, 3.

Gledhill, M., van den Berg, C.M.G., 1994. Determination of complexation of iron(III) with natural organic complexing ligands in seawater using cathodic stripping voltammetry. Marine Chemistry, 47(1): 41-54.

Goldberg, E.D., 1954. Marine Geochemistry 1. Chemical Scavengers of the Sea. The Journal of Geology, 62(3): 249-265.

Gorgues, T., Menkes, C., Aumont, O., 2009. The iron phases, a crucial factor for biomass variability in the Pacific HNLC region?, 2nd GEOTRACES Data-Model Synergy Workshop Report., Ecole Normale Supérieure, Paris, France.

Grégori, G., Citterio, S., Ghiani, A., Labra, M., Sgorbati, S., Brown, S., Denis, M., 2001. Resolution of Viable and Membrane-Compromised Bacteria in Freshwater and Marine Waters Based on Analytical Flow Cytometry and Nucleic Acid Double Staining. Applied and Environmental Microbiology, 67(10): 4662-4670.

Hassler, C.S., Alasonati, E., Mancuso Nichols, C.A., Slaveykova, V.I., 2011. Exopolysaccharides produced by bacteria isolated from the pelagic Southern Ocean - Role in Fe binding, chemical reactivity, and bioavailability. Marine Chemistry, 123(1-4): 88-98.

Hatta, M., Measures, C.I., Selph, K.E., Zhou, M., Hiscock, W.T., 2013. Iron fluxes from the shelf regions near the South Shetland Islands in the Drake Passage during the austral-winter 2006. Deep Sea Research Part II: Topical Studies in Oceanography, 90: 89-101.

Hausrath, E.M., Neaman, A., Brantley, S.L., 2009. Elemental release rates from dissolving basalt and granite with and without organic ligands. American Journal of Science, 309(8): 633-660.

Haynert, K., Schönfeld, J., Riebesell, U., Polovodova, I., 2011. Biometry and dissolution features of the benthic foraminifer Ammonia aomoriensis at high pCO2. Marine Ecology Progress Series, 432: 53-67.

Homoky, W.B., John, S.G., Conway, T.M., Mills, R.A., 2013. Distinct iron isotopic signatures and supply from marine sediment dissolution. Nature Communications, 4.

Ingall, E.D., Diaz, J.M., Longo, A.F., Oakes, M., Finney, L., Vogt, S., Lai, B., Yager, P.L., Twining, B.S., Brandes, J.A., 2013. Role of biogenic silica in the removal of iron from the Antarctic seas. Nature Communications, 4.

Jeandel, C., Peucker-Ehrenbrink, B., Jones, M.T., Pearce, C.R., Oelkers, E.H., Godderis, Y., Lacan, F., Aumont, O., Arsouze, T., 2011. Ocean margins: The missing term in oceanic element budgets? Eos, Transactions American Geophysical Union, 92(26): 217-218.

Jeandel, C., Rutgers van der Loeff, M., Lam, P.J., Roy-Barman, M., Sherrell, R.M., Kretschmer, S., German, C., Dehairs, F., 2015. What did we learn about ocean particle dynamics in the GEOSECS-JGOFS era? Progress in Oceanography, 133: 6-16.

Jickells, T.D., An, Z.S., Andersen, K.K., Baker, A.R., Bergametti, G., Brooks, N., Cao, J.J., Boyd, P.W., Duce, R.A., Hunter, K.A., Kawahata, H., Kubilay, N., laRoche, J., Liss, P.S., Mahowald, N., Prospero, J.M., Ridgwell, A.J., Tegen, I., Torres, R., 2005. Global Iron Connections Between Desert Dust, Ocean Biogeochemistry, and Climate. Science, 308(5718): 67-71.

Johnson, K.S., Gordon, R.M., Coale, K.H., 1997. What controls dissolved iron concentrations in the world ocean? Marine Chemistry, 57(3-4): 137-161. 
Jones, M.T., Pearce, C.R., Jeandel, C., Gislason, S.R., Eiriksdottir, E.S., Mavromatis, V., Oelkers, E.H., 2012a. Riverine particulate material dissolution as a significant flux of strontium to the oceans. Earth and Planetary Science Letters, 355-356: 51-59.

Jones, M.T., Pearce, C.R., Oelkers, E.H., 2012b. An experimental study of the interaction of basaltic riverine particulate material and seawater. Geochimica et Cosmochimica Acta, 77: 108-120.

Kalnejais, L.H., Martin, W.R., Signell, R.P., Bothner, M.H., 2007. Role of Sediment Resuspension in the Remobilization of Particulate-Phase Metals from Coastal Sediments. Environmental Science \& Technology, 41(7): 2282-2288.

Kleypas, J.A., Langdon, C., 2013. Coral Reefs and Changing Seawater Carbonate Chemistry, Coral Reefs and Climate Change: Science and Management. American Geophysical Union, pp. 73110.

Klinkhammer, G.P., Bender, M.L., 1980. The distribution of manganese in the Pacific Ocean. Earth and Planetary Science Letters, 46(3): 361-384.

Kretschmer, S., Geibert, W., Rutgers van der Loeff, M.M., Schnabel, C., Xu, S., Mollenhauer, G., 2011. Fractionation of $230 \mathrm{Th}, 231 \mathrm{~Pa}$, and $10 \mathrm{Be}$ induced by particle size and composition within an opal-rich sediment of the Atlantic Southern Ocean. Geochimica et Cosmochimica Acta, 75(22): 6971-6987.

Kubicki, J.D., Apitz, S.E., 1999. Models of natural organic matter and interactions with organic contaminants. Organic Geochemistry, 30(8, Part 2): 911-927.

Kubicki, J.D., Schroeter, L.M., Itoh, M.J., Nguyen, B.N., Apitz, S.E., 1999. Attenuated total reflectance Fourier-transform infrared spectroscopy of carboxylic acids adsorbed onto mineral surfaces. Geochimica et Cosmochimica Acta, 63(18): 2709-2725.

Labatut, M., Lacan, F., Pradoux, C., Chmeleff, J., Radic, A., Murray, J.W., Poitrasson, F., Johansen, A.M., Thil, F., 2014. Iron sources and dissolved-particulate interactions in the seawater of the Western Equatorial Pacific, iron isotope perspectives. Global Biogeochemical Cycles, 28(10): 1044-1065.

Laës, A., Blain, S., Laan, P., Ussher, S.J., Achterberg, E.P., Tréguer, P., de Baar, H.J.W., 2007. Sources and transport of dissolved iron and manganese along the continental margin of the Bay of Biscay. Biogeosciences, 4(2): 181-194.

Lagerström, M.E., Field, M.P., Séguret, M., Fischer, L., Hann, S., Sherrell, R.M., 2013. Automated on-line flow-injection ICP-MS determination of trace metals ( $\mathrm{Mn}, \mathrm{Fe}, \mathrm{Co}, \mathrm{Ni}, \mathrm{Cu}$ and $\mathrm{Zn}$ ) in open ocean seawater: Application to the GEOTRACES program. Marine Chemistry, 155: 7180.

Lam, P.J., Bishop, J.K.B., 2008. The continental margin is a key source of iron to the HNLC North Pacific Ocean. Geophysical Research Letters, 35(7): 608.

Lam, P.J., Bishop, J.K.B., Henning, C.C., Marcus, M.A., Waychunas, G.A., Fung, I.Y., 2006. Wintertime phytoplankton bloom in the subarctic Pacific supported by continental margin iron. Global Biogeochemical Cycles, 20(1): n/a-n/a.

Landing, W.M., Bruland, K.W., 1980. Manganese in the North Pacific. Earth and Planetary Science Letters, 49(1): 45-56.

Landing, W.M., Bruland, K.W., 1987. The contrasting biogeochemistry of iron and manganese in the Pacific Ocean. Geochimica et Cosmochimica Acta, 51(1): 29-43.

Lea, D., 2003. Trance elements in foraminiferal calcite, Modern Foraminifera. Springer Netherlands, pp. 259-277.

Lewis, B.L., Landing, W.M., 1991. The biogeochemistry of manganese and iron in the Black Sea. Deep Sea Research Part A. Oceanographic Research Papers, 38, Supplement 2: S773-S803.

Loucaides, S., Michalopoulos, P., Presti, M., Koning, E., Behrends, T., Van Cappellen, P., 2010. Seawater-mediated interactions between diatomaceous silica and terrigenous sediments: Results from long-term incubation experiments. Chemical Geology, 270(1-4): 68-79.

Luther, G.W., Kostka, J.E., Church, T.M., Sulzberger, B., Stumm, W., 1992. Progress in Marine Chemistry Seasonal iron cycling in the salt-marsh sedimentary environment: the importance of ligand complexes with $\mathrm{Fe}$ (II) and $\mathrm{Fe}$ (III) in the dissolution of $\mathrm{Fe}$ (III) minerals and pyrite, respectively. Marine Chemistry, 40(1): 81-103.

Martin, J.H., Fitzwater, S.E., 1988. Iron deficiency limits phytoplankton growth in the north-east Pacific subarctic. Nature, 331(6154): 341-343. 
Mc Cave, I.N., 2009. Nepheloid layers. In: Ldt, E. (Ed.), Measurement Techniques, Platforms \& Sensors pp. 647.

McCave, I.N., 1986. Local and global aspects of the bottom nepheloid layers in the world ocean. Netherlands Journal of Sea Research, 20(2): 167-181.

Michalopoulos, P., Aller, R.C., Reeder, R.J., 2000. Conversion of diatoms to clays during early diagenesis in tropical, continental shelf muds. Geology, 28(12): 1095-1098.

Middag, R., de Baar, H.J.W., Laan, P., Huhn, O., 2012. The effects of continental margins and water mass circulation on the distribution of dissolved aluminum and manganese in Drake Passage. Journal of Geophysical Research: Oceans, 117(C1): 019.

Noble, A.E., Lamborg, C.H., Ohnemus, D.C., Lam, P.J., Goepfert, T.J., Measures, C.I., Frame, C.H., Casciotti, K.L., DiTullio, G.R., Jennings, J., Saito, M.A., 2012. Basin-scale inputs of cobalt, iron, and manganese from the Benguela-Angola front to the South Atlantic Ocean. Limnology and Oceanography, 57(4): 989-1010.

Obata, H., Karatani, H., Nakayama, E., 1993. Automated determination of iron in seawater by chelating resin concentration and chemiluminescence detection. Analytical Chemistry, 65(11): 1524-1528.

Obernosterer, I., Christaki, U., Lefèvre, D., Catala, P., Van Wambeke, F., Lebaron, P., 2008. Rapid bacterial mineralization of organic carbon produced during a phytoplankton bloom induced by natural iron fertilization in the Southern Ocean. Deep Sea Research Part II: Topical Studies in Oceanography, 55(5-7): 777-789.

Oelkers, E.H., Benning, L.G., Lutz, S., Mavromatis, V., Pearce, C.R., Plümper, O., 2015. The efficient long-term inhibition of forsterite dissolution by common soil bacteria and fungi at Earth surface conditions. Geochimica et Cosmochimica Acta, 168: 222-235.

Oelkers, E.H., Gislason, S.R., Eiriksdottir, E.S., Jones, M., Pearce, C.R., Jeandel, C., 2011. The role of riverine particulate material on the global cycles of the elements. Applied Geochemistry, 26: S365-S369.

Oelkers, E.H., Schott, J., 1998. Does organic acid adsorption affect alkali-feldspar dissolution rates? Chemical Geology, 151(1-4): 235-245.

Park, Y.-H., Roquet, F., Durand, I., Fuda, J.-L., 2008. Large-scale circulation over and around the Northern Kerguelen Plateau. Deep Sea Research Part II: Topical Studies in Oceanography, 55(5-7): 566-581.

Park, Y.H., Lee, J.H., Durand, I., Hong, C.S., 2014. Validation of Thorpe-scale-derived vertical diffusivities against microstructure measurements in the Kerguelen region. Biogeosciences, 11(23): 6927-6937.

Patrick, S., Holding, A.J., 1985. The effect of bacteria on the solubilization of silica in diatom frustules. Journal of Applied Bacteriology, 59(1): 7-16.

Pearce, C.R., Jones, M.T., Oelkers, E.H., Pradoux, C., Jeandel, C., 2013. The effect of particulate dissolution on the neodymium (Nd) isotope and Rare Earth Element (REE) composition of seawater. Earth and Planetary Science Letters, 369-370: 138-147.

Pena, L.D., Cacho, I., Calvo, E., Pelejero, C., Eggins, S., \& , Sadekov, A., 2008. Characterization of contaminant phases in foraminifera carbonates by electron microprobe mapping. Geochemistry, Geophysics, Geosystems,, 9(7).

Planquette, H., Sanders, R.R., Statham, P.J., Morris, P.J., Fones, G.R., 2011. Fluxes of particulate iron from the upper ocean around the Crozet Islands: A naturally iron-fertilized environment in the Southern Ocean. Global Biogeochemical Cycles, 25(2): GB2011.

Planquette, H., Statham, P.J., Fones, G.R., Charette, M.A., Moore, C.M., Salter, I., Nédélec, F.H., Taylor, S.L., French, M., Baker, A.R., Mahowald, N., Jickells, T.D., 2007. Dissolved iron in the vicinity of the Crozet Islands, Southern Ocean. Deep Sea Research Part II: Topical Studies in Oceanography, 54(18-20): 1999-2019.

Prentice, K., Jones, T.D., Lees, J., Young, J., Bown, P., Langer, G., \& , Fearn, S., 2014. Trace metal $(\mathrm{Mg} / \mathrm{Ca}$ and $\mathrm{Sr} / \mathrm{Ca})$ analyses of single coccoliths by Secondary Ion Mass Spectrometry. Geochimica et Cosmochimica Acta, 146: 90-106.

Puig, P., Madron, X.D.d., Salat, J., Schroeder, K., Martin, J., Karageorgis, A.P., Palanques, A., Roullier, F., Lopez-Jurado, J.L., Emelianov, M., Moutin, T., Houpert, L., 2013. Thick bottom 
nepheloid layers in the western Mediterranean generated by deep dense shelf water cascading. Progress in Oceanography, 111: 1-23.

Quéroué, F., Sarthou, G., Planquette, H.F., Bucciarelli, E., Chever, F., van der Merwe, P., Lannuzel, D., Townsend, A.T., Cheize, M., Blain, S., d'Ovidio, F., Bowie, A.R., 2015. High variability in dissolved iron concentrations in the vicinity of the Kerguelen Islands (Southern Ocean). Biogeosciences, 12(12): 3869-3883.

Raiswell, R., Canfield, D.E., 2012. The Iron Biogeochemical Cycle Past and Present. Geochemical Perspectives, 1(1): 1-2.

Roy-Barman, M., Jeandel, C., 2016. Marine Geochemistry. Ocean Circulation, Carbon Cycle and Climate Change. Oxford University Press, 432 pp.

Rue, E.L., Bruland, K.W., 1995. Complexation of iron(III) by natural organic ligands in the Central North Pacific as determined by a new competitive ligand equilibration/adsorptive cathodic stripping voltammetric method. Marine Chemistry, 50(1-4): 117-138.

Ruzic, I., 1982. Theoritical aspects of the direct titration of natural waters and its information yield for trace metal speciation. Analytica Chimica Acta, 140: 99-113.

Saager, P.M., De Baar, H.J.W., Burkill, P.H., 1989. Manganese and iron in Indian Ocean waters. Geochimica et Cosmochimica Acta, 53(9): 2259-2267.

Sandy, M., Butler, A., 2009. Microbial Iron Acquisition: Marine and Terrestrial Siderophores. Chemical Reviews, 109(10): 4580-4595.

Sarthou, G., Baker, A.R., Blain, S., Achterberg, E.P., Boye, M., Bowie, A.R., Croot, P., Laan, P., de Baar, H.J.W., Jickells, T.D., Worsfold, P.J., 2003. Atmospheric iron deposition and seasurface dissolved iron concentrations in the eastern Atlantic Ocean. Deep Sea Research Part I: Oceanographic Research Papers, 50(10-11): 1339-1352.

Saulnier, I., Mucci, A., 2000. Trace metal remobilization following the resuspension of estuarine sediments: Saguenay Fjord, Canada. Applied Geochemistry, 15(2): 191-210.

Schallenberg, C., van der Merwe, P., Chever, F., Cullen, J.T., Lannuzel, D., Bowie, A.R., 2015. Dissolved iron and iron(II) distributions beneath the pack ice in the East Antarctic $\left(120^{\circ} \mathrm{E}\right)$ during the winter/spring transition. Deep Sea Research Part II: Topical Studies in Oceanography.

Schlosser, C., Schmidt, K., Aquilina, A., Homoky, W.B., Castrillejo, M., Mills, R.A., Patey, M.D., Fielding, S., Atkinson, A., Achterberg, E.P., 2017. Mechanisms of dissolved and labile particulate iron supply to shelf waters and phytoplankton blooms off South Georgia, Southern Ocean. Biogeosciences Discuss., 2017: 1-49.

Sherrell, R.M., Paul Field, M., Gao, Y., 1998. Temporal variability of suspended mass and composition in the Northeast Pacific water column: relationships to sinking flux and lateral advection. Deep Sea Research Part II: Topical Studies in Oceanography, 45(4): 733-761.

Slemons, L.O., Murray, J.W., Resing, J., Paul, B., Dutrieux, P., 2010. Western Pacific coastal sources of iron, manganese, and aluminum to the Equatorial Undercurrent. Global Biogeochemical Cycles, 24(3): GB3024.

Staudigel, H., Chastain, R.A., Yayanos, A., Bourcier, W., 1995. The Mantle-Ocean connection Biologically mediated dissolution of glass. Chemical Geology, 126(2): 147-154.

Stefánsdóttir, M.B., Gíslason, S.R., 2005. The erosion and suspended matter/seawater interaction during and after the 1996 outburst flood from the Vatnajökull Glacier, Iceland. Earth and Planetary Science Letters, 237(3-4): 433-452.

Stumm, W., Furrer, G., Wieland, E., Zinder, B., 1985. The Effects of Complex-Forming Ligands on the Dissolution of Oxides and Aluminosilicates. In: Drever, J. (Ed.), The Chemistry of Weathering. Nato ASI Series. Springer Netherlands, pp. 55-74.

Sunda, W.G., 2012. Feedback Interactions between Trace Metal Nutrients and Phytoplankton in the Ocean. Frontiers in Microbiology, 3: 204.

Tagliabue, A., Aumont, O., Bopp, L., 2014a. The impact of different external sources of iron on the global carbon cycle. Geophysical Research Letters, 41(3): 920-926.

Tagliabue, A., Bopp, L., Aumont, O., 2009. Evaluating the importance of atmospheric and sedimentary iron sources to Southern Ocean biogeochemistry. Geophysical Research Letters, 36(13): 601 . 
Tagliabue, A., Bopp, L., Dutay, J.-C., Bowie, A.R., Chever, F., Jean-Baptiste, P., Bucciarelli, E., Lannuzel, D., Remenyi, T., Sarthou, G., Aumont, O., Gehlen, M., Jeandel, C., 2010. Hydrothermal contribution to the oceanic dissolved iron inventory. Nature Geosci, 3(4): 252256.

Tagliabue, A., Sallee, J.-B., Bowie, A.R., Levy, M., Swart, S., Boyd, P.W., 2014b. Surface-water iron supplies in the Southern Ocean sustained by deep winter mixing. Nature Geosci, 7(4): 314320.

Taylor, S.R., McLennan, S.M., 1995. The geochemical evolution of the continental crust. Reviews of Geophysics, 33(2): 241-265.

Tebo, B.M., Bargar, J.R., Clement, B.G., Dick, G.J., Murray, K.J., Parker, D., Verity, R., Webb, S.M., 2004. Biogenic manganese oxides : Properties and Mechanisms of Formation. Annual Review of Earth and Planetary Sciences, 32(1): 287-328.

Thorseth, I.H., Furnes, H., Tumyr, O., 1995. Textural and chemical effects of bacterial activity on basaltic glass: an experimental approach. Chemical Geology, 119(1-4): 139-160.

Titschack, J., Goetz-Neunhoeffer, F., Neubauer, J., 2011. Magnesium quantification in calcites $[(\mathrm{Ca}, \mathrm{Mg}) \mathrm{CO} 3]$ by Rietveld-based XRD analysis: Revisiting a well-established method, American Mineralogist, pp. 1028.

Tortell, P.D., Maldonado, M.T., Granger, J., Price, N.M., 1999. Marine bacteria and biogeochemical cycling of iron in the oceans. Federation of European Microbiological Societies Microbiology Ecology, 29(1): 1-11.

Van Cappellen, P., Viollier, E., Roychoudhury, A., Clark, L., Ingall, E., Lowe, K., Dichristina, T., 1998. Biogeochemical Cycles of Manganese and Iron at the Oxic-Anoxic Transition of a Stratified Marine Basin (Orca Basin, Gulf of Mexico). Environmental Science \& Technology, 32(19): 2931-2939.

van der Merwe, P., Bowie, A.R., Quéroué, F., Armand, L., Blain, S., Chever, F., Davies, D., Dehairs, F., Planchon, F., Sarthou, G., Townsend, A.T., Trull, T.W., 2015. Sourcing the iron in the naturally fertilised bloom around the Kerguelen Plateau: particulate trace metal dynamics. Biogeosciences, 12(3): 739-755.

Venchiarutti, C., Jeandel, C., Roy-Barman, M., 2008. Particle dynamics study in the wake of Kerguelen Island using thorium isotopes. Deep Sea Research Part I: Oceanographic Research Papers, 55(10): 1343-1363.

Wainright, S.C., 1987. Stimulation of Heterotrophic Microplankton Production by Resuspended Marine Sediments. Science, 238(4834): 1710-1712.

Witter, A.E., Hutchins, D.A., Butler, A., Luther Iii, G.W., 2000. Determination of conditional stability constants and kinetic constants for strong model Fe-binding ligands in seawater. Marine Chemistry, 69(1-2): 1-17.

Ziervogel, K., Dike, C., Asper, V., Montoya, J., Battles, J., D'souza, N., Passow, U., Diercks, A., Esch, M., Joye, S., Dewald, C., Arnosti, C., Enhanced particle fluxes and heterotrophic bacterial activities in Gulf of Mexico bottom waters following storm-induced sediment resuspension. Deep Sea Research Part II: Topical Studies in Oceanography.

Ziervogel, K., Dike, C., Asper, V., Montoya, J., Battles, J., D'souza, N., Passow, U., Diercks, A., Esch, M., Joye, S., Dewald, C., Arnosti, C., 2016. Enhanced particle fluxes and heterotrophic bacterial activities in Gulf of Mexico bottom waters following storm-induced sediment resuspension. Deep Sea Research Part II: Topical Studies in Oceanography, 129: 77-88. 


\section{Figures Captions}

Fig. 1: a) Sampling sites (red dots) for the sediments BioSi (A3) (50 $\left.36.93 S, 7^{\circ} 04.55 E\right)$; $B i o S i+C a(C 11)$ $\left(51^{\circ} 38.66 \mathrm{~S} ; 7^{\circ} 58.96 \mathrm{E}\right)$; Basalt $(\mathrm{C} 1)\left(53^{\circ} 11.25 \mathrm{~S} ; 7^{\circ} 51.15 \mathrm{E}\right)$ and seawater SOSW $\left(\mathrm{E}^{\circ}\right)\left(48^{\circ} 40 \mathrm{~S} ; 7^{\circ} 88 \mathrm{E}\right.$; $48^{\circ} 40 \mathrm{E}$ ) collected around Kerguelen Island in the Southern Ocean. Sediments were collected at $150 \mathrm{~m}$ depth for Basalt, $530 \mathrm{~m}$ for BioSi and $3350 \mathrm{~m}$ for BioSi+Ca during KEOPS-1 (Blain et al., 2007). The SOSW was collected at $40 \mathrm{~m}$ depth at station E5 during KEOPS-2 (Quéroué et al., 2015). b) Schematic of the resuspended sediment incubation sampling and filtration setup, showing individual steps for one filtration line including 1) an acid cleaning step of the filtration line ; 2) an ultra-pure water rinsing step of the filtration line; 3) collection of the Control using filtered SOSW and 4) collection of samples from the 10-L carboyusing teflon tubing, extending down $1 / 3^{\text {rd }}$ of carboy heigh. See section 2.1 for a complete description of the sampling procedure. The entire process was performed in a ISO 5 laboratory and grey background indicated processes carried out under a laminar flow hood.

Fig. 2: SEM images of sediment BioSi (A3) before (a and b) and after 14-months of incubation (c and d). (1) centric diatoms; (2) diatom fragments; (3) Fragilariopsis sp. and fragments of (4) Eucampia antarctica; (5) aggregates of diatom debris; White dashed line shows (6) biofilm contours with area in white square enlarged in (d) showing biofilm with incorporated bacteria covering diatom fragments. Note differences in scale bars.

Fig. 3: SEM images of sediment BioSi+Ca (C11) before (a, b, and c) and after 14-months of incubation (d). (1) centric diatoms; (2) diatom fragments; (3) basaltic fragments; (4) foraminifera skeletons; (5) biofilm covering diatoms fragments and a basaltic grain with white dashed line shows the contours of the biofilm. Note differences in scale bars.

Fig. 4: SEM images of sediment composed of basaltic grains (C1) before (a, b and c) and after 14-months of incubation (d, e and f). (1) Example of grain morphologies and texture found within the pristine sediment; (2) diatom fragments inside vesicles of a basaltic glassy particle; (3) non-altered basaltic glass, note the stepped appearance of the conchoidal fracture; (4) biofilm with incorporated bacteria covering the basaltic glass with white dashed lines delimiting biofilm contours; (5) altered surface of basaltic glass; 6) Bacteria embedded in the basaltic glass surface. Note differences in scale bars.

Fig. 5: SEM images and SEM-EDS mapping of the biofilm recovering a basaltic grain of Basalt (C1) (a) after 14-months of incubation with mapping area outlined in the white square and enlarged in (b). (b) shows the boundary (white dashed lines) between (1) the biofilm and (2) the altered basaltic glass at the surface of a basaltic grain. A colour was assigned to each element: green for Fe; light blue for Cl; pink for $\mathrm{Mg}$; dark and light yellow for $\mathrm{Si}$ and $\mathrm{Al}$ respectively, to show the basaltic glass matrix; and red for $\mathrm{C}$. Arrows (3) pointed out dispersed bacteria with high $\mathrm{C}$ content. Fe, together with $\mathrm{Cl}$ and $\mathrm{Mg}$ were concentrated within the biofilm. c) The presence of $\mathrm{Fe}, \mathrm{Mg}, \mathrm{Cl}$ and additionally $\mathrm{Ti}$ within the biofilm was confirmed by the comparison of two SED-EDS spectra performed within the biofilm (red) and outside (yellow). d) The presence of $\mathrm{Fe}$ and (e) Ti within the biofilm was confirmed by SEM-EDS spectra performed on a biofilm portion along the grey dotted line on $b$ ). The edge of the biofilm is highlighted by the black dashed line on d) and e). Note differences in scale bars.

Fig. 6: Evolution of a) dFe (nmol $\left.L^{-1}\right)$, b) dMn $\left(n m o l L^{-1}\right)$ and c) dSi $\left(\mu m o l L^{-1}\right)$ over the 14-month incubation of BioSi sediment (A3, green diamonds), BioSi+Ca (C11, blue circles) and of Basalt sediment (C1, grey triangles). The black line and small black filled circles indicates the Control concentrations of $\mathrm{dSi}$, dFe, and dMn in SOSW in the absence of sediment (Table 2).

Fig. 7: Evolution of a) viable bacterial abundances and b) excess concentration of Fe(III) organic ligands ( $L_{\text {Excess }}$ ) over the 14-month incubation period in BioSi (A3, green diamonds), BioSi+Ca (C11, blue circles) and Basalt (C1, grey triangles) treatments. The black line indicates variations of SOSW in the absence of sediment. " $S$ " indicates that ligands were saturated, meaning fully complexed with $\mathrm{Fe}(\mathrm{III})$ and that no free 
ligand was measured. "*” indicates that the sample was contaminated. Missing bars indicate that no sample was collected.

Fig. 8 : a) Variations of dissolved Fe concentrations ( $\Delta \mathrm{dFe})$ and b) dissolved Mn concentrations $(\Delta \mathrm{dMn})$ released during the incubation for both diatomaceous rich sediments, BioSi (green diamonds) and $\mathrm{BioSi}+\mathrm{Ca}$ (blue circles) as a function of released dSi concentration ( $\Delta \mathrm{dSi}$ ). The $\Delta$ 's were calculated by substracting the initial values of SOSW from the dissolved concentrations of each variable measured in the BioSi and BioSi+Ca carboys. a) from $\sim 2 \mu \mathrm{mol} \mathrm{L}^{-1}$ to $\sim 6 \mu \mathrm{mol} \mathrm{L}^{-1}$ of $\Delta \mathrm{dSi}$, the corresponding $\Delta \mathrm{dFe}$ (black outlined symbols) showed a significant linear correlation $\left(y=0.71 \mathrm{x}-1.44, R^{2}=0.70, p=0.0047\right)$. This correlation was applicable from day 28 until the end of BioSi sediment incubation, and from day 98 onwards for BioSi+Ca sediment incubation. b) For $\Delta \mathrm{dMn}$, a linear correlation was only observed for BioSi+Ca sediment $\left(\mathrm{y}=2.52 \mathrm{x}+1.30, \mathrm{R}^{2}=0.87, \mathrm{p}=0.006\right)$.

Fig. 9: Concentration of $\mathrm{dMn}\left(\mathrm{nmol} \mathrm{L}^{-1}\right)$ in BioSi versus viable bacteria density showing the dependence of Mn oxyhydroxides formation $\left(\mathrm{MnO}_{\mathrm{x}}\right.$, through the decrease in $\left.\mathrm{dMn}\right)$ on the increasing bacterial abundances (cells $\mathrm{mL}^{-1}$ ). This allows the determination of a threshold (dark line) beyond which dMn concentrations are minimum. The threshold was determined using the equation represented by the grey line $y=-1.31 .10^{-7} x+0.301,\left(R^{2}=0.85, p<0.001, n=13\right)$ leading to a bacterial density threshold of $2.30 x 10^{6}$ cells $\mathbf{m L}^{-1}$.

Fig.10: Overview of the processes driving the transfer of trace metal from the particulate to the dissolved pool during the incubation of sediments Basalt (C1), BioSi (A3) and BioSi+Ca (C11) and summary of the $\mathrm{dFe}$ and $\mathrm{dMn}$ release to or removal from the dissolved phase. Two main particulate biogenic trace metal reservoirs were identified; namely biogenic silica, releasing $\mathrm{dFe}$ and calcite, releasing $\mathrm{dMn}$, whereas Basalt released both trace metals. The roles played by bacteria are also highlighted: the sequestration of Fe inside the biofilm formed at the surface of the basaltic grains, the decreasing $\mathrm{pH}$ that have certainly initiated the dissolution of the calcite and their involvement in the formation of $\mathrm{Mn}$ oxyhydroxides $\left(\mathrm{MnO}_{\mathrm{x}}\right)$ that scavenged dFe. 


\section{Appendix Captions}

Fig. A1: BioSi (A3) sediment XRD diffractogram before (black) and after (red) incubation.

Fig. A2: BioSi+Ca (C11) sediment XRD diffractogram before (black) and after (red) incubation.

Fig. A3: Basalt (C1) sediment XRD diffractogram before (black) and after (red) incubation.

Fig.A4: SEM secondary electron pictures of BioSi +Ca (C11) sediment before incubation, pointed out some debris of (1) Fragilariopsis sp, with b) enlargement of the white square on a).

Fig.A5: a) SEM secondary electron picture of a broken frustule in the BioSi (A3) sediment before incubation with b) enlargement on the wall of the frustule (white square on a) with coating likely corresponding to organic matter.

Fig. A6: a) EDS X-ray spectrum performed on a precipitate (black contours on (b)), that contained Fe (red squares) and that was identified at the surface of diatom frustule debris at the end of $\mathrm{BioSi}+\mathrm{Ca}(\mathrm{C11})$ incubation. The presence of $\mathrm{Al}, \mathrm{Mg}, \mathrm{Na}, \mathrm{K}$ and $\mathrm{Fe}$ most likely indicates clays belonging to the smectite group.

Fig. A7. a) EDS X-ray spectrum of a Fe-Ti oxide performed in the basaltic glass Basalt (C1) and showing the presence of $\mathrm{Fe}$ (red squares) and Mn (green squares). The location of the spectrum was identified on the b) SEM backscatter image with the pink star. 


\section{Table Captions}

Table 1: Sampling details and initial composition of the three sediments BioSi (A3), BioSi+Ca (C11) and Basalt (C1) including major elements (weight \%); mineralogical composition (\% weight of crystalline phases present in each sediment, i.e., without considering amorphous silica). Note that amorphous silica was detected in BioSi and BioSi+Ca by XRD from distortion of the baseline (Fig.A1 and Fig.A2 for spectra); such phase was not observed (n.o.) on Basalt sediment spectra (Fig. A3). Experimental sediment incubation conditions are indicated as mass of sediment and volumes of SOSW used. Changes in the mineralogical composition measured by XRD at the end of the incubation can be found in Figs. A1; A2 and A3. "**" indicates a seawater-origin.

Table 2: pH, dissolved silicon $\left(\mathrm{dSi}, \mu \mathrm{mol} \mathrm{L}^{-1}\right)$, dissolved iron $\left(\mathrm{dFe}, \mathrm{nmol} \mathrm{L}^{-1}\right)$, dissolved manganese $(\mathrm{dMn}$, nmol $\left.\mathrm{L}^{-1}\right)$, viable bacteria $\left(10^{5}\right.$ cells $\left.\mathrm{mL}^{-1}\right)$, excess Fe organic ligand concentrations (Excess $\mathrm{L}$, $n E q$ of $\mathrm{Fe}(\mathrm{III})$ ) and associated conditional stability constants ( $\mathrm{Log} \mathrm{K}^{\prime}{ }_{\mathrm{Fe} 3+\mathrm{L}}$ ) over the course of incubation (in days) for sediments BioSi (A3), BioSi+Ca (C11) and Basalt (C1) and for SOSW containing no sediment (Control). "S" indicates saturation of the ligands. Some of the parameters were not sampled (n.s) to limit the loss of volume at $20 \%$ by the end of the experiment. In some cases, parameters could not be determined (n.d) due to analytical problems or were not run (n.r). Contaminated samples (C) are also indicated. Note that for viable bacteria density, samples were taken in duplicates after day 41, allowing standard deviation estimations; before, only one sample was available. The first line at day 0.21 in italics, are the initial conditions in the Control.

Table 3: Estimation of the mean dissolution rates and summary of the dissolved concentrations of Fe, Mn and Si released or removed $(\Delta)$ after 423 days for each sediment incubation. Using the initial particulate stocks of $\mathrm{Si}$ (pSi), Fe (pFe) and Mn (pMn) calculated with Table 1, the percentages of the particulate stock that was dissolved or desorbed at the end of the incubation were estimated for each sediment. 
Table 1

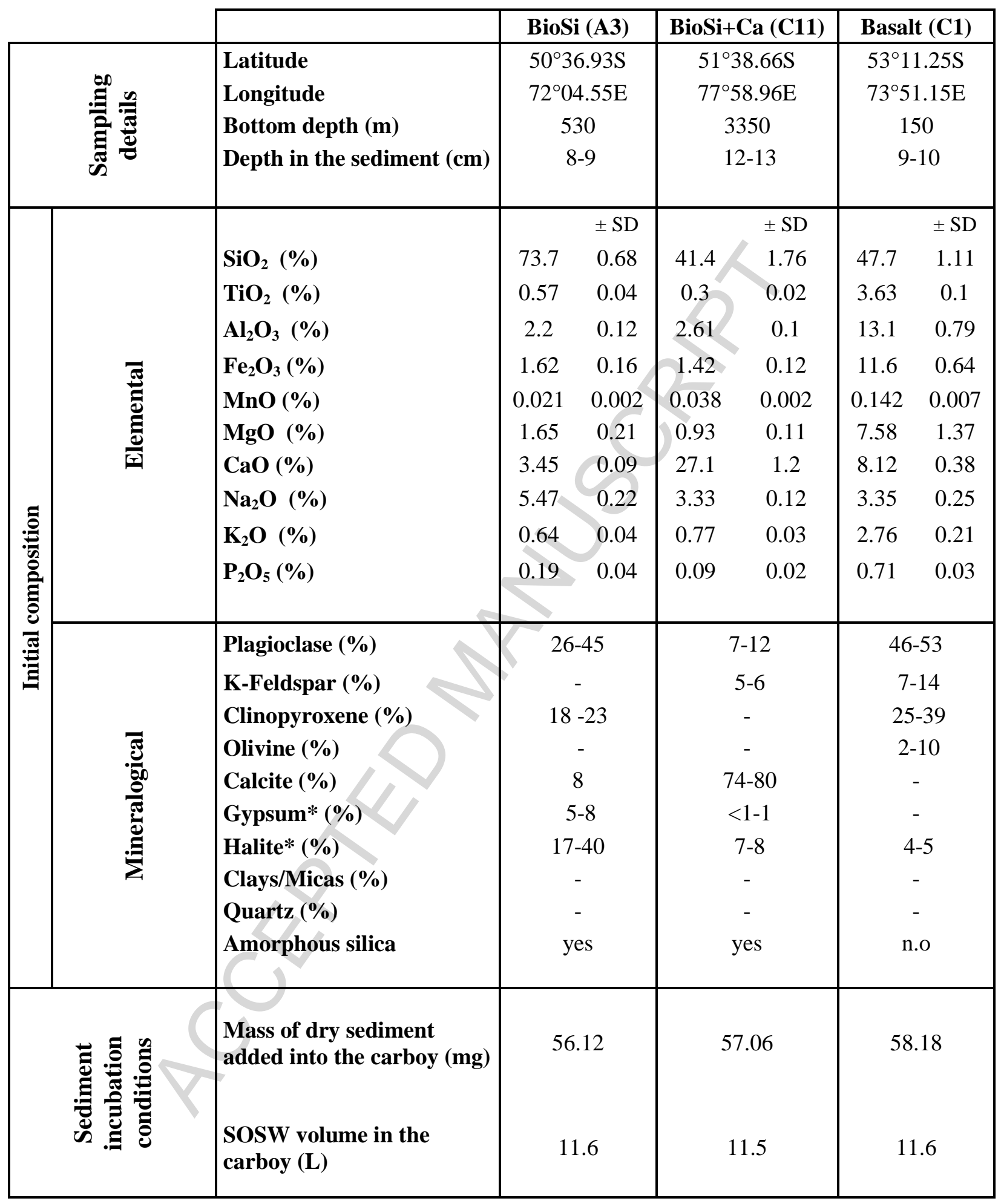


Table 2

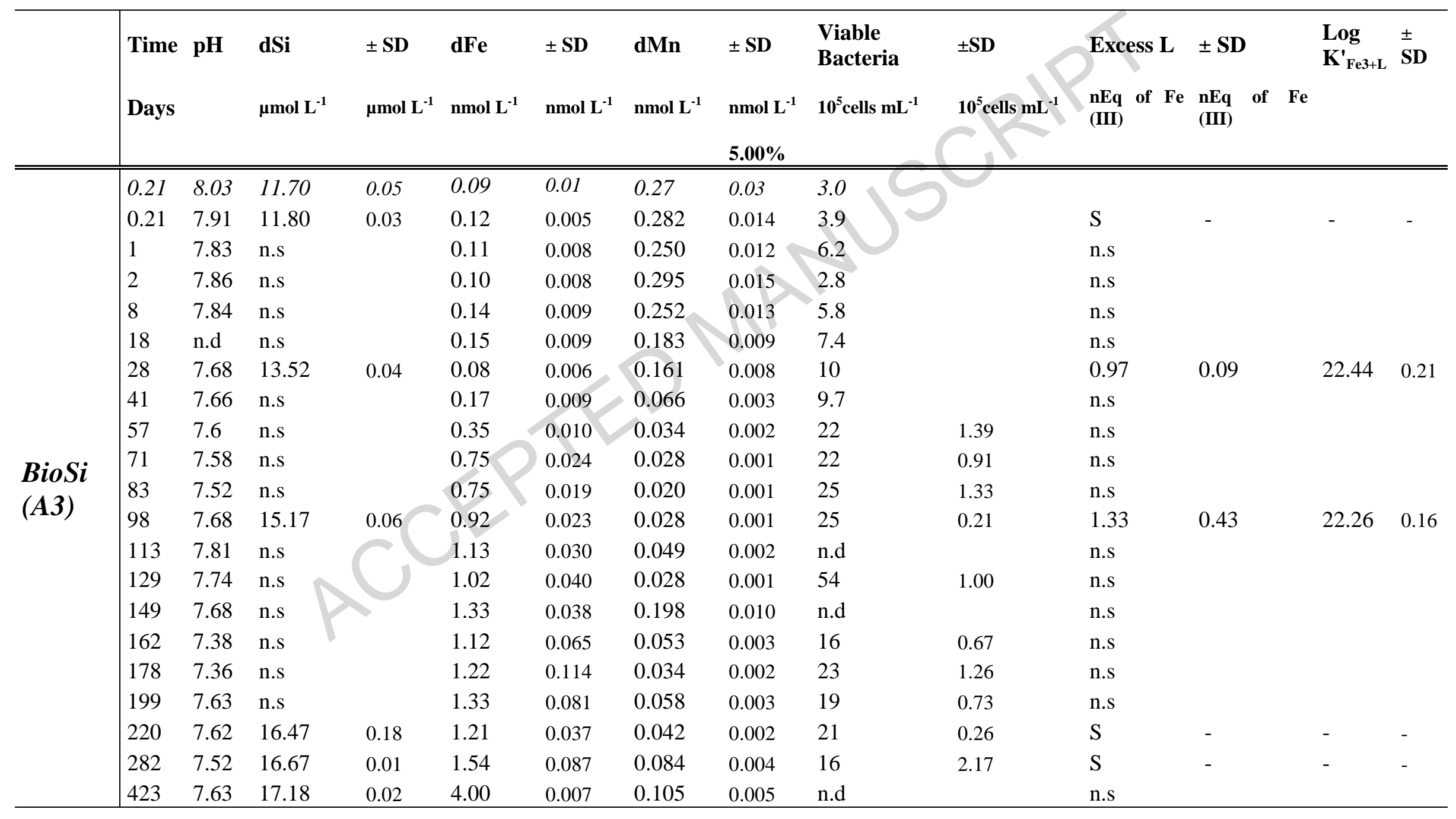


Table 2 (continued)

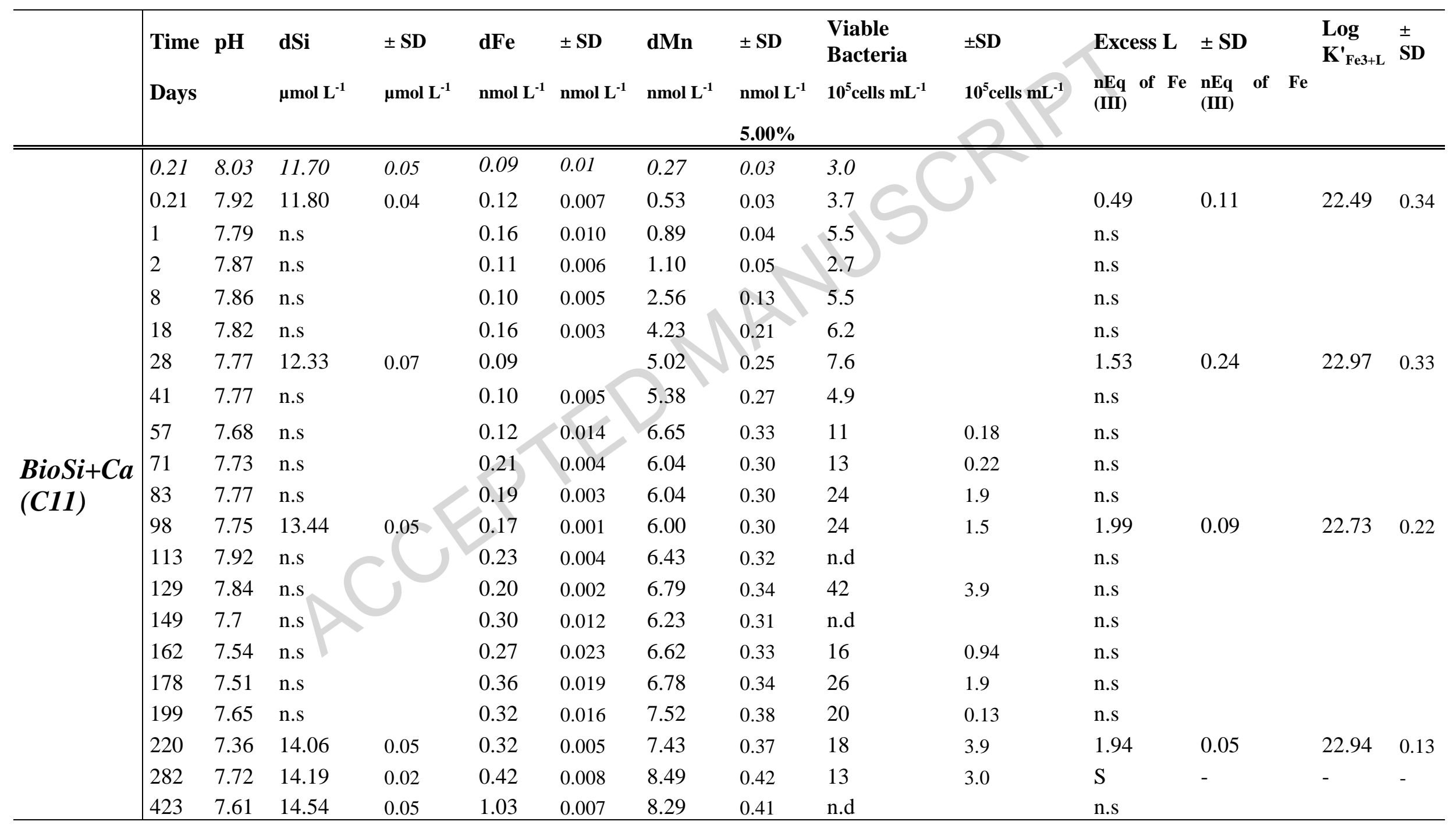


Table2 (continued)

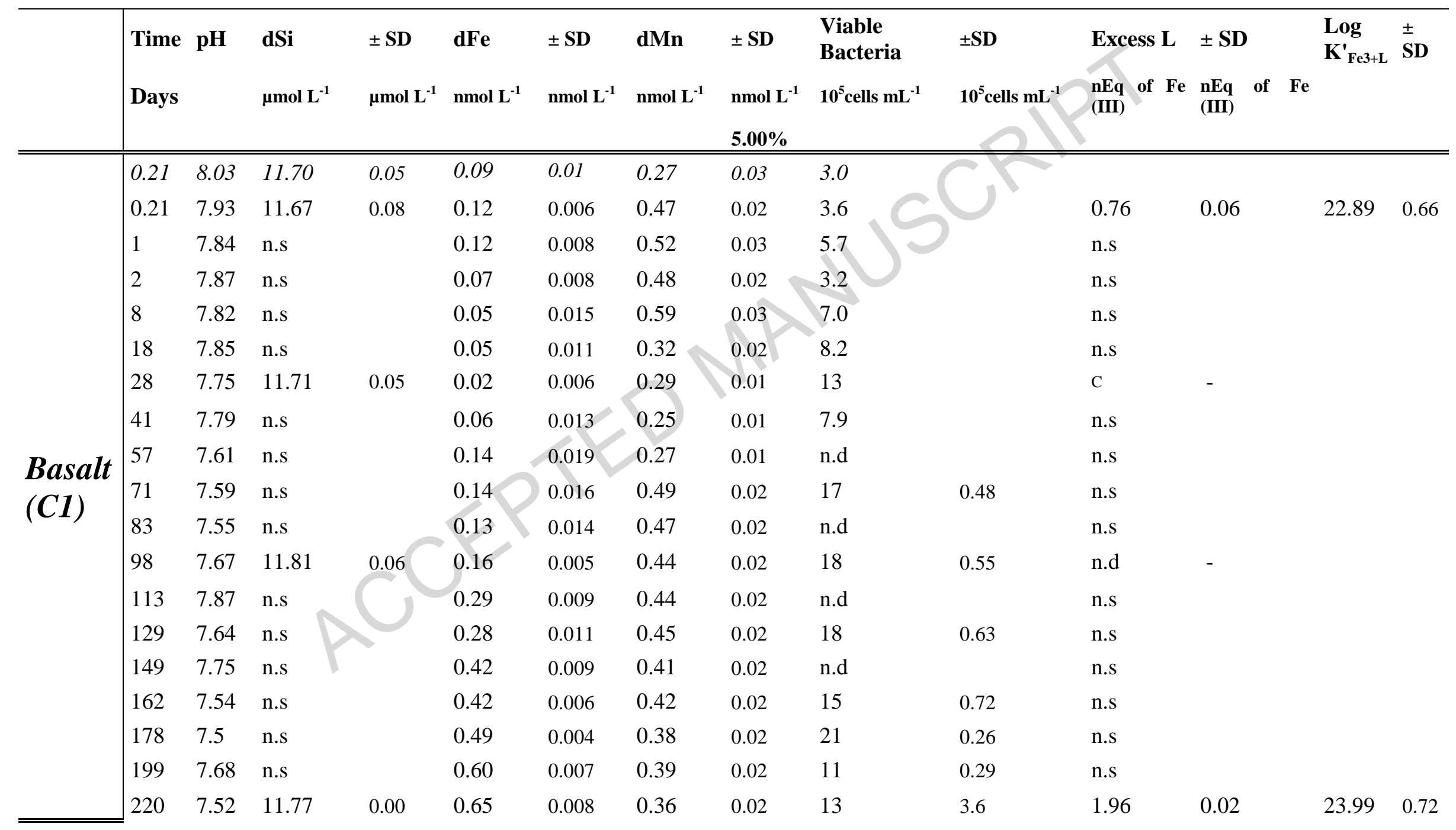




\begin{tabular}{|llllllllllll}
282 & 7.75 & 11.82 & 0.03 & 0.57 & 0.009 & 0.42 & 0.02 & 8.3 & 0.59 & 0.68 & 0.11 \\
423 & 7.58 & 11.83 & 0.00 & 1.18 & 0.009 & 0.54 & 0.03 & n.d & & n.s & \\
\hline
\end{tabular}

Table 2 (continued)

\begin{tabular}{|c|c|c|c|c|c|c|c|c|c|c|}
\hline & $\begin{array}{l}\text { Time } \\
\text { Days }\end{array}$ & pH & $\begin{array}{l}\text { dSi } \\
\mu \mathrm{mol} \mathrm{L}{ }^{-1}\end{array}$ & $\begin{array}{l} \pm \mathrm{SD} \\
\mu \mathrm{mol} \mathrm{L}\end{array}$ & $\begin{array}{l}\text { dFe } \\
\text { nmol L }^{-1}\end{array}$ & $\begin{array}{l} \pm \mathrm{SD} \\
\mathrm{nmol} \mathrm{L}^{-1}\end{array}$ & $\begin{array}{l}\text { dMn } \\
\text { nmol L }^{-1}\end{array}$ & $\begin{array}{l} \pm \text { SD } \\
\text { nmol }\end{array}$ & $\begin{array}{l}\text { Viable } \\
\text { Bacteria } \\
10^{5} \text { cells } \mathrm{mL}^{-1}\end{array}$ & $\begin{array}{l} \pm \mathrm{SD} \\
10^{5} \text { cells } \mathrm{mL}^{-1}\end{array}$ \\
\hline \multirow{20}{*}{ SOSW } & 0.21 & 8.03 & 11.70 & 0.05 & 0.09 & 0.01 & 0.27 & 0.03 & 3.0 & \\
\hline & 1 & 7.94 & n.s & & 0.10 & 0.01 & 0.28 & 0.04 & 4.4 & \\
\hline & 2 & 7.96 & n.s & & 0.09 & 0.01 & 0.28 & 0.03 & 3.2 & \\
\hline & 8 & 7.97 & n.s & & 0.07 & 0.02 & 0.27 & 0.03 & 3.8 & \\
\hline & 18 & 7.85 & n.s & & 0.12 & 0.03 & 0.22 & 0.06 & 7.1 & \\
\hline & 28 & 7.99 & 11.66 & 0.04 & 0.06 & 0.01 & n.r & & 7.2 & \\
\hline & 41 & 7.98 & n.s & & 0.01 & 0.01 & n.r & & 7.5 & \\
\hline & 57 & 8.06 & n.s & & 0.06 & 0.01 & n.r & & 5.7 & 0.13 \\
\hline & 71 & 8.16 & n.s & & 0.12 & 0.02 & 0.33 & 0.05 & 4.8 & 0.46 \\
\hline & 83 & 8.16 & n.s & & 0.09 & 0.01 & n.r & & 6.2 & 1.0 \\
\hline & 98 & 8.18 & 11.62 & 0.05 & 0.06 & 0.01 & 0.31 & 0.06 & 8.1 & 0.19 \\
\hline & 113 & 8.24 & n.s & & 0.09 & 0.02 & $\mathrm{n} . \mathrm{r}$ & & & \\
\hline & 129 & 8.21 & n.s & & 0.09 & 0.01 & 0.29 & 0.07 & 5.0 & 0.11 \\
\hline & 149 & 8.09 & n.s & & C & & n.r & & & \\
\hline & 162 & 8.09 & n.s & & 0.12 & 0.01 & 0.27 & 0.05 & 4.7 & 0.06 \\
\hline & 178 & 8.12 & n.s & & 0.14 & 0.02 & 0.28 & 0.05 & 7.0 & 1.1 \\
\hline & 199 & 8.09 & n.s & & 0.10 & 0.01 & n.r & & 2.7 & 0.45 \\
\hline & 220 & 8.09 & 11.55 & 0.11 & 0.13 & 0.03 & 0.30 & 0.10 & 5.2 & 0.15 \\
\hline & 282 & 8.02 & 11.60 & 0.02 & 0.10 & 0.04 & 0.24 & 0.05 & 7.7 & 0.20 \\
\hline & 423 & 7.84 & 11.61 & 0.01 & $\mathrm{C}$ & & 0.19 & 0.07 & & \\
\hline
\end{tabular}




\begin{tabular}{|c|c|c|c|c|c|c|c|}
\hline & Elements & $\begin{array}{l}\text { BioSi } \\
\text { (A3) }\end{array}$ & $\pm \mathrm{SD}$ & $\begin{array}{l}\mathrm{BioSi}+\mathrm{Ca} \\
\text { (C11) }\end{array}$ & $\pm \mathrm{SD}$ & $\begin{array}{l}\text { Basalt } \\
\text { (C1) }\end{array}$ & $\pm \mathrm{SD}$ \\
\hline $\begin{array}{l}\text { Mean dissolution (+) } \\
\text { or precipitation (-) } \\
\text { rates }\end{array}$ & $\begin{array}{ll}\mathbf{d F e} & \left(\mathrm{pmol} \mathrm{L}^{-1} \mathrm{~d}^{-1)}\right. \\
\mathbf{d M n} & \left(\mathrm{pmol} \mathrm{L}^{-1} \mathrm{~d}^{-1)}\right. \\
\mathbf{d S i} & \left(\mathrm{nmol} \mathrm{L}^{-1} \mathrm{~d}^{-1}\right) \\
\end{array}$ & $\begin{array}{l}+7.77 \\
-0.40 \\
+11.62 \\
\end{array}$ & $\begin{array}{l}0.61 \\
0.18 \\
2.75 \\
\end{array}$ & $\begin{array}{l}+1.74 \\
+16.99 \\
+6.26 \\
\end{array}$ & $\begin{array}{l}0.18 \\
3.23 \\
1.28 \\
\end{array}$ & $\begin{array}{l}+2.57 \\
+0.09 \\
+0.33 \\
\end{array}$ & $\begin{array}{l}0.16 \\
0.19 \\
0.11 \\
\end{array}$ \\
\hline $\begin{array}{l}\text { Dissolved } \\
\text { concentrations } \\
\text { released (+) or } \\
\text { removed (-) }\end{array}$ & \begin{tabular}{|ll}
$\Delta \mathbf{d F e}$ & $\left(\mathrm{nmol} \mathrm{L}^{-1}\right)$ \\
$\Delta \mathbf{d M n}$ & $\left(\mathrm{nmol} \mathrm{L} \mathrm{L}^{-1}\right)$ \\
$\Delta \mathbf{d S i}$ & $\left(\mu \mathrm{mol} \mathrm{L}^{-1}\right)$
\end{tabular} & $\begin{array}{l}+3.91 \\
-0.16 \\
+5.48\end{array}$ & $\begin{array}{l}0.04 \\
0.07 \\
0.07\end{array}$ & $\begin{array}{l}+0.94 \\
+8.03 \\
+2.84\end{array}$ & $\begin{array}{l}0.04 \\
0.42 \\
0.10\end{array}$ & $\begin{array}{l}+1.09 \\
+0.28 \\
+0.13\end{array}$ & $\begin{array}{l}0.04 \\
0.09 \\
0.05\end{array}$ \\
\hline particulate & $\begin{array}{ll}\mathbf{p F e} & (\mu \mathrm{mol}) \\
\mathbf{p M n} & (\mu \mathrm{mol}) \\
\mathbf{p S i} & (\mu \mathrm{mol})\end{array}$ & $\begin{array}{l}11.4 \\
0.17 \\
689\end{array}$ & $\begin{array}{l}1.1 \\
0.01 \\
6\end{array}$ & $\begin{array}{l}10.2 \\
0.308 \\
393 \\
\end{array}$ & $\begin{array}{l}0.8 \\
0.014 \\
0.2\end{array}$ & $\begin{array}{l}84.7 \\
1.16 \\
462\end{array}$ & $\begin{array}{l}4.7 \\
0.06 \\
0.1\end{array}$ \\
\hline $\begin{array}{llr}\text { Particulate } & \text { stock } \\
\text { dissolved } & (-) & \text { or } \\
\text { enriched }(+) & & \\
\end{array}$ & $\begin{array}{l}\text { pFe } \\
\text { pMn } \\
\text { pSi }\end{array}$ & $\begin{array}{l}-0.40 \\
+1.06 \\
-9.23\end{array}$ & $\begin{array}{l}0.04 \\
0.42 \\
0.20\end{array}$ & $\begin{array}{l}-0.11 \\
-30.10 \\
-8.30\end{array}$ & $\begin{array}{l}0.01 \\
2.91 \\
0.64\end{array}$ & \begin{tabular}{|l|}
-0.015 \\
-0.280 \\
-0.330
\end{tabular} & $\begin{array}{l}0.001 \\
0.100 \\
0.040\end{array}$ \\
\hline
\end{tabular}


Figure 1

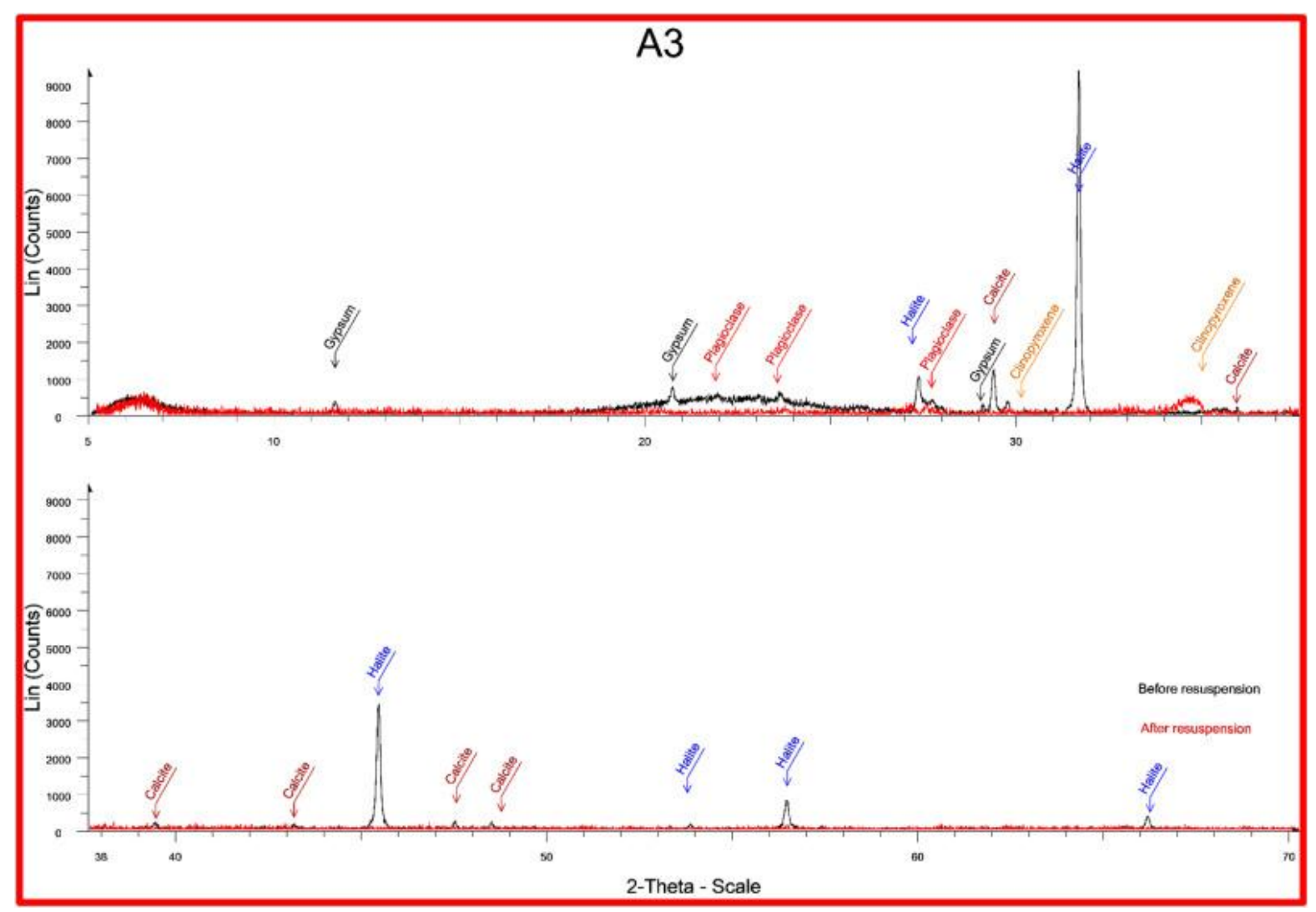

Figure 2

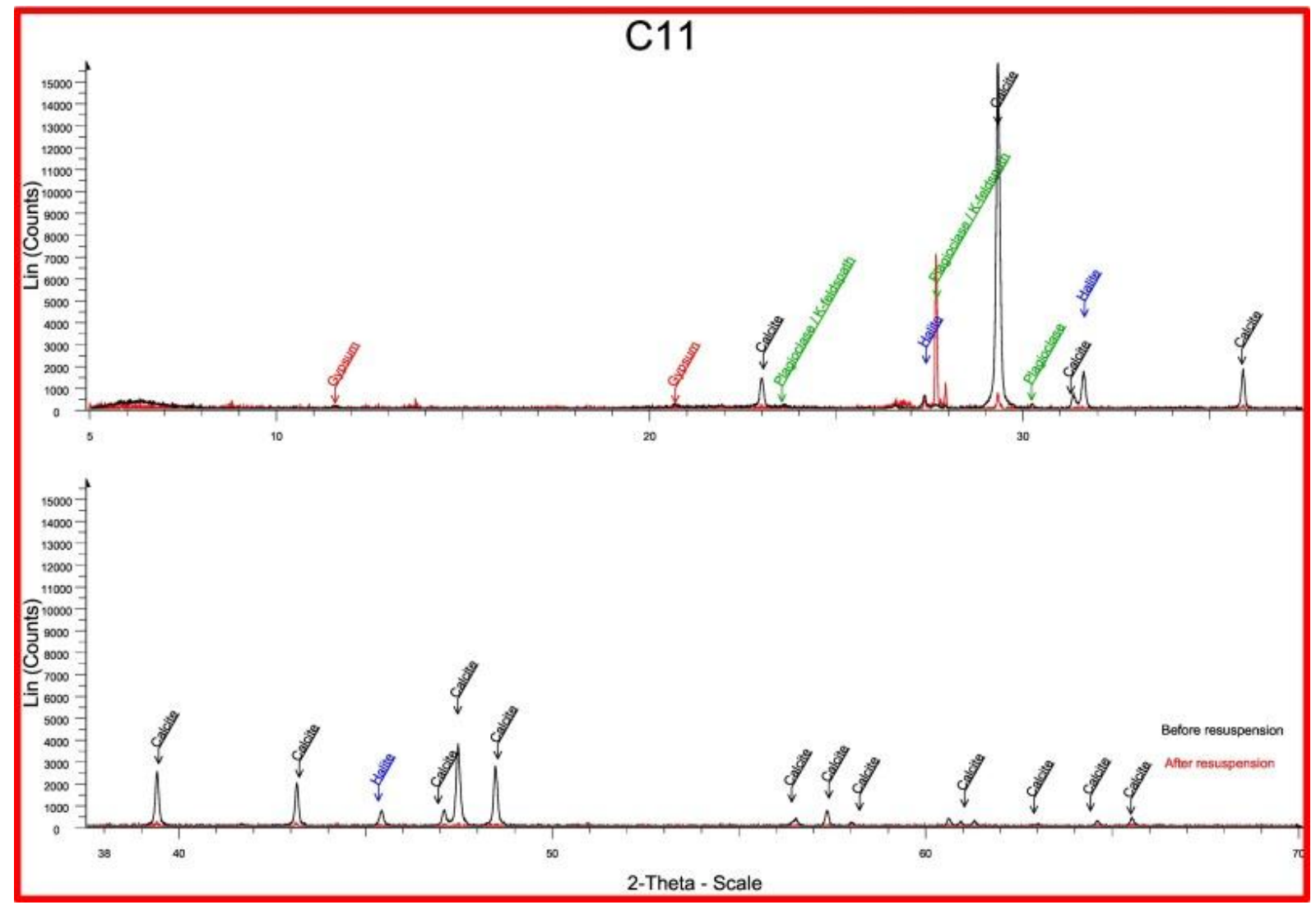


Figure 3

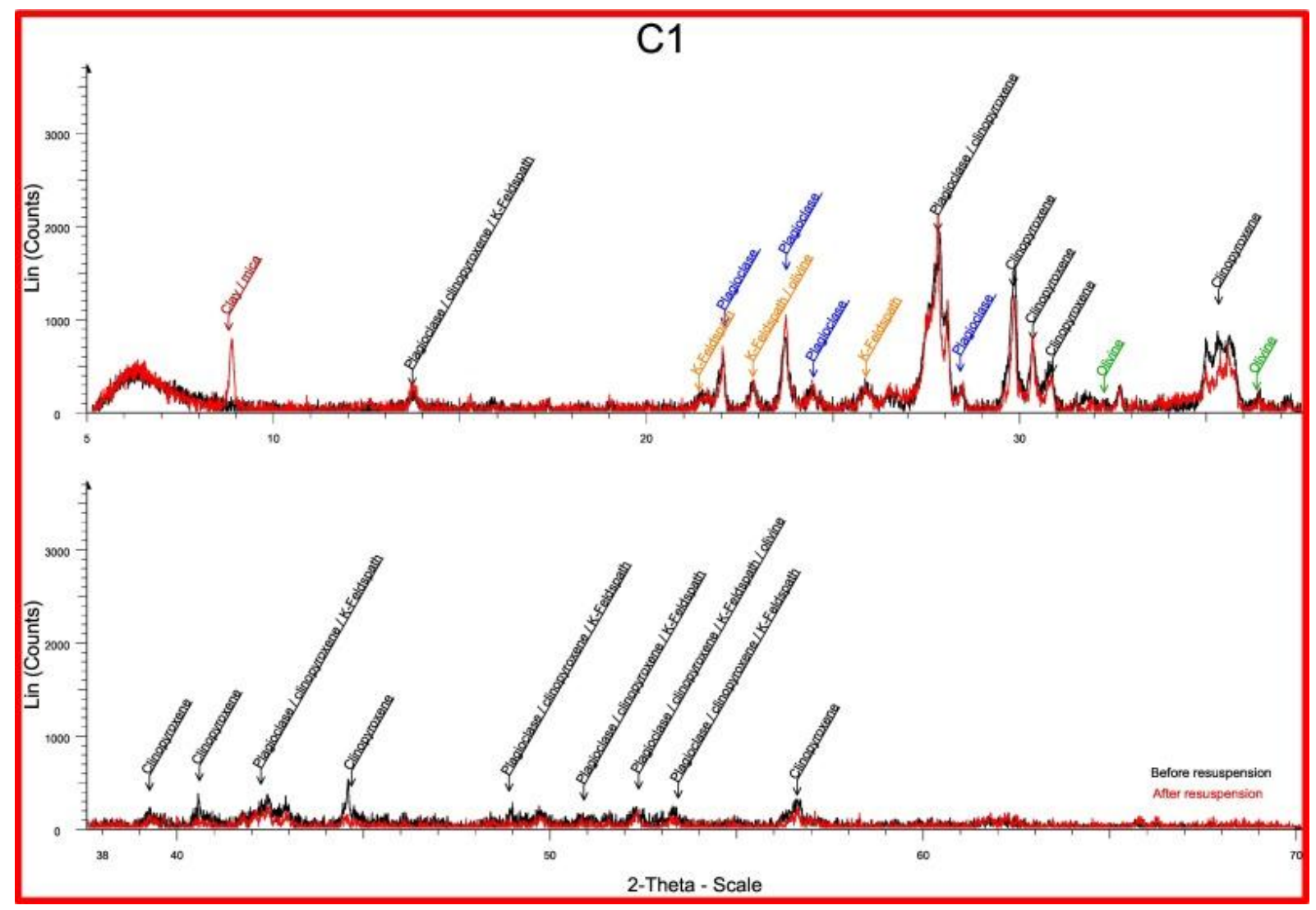

Figure 4
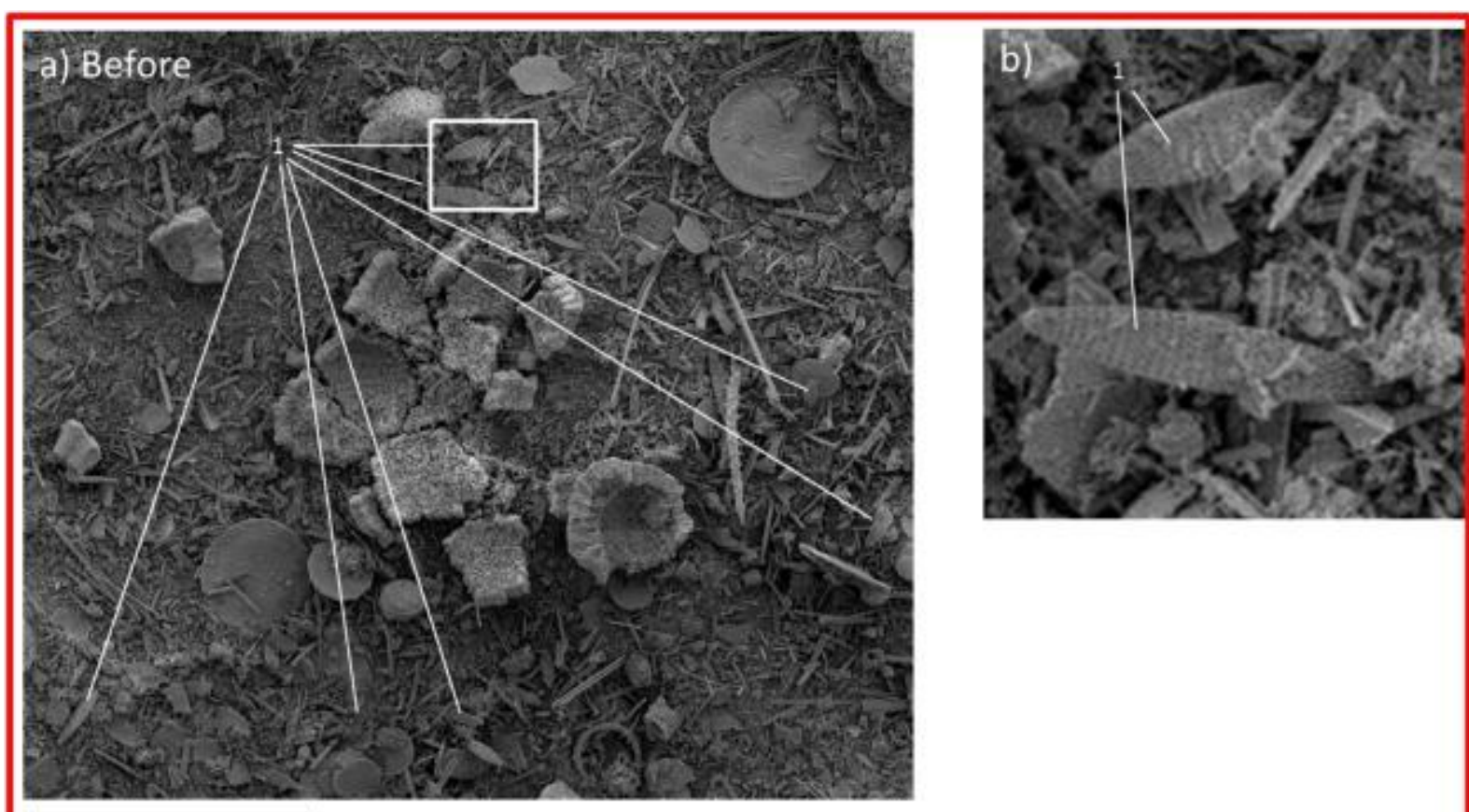

$200 \mu \mathrm{m}$ 
Figure 5

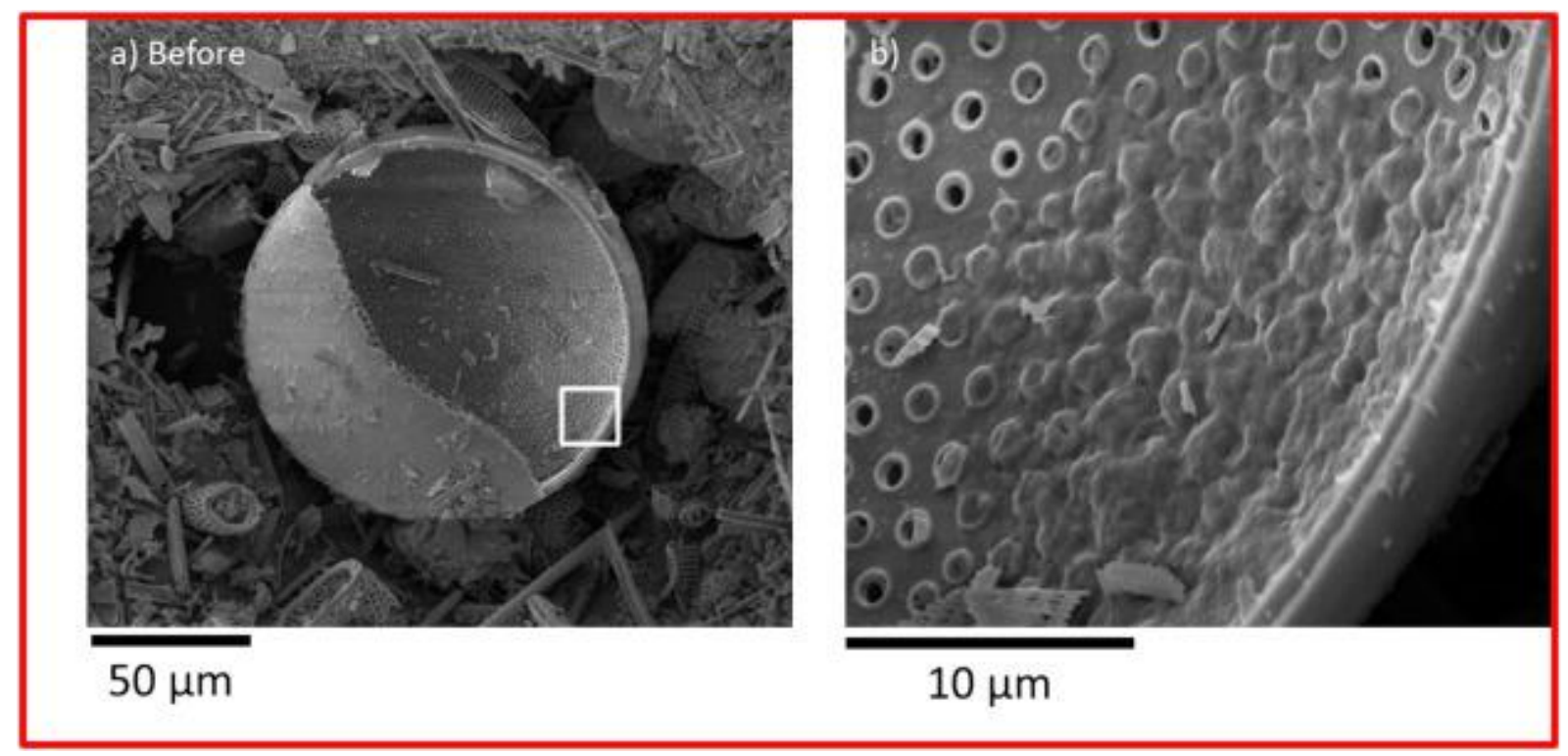

Figure 6

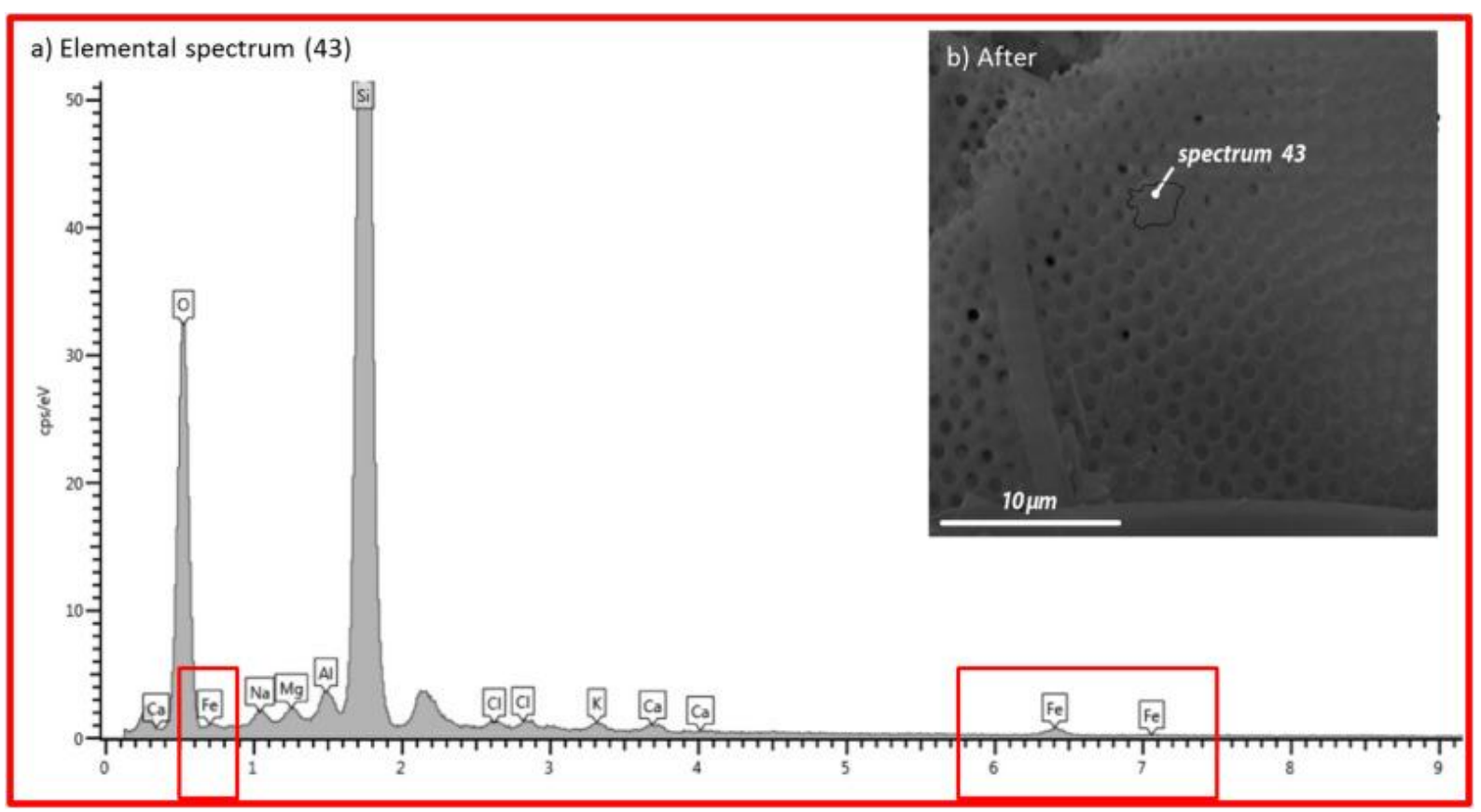


Figure 7

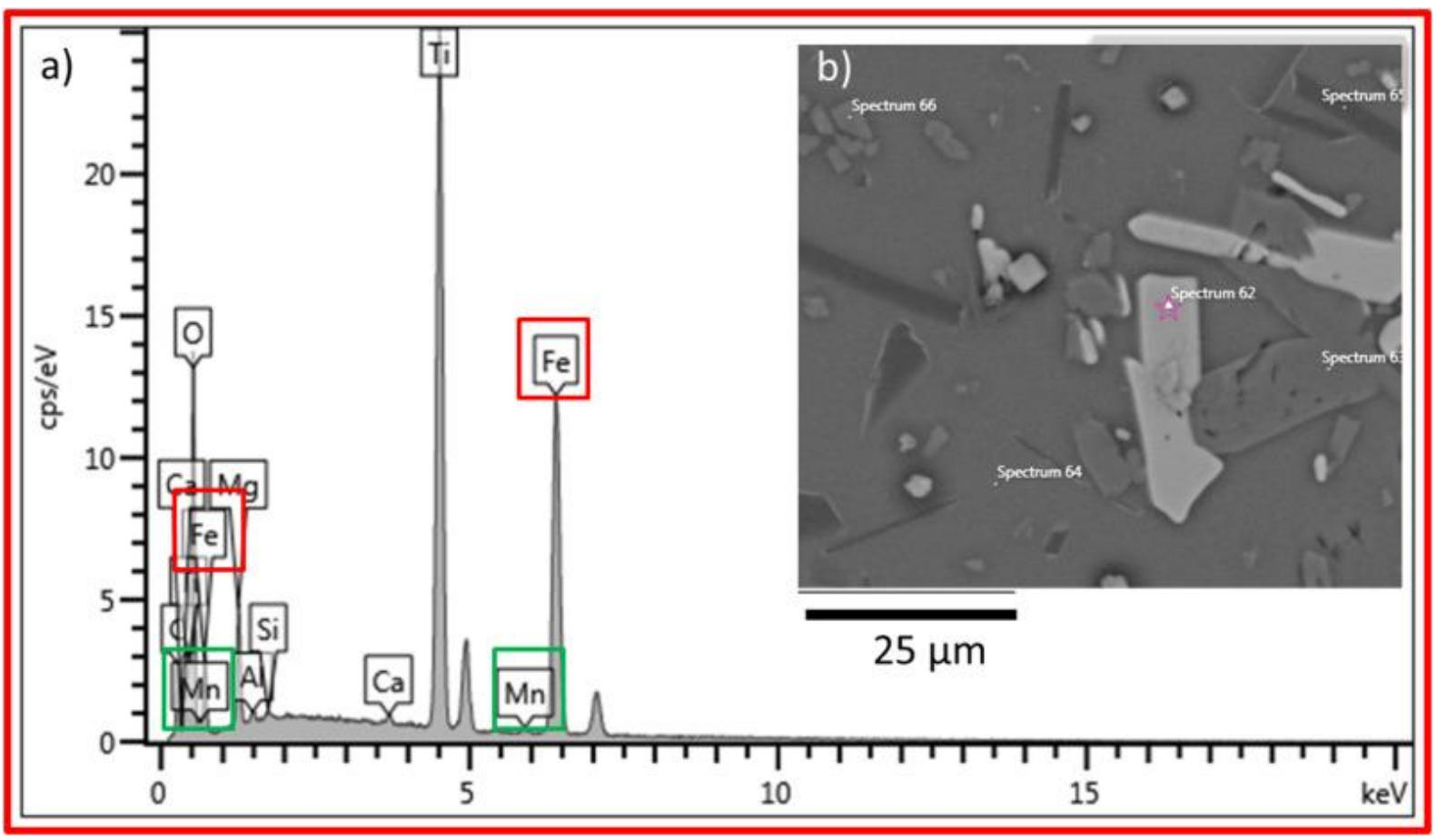

Figure 8
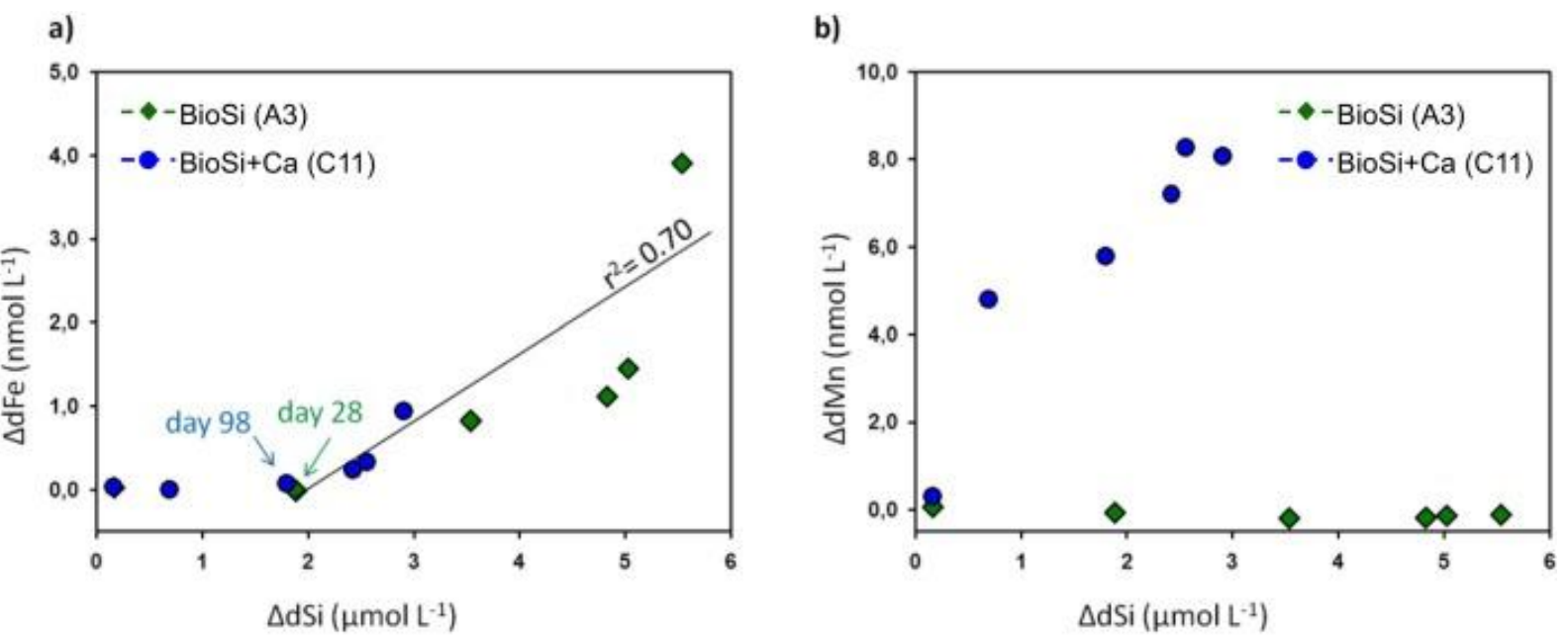
Figure 9

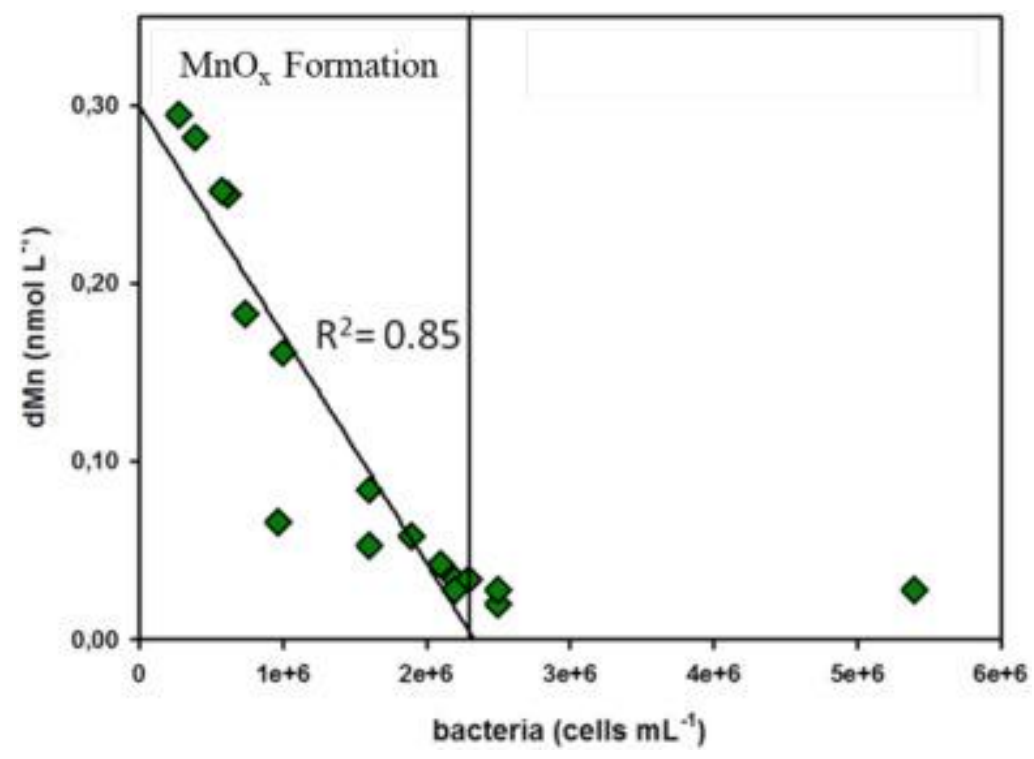

Figure 10

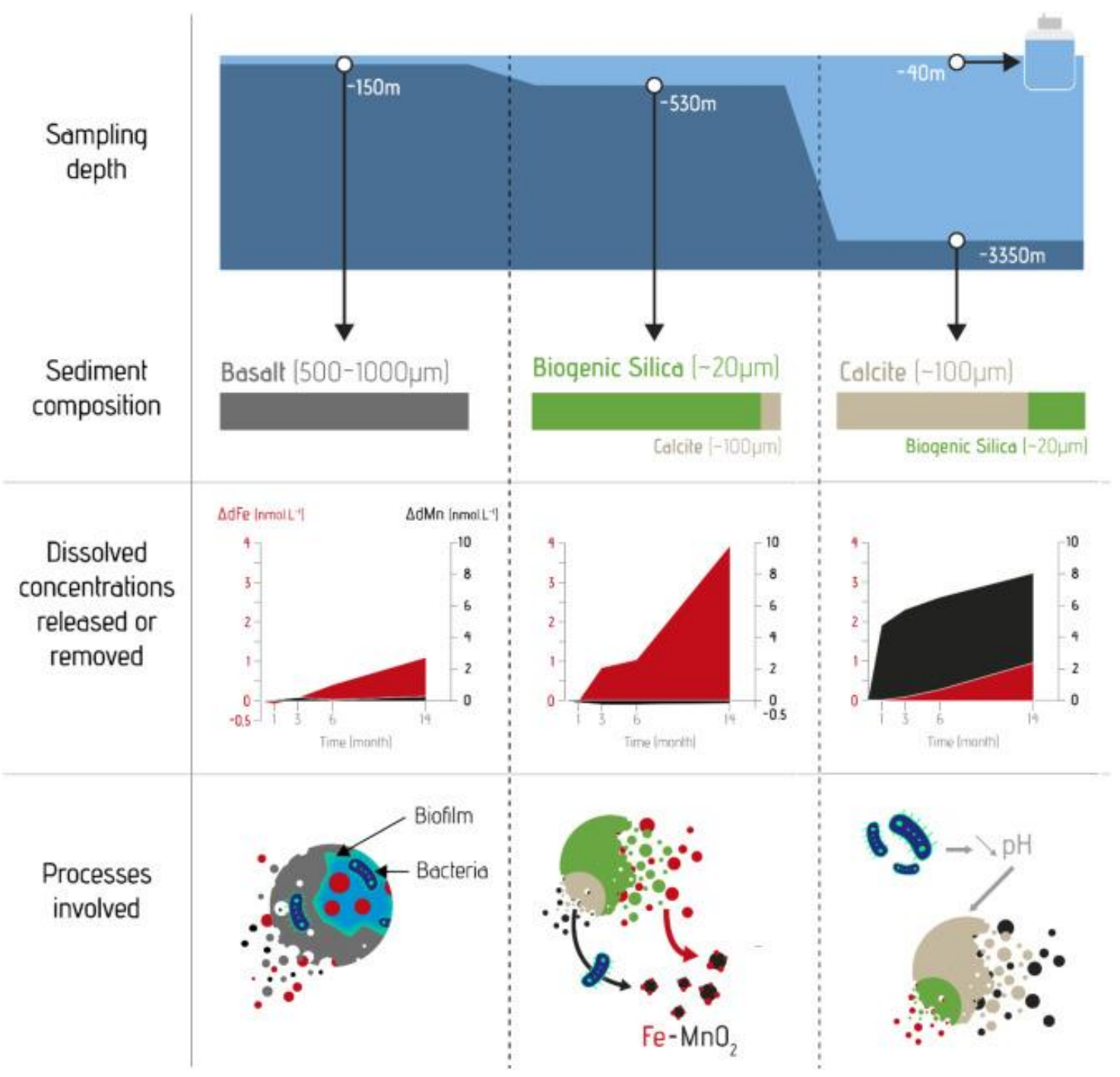


Figure A1

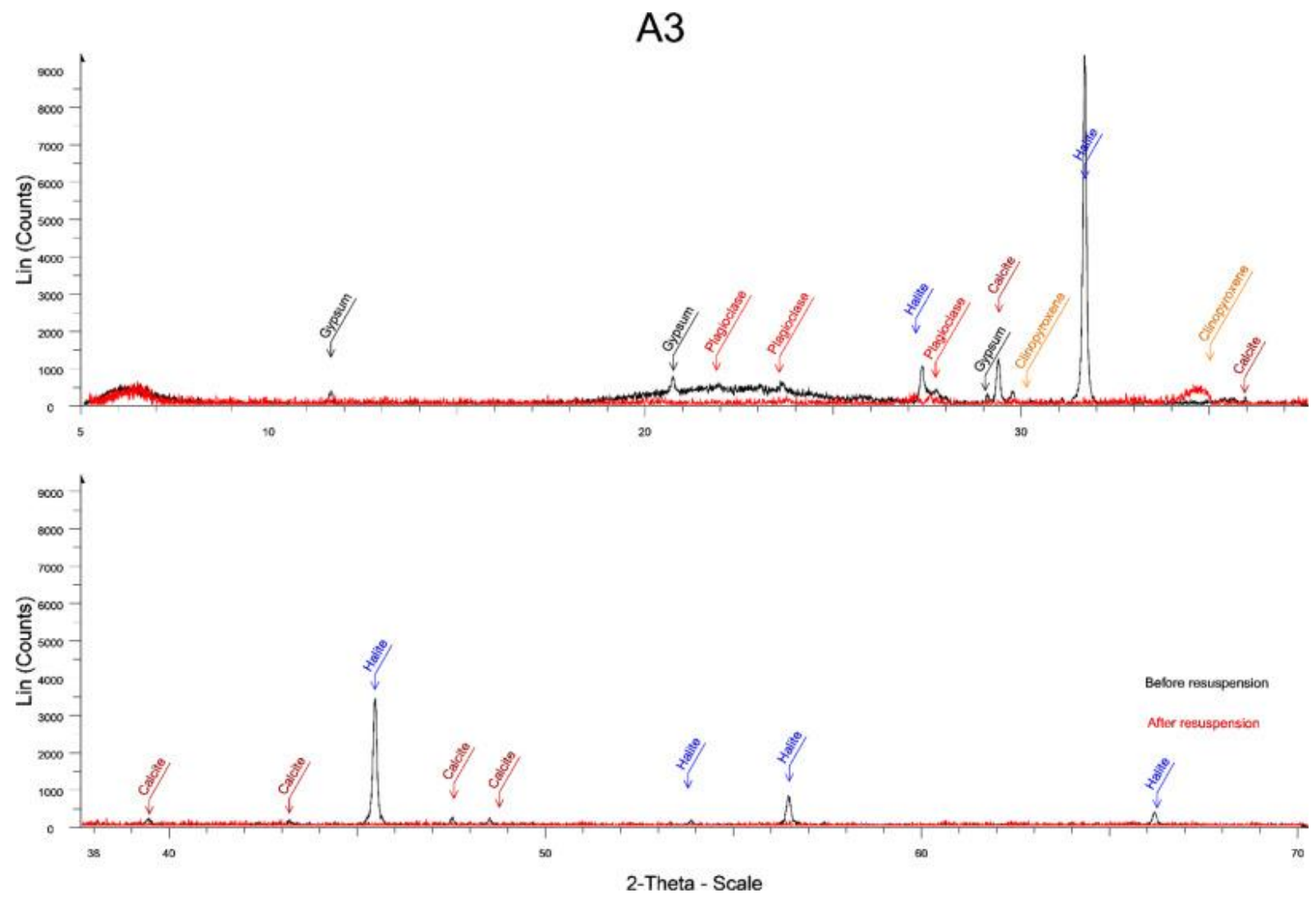

Figure A2
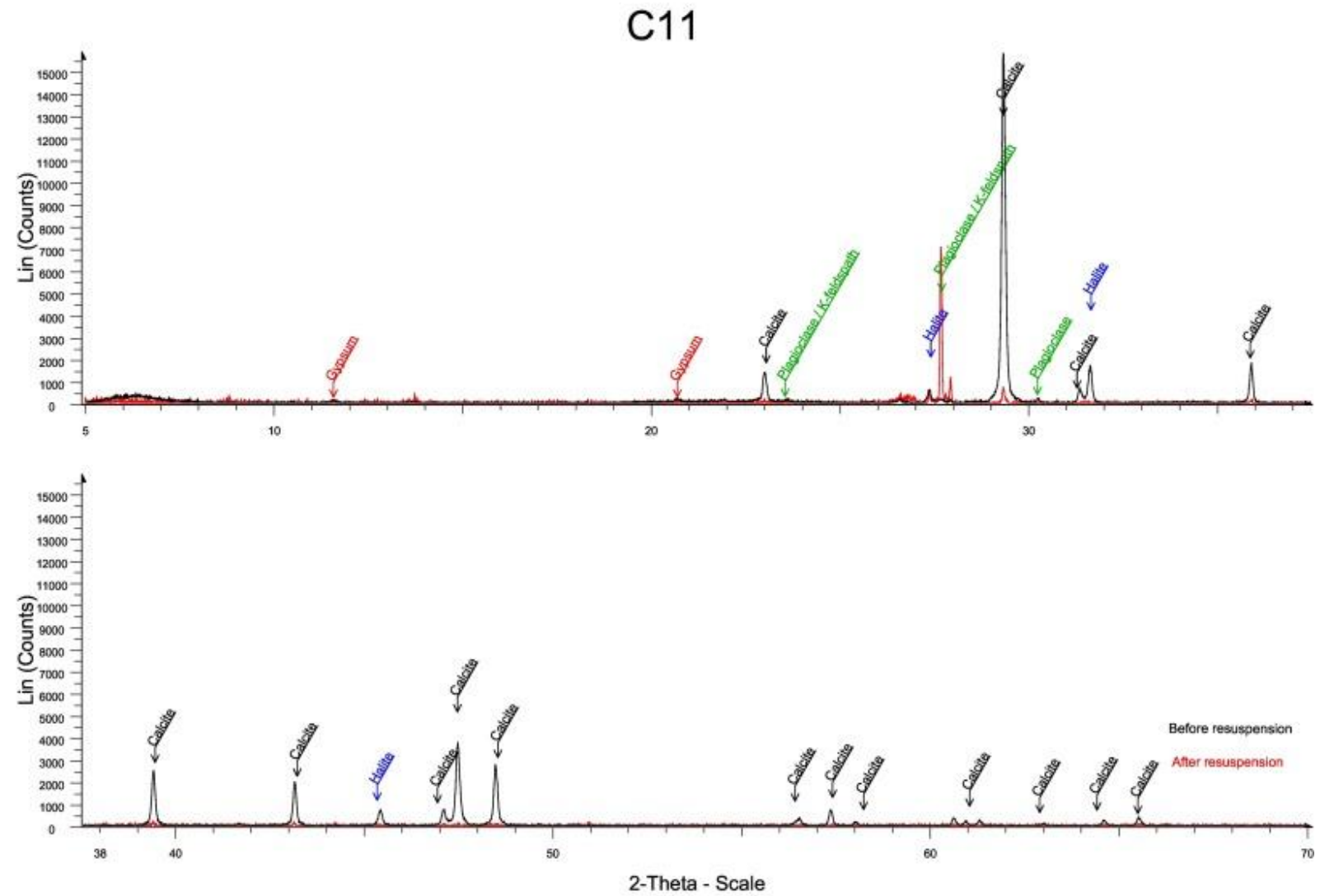
Figure A3
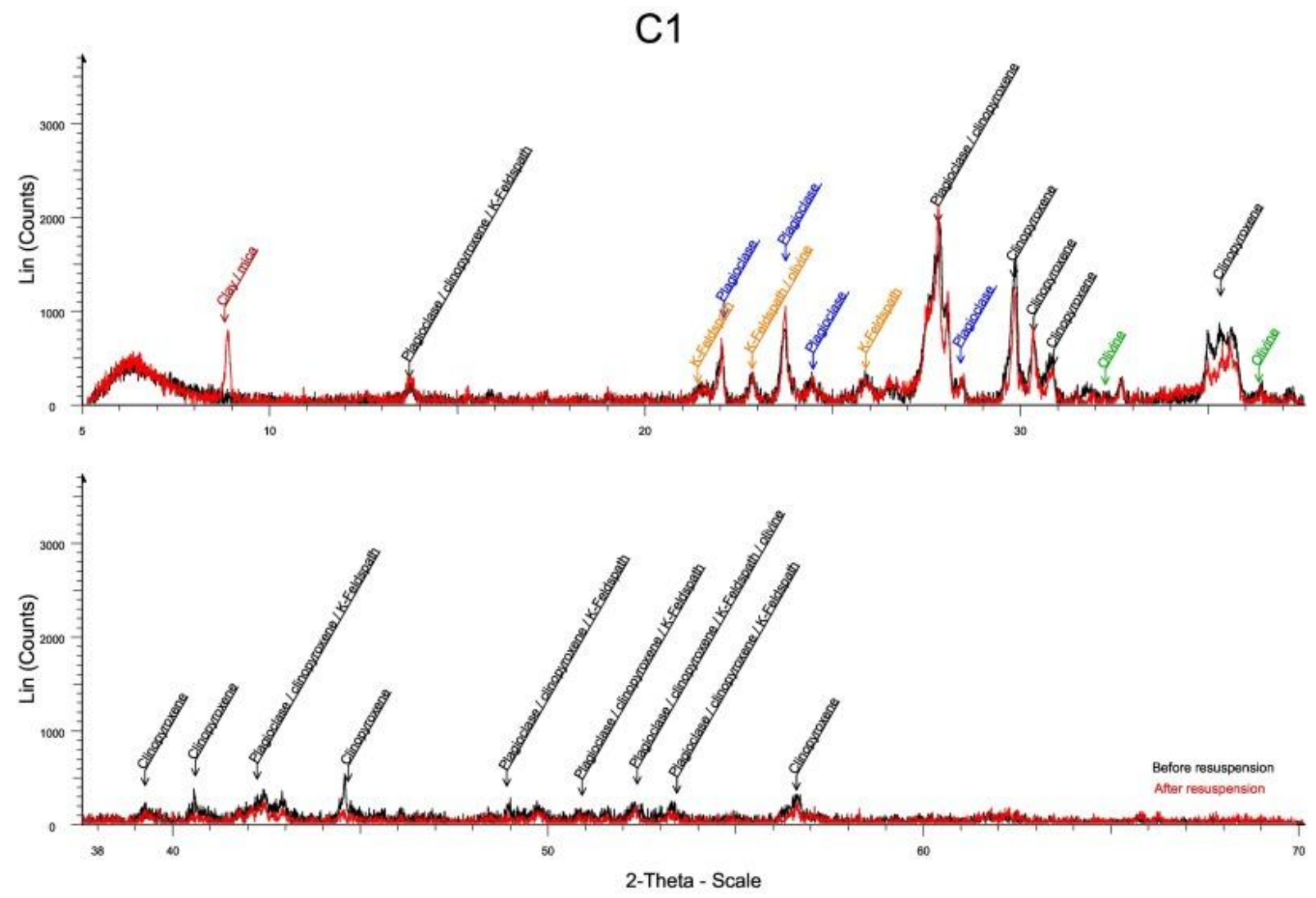

Figure A4
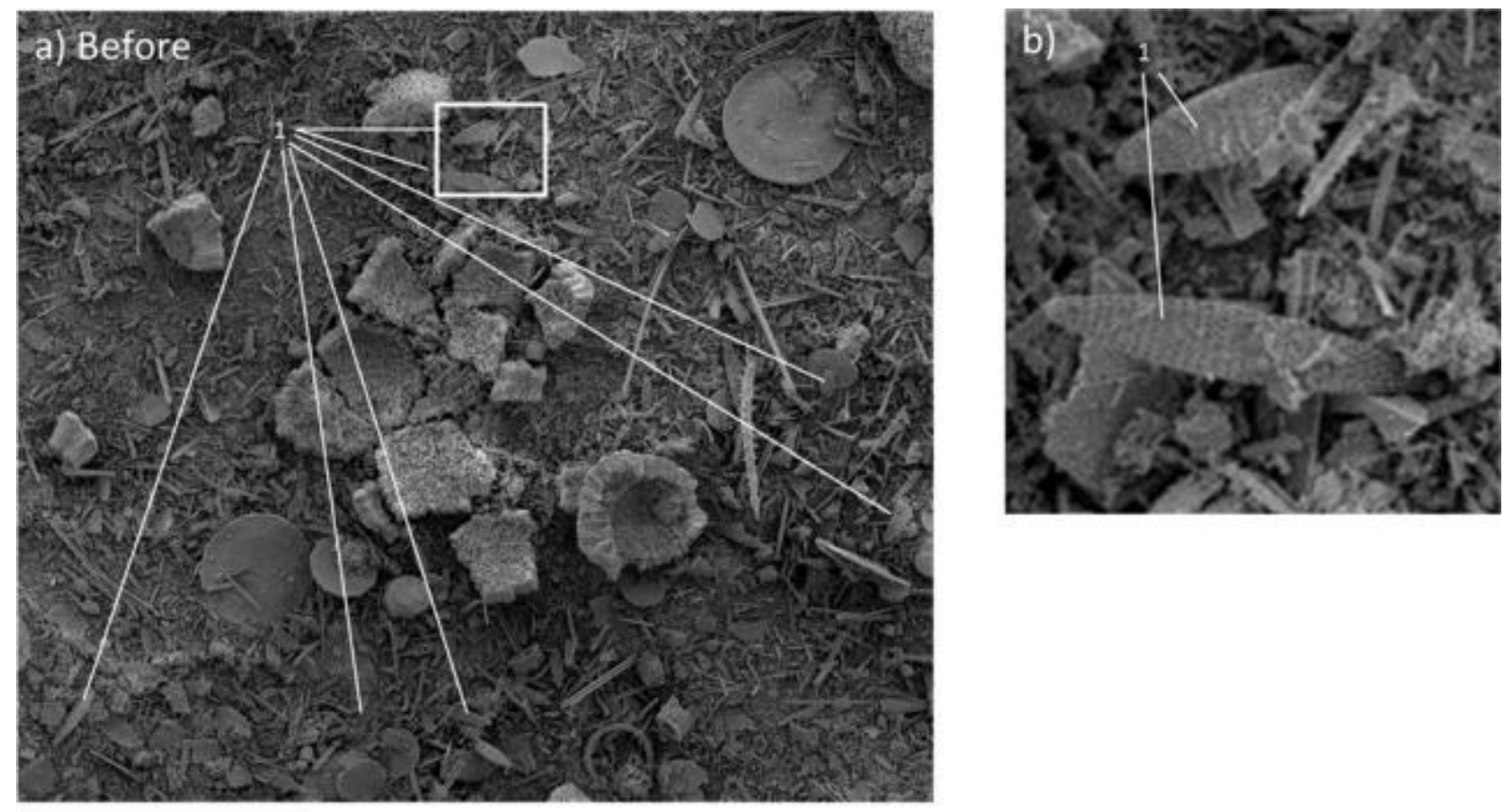

$200 \mu \mathrm{m}$ 
Figure A5

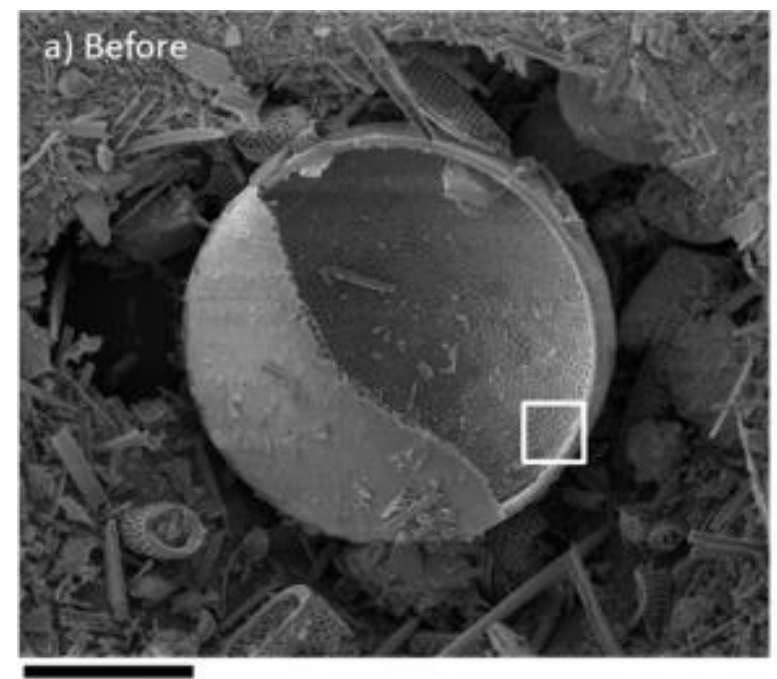

$50 \mu \mathrm{m}$

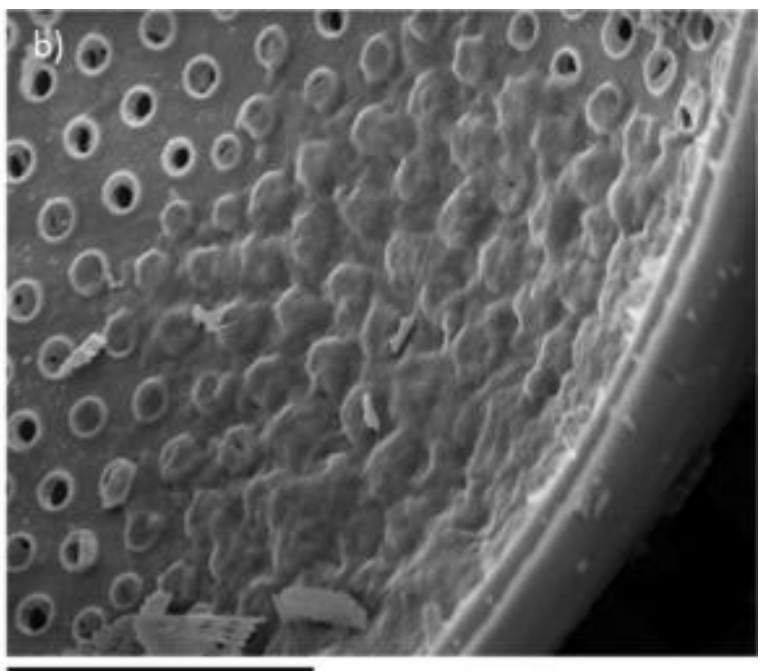

$10 \mu \mathrm{m}$

Figure A6

a) Elemental spectrum (43)

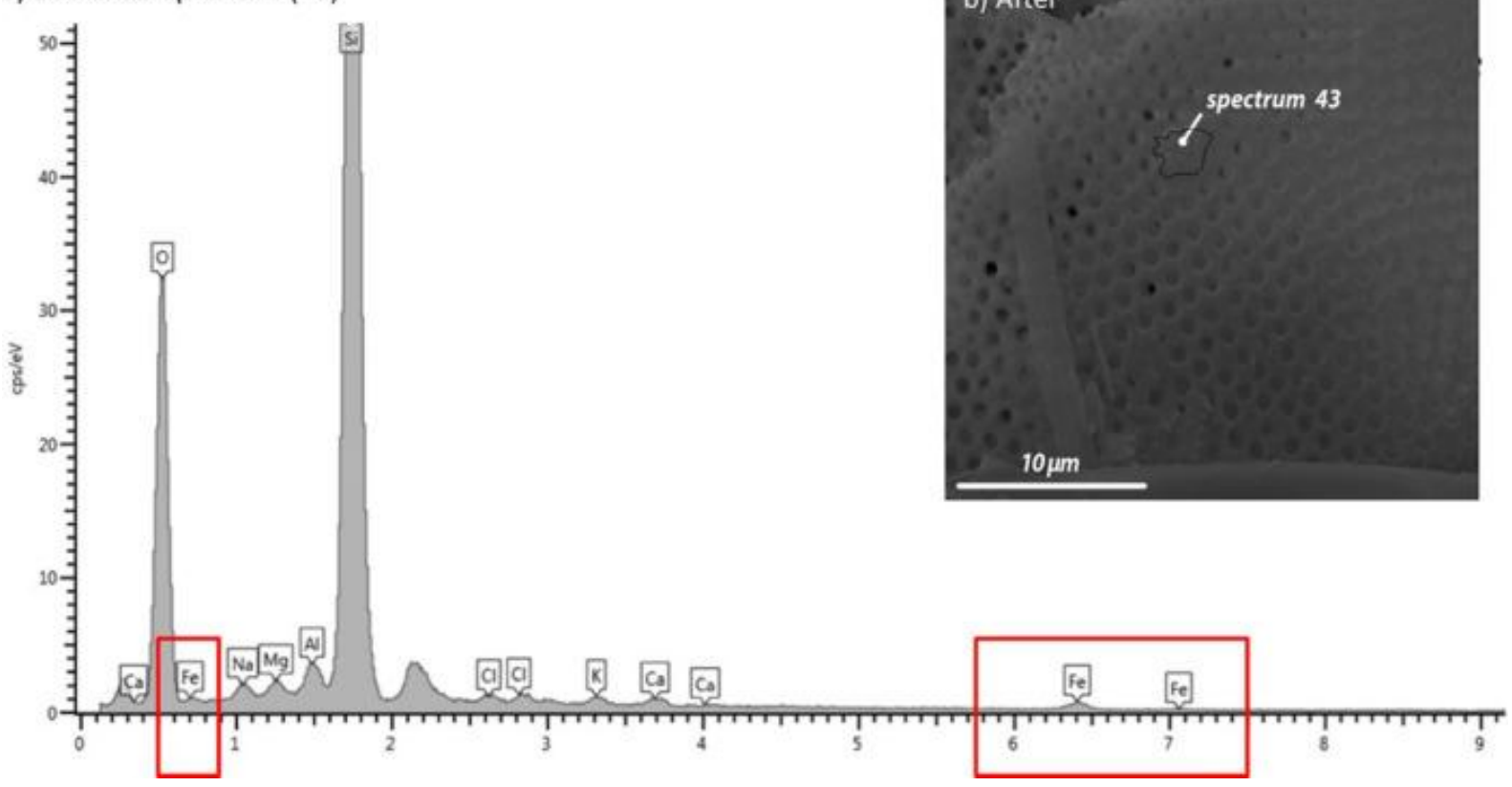


Figure A7

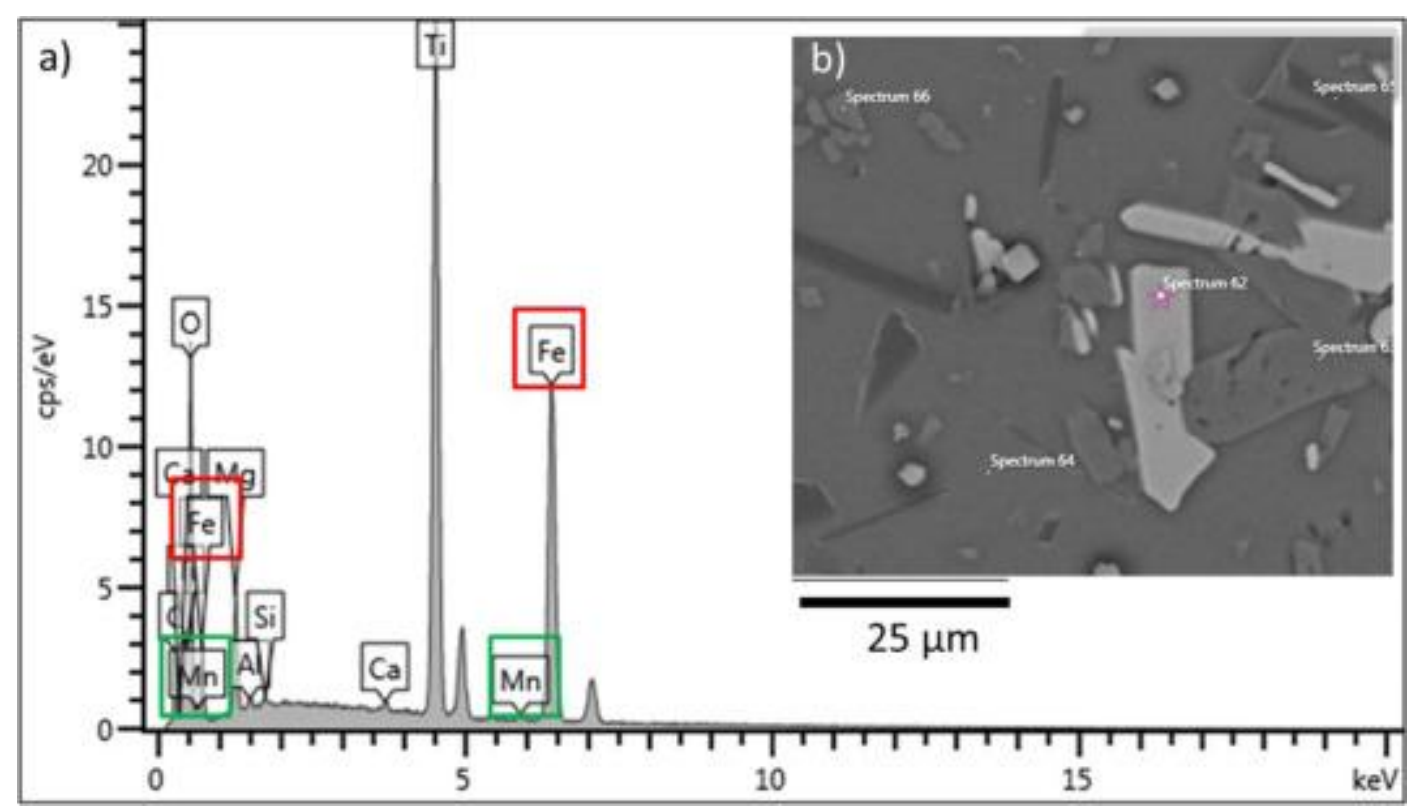

